\title{
STRUCTURAL BENEFITS OF HEMPCRETE INFILL IN TIMBER STUD WALLS
}

By

Agnita Mukherjee

A thesis submitted to the Department of Civil Engineering In conformity with the requirements for the degree of

Master of Applied Science

Queen's University

Kingston, Ontario, Canada

January, 2012 
The problems that exist in the world today cannot be solved by the level of thinking

\author{
that created them
}

Albert Einstein

A very Faustian choice is upon us: whether to accept our corrosive and risky behavior as the unavoidable price of population and economic growth, or to take stock of ourselves and search for a new environmental ethic.

E. O. Wilson 


\begin{abstract}
Due to an increase in environmental consciousness in the construction industry there has been increasing interest in using natural building materials like rammed earth construction, straw bale construction and hempcrete construction. These materials have very small embodied energy and are carbon negative or carbon neutral.
\end{abstract}

Hempcrete is a bio-composite mix made up of hemp shive, lime, cement and water. There has been extensive research undertaken on the thermal, acoustic, and mechanical properties of hempcrete. It has low density, good thermal and acoustic insulation properties, and can passively regulate humidity in a built environment. However it also has low compressive strength and modulus of elasticity. Thus hempcrete cannot be used as a direct load bearing material but can used as an infill material in timber stud walls.

This thesis investigates how hempcrete can have beneficial structural effects by preventing buckling of timber (increasing the buckling load) columns when used as an infill in between columns in a timber stud wall. Eight timber walls were constructed (both half scale 1200mm high; and full scale - up to $2133 \mathrm{~mm}$ high) with varying column dimensions. Six of the walls were infilled with hempcrete of varying density. Two walls were not infilled and were baseline tests. All walls were tested in compression. It was found that high density hempcrete $\left(715 \mathrm{~kg} / \mathrm{m}^{3}\right)$ not only prevented weak axis buckling of columns but also carried some direct load. Low density hempcrete was also successful in preventing weak axis buckling of the infilled walls. In-filled walls failed in strong axis buckling at a load twice (for half scale walls with $38 x 89 \mathrm{~mm}$ columns) or 4 times(full scale walls with $38 x 235 \mathrm{~mm}$ columns) that of the unfilled walls. An analytical model based on buckling of a strut on an elastic foundation was proposed to predict the maximum strength hempcrete can add to a wall by preventing buckling. The timber 
column strength equations from CSA -O86-01 closely predicted the buckling load of the walls from the experiments. The results from the model were also put in design equations from CSA O86-01 to predict practical failure loads if the walls failed by buckling into hempcrete. Although only a single test result was available, it was in good agreement with the model predictions. 


\section{Acknowledgement}

Queen's University has been the ideal setting for the past two years of study. The selfless acts of faculty, staff, friends, and family have culminated into a productive and memorable university experience.

First, I thank my supervisor, Dr. Colin MacDougall. You have been my inspiration. Your environmental consciousness has led me to a unique and interesting research program. One that has exposed me to yet another discipline of Civil Engineering and one that will undoubtedly help shape my career. Your guidance kept me on track and your expertise helped me make sense of the numbers. Thank You.

I would like to thank all professors of the civil engineering department for whom I could develop better understanding of structural engineering

The administrative and technical support staff is undoubtedly the best in the business. Your work ethic and friendly demeanour made it possible to focus on my research without distraction. Thanks, Maxine Wilson, Cathy Wager, Diann King, Paul Thrasher, Lloyd Rhymer, Jamie Escobar, Neil Porter, Adam Reczek, and Bill Boulton.

I would like to thank my colleagues in Room 119. You taught me to use the machines in the laboratory, lent me expensive instrumentation, and made me feel at home in a new country. Thanks Mark Nelson, Hale Mathieson, Jose Aguilera, Mike Brown, Ramin Rameshni, Doug Tomlinson, Sarah Zakaib, Michael Dutton, Graham Tattersall, Danielle Derosa, Amanda Eldridge and Nic Wootton. 
Thanks go out to the summer students who endured painfully high degree of attention to details. Without your hard work using the shovels and hammer drills, I would have had to do it myself. Thanks Alanna Erdle, Kenneth Mak, Michael Dutton, and Graham Tattersall.

I would like to thank Queens University for the financial support.

I would like to thank my Mom and Dad, brother (Aniruddha) and sister (Lopamudra) who helped me to grow up in a highly supportive and environmentally conscious atmosphere.

Lastly I would like to thank my husband Avik Halder for his constant help and support without which this thesis would not have been possible. 


\section{TABLE OF CONTENTS}

\section{TABle of Contents}

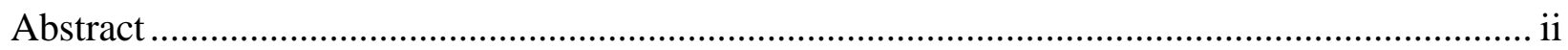

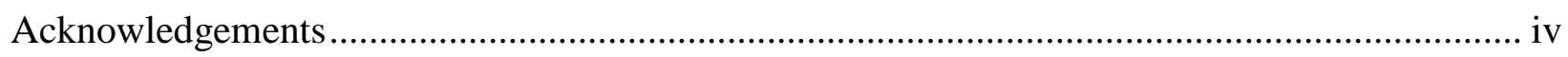

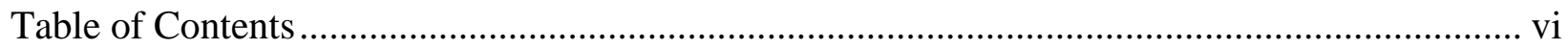

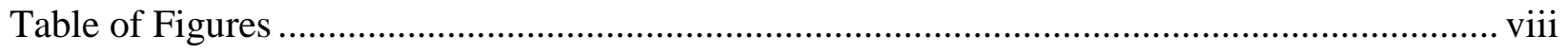

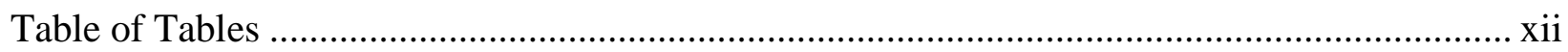

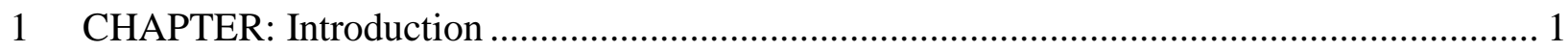

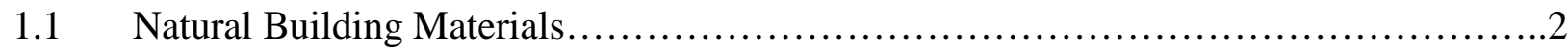

1.1.1 What is hempcrete? ..................................................................................... 3

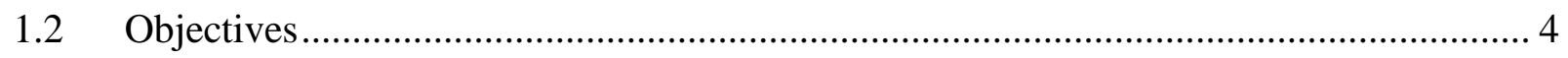

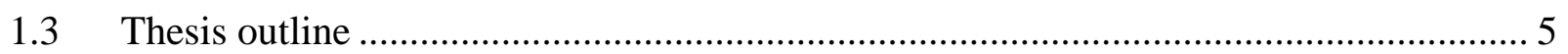

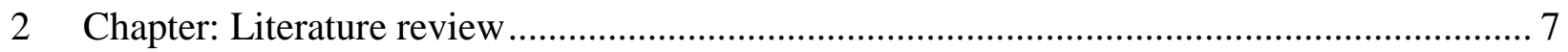

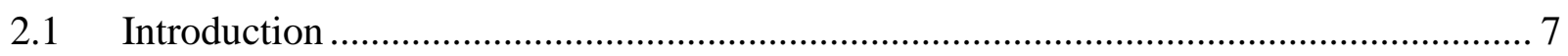

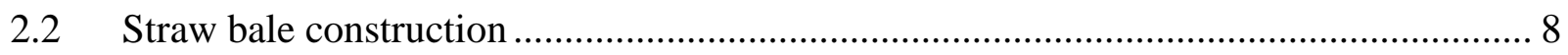

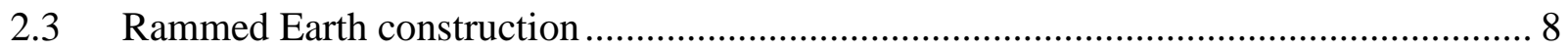

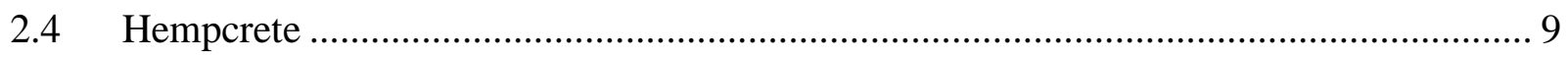

2.4.1 Hempcrete Research ....................................................................................... 10

2.4.2 Lack of structural research on hempcrete ……….................................................... 12

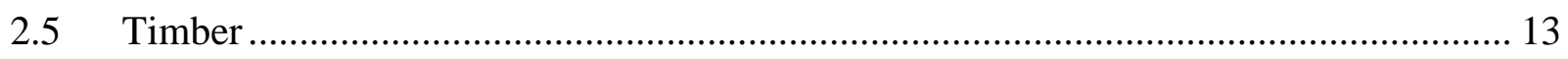

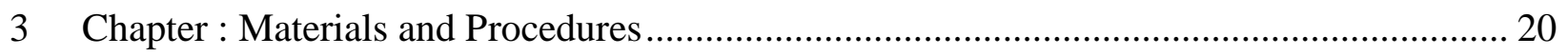

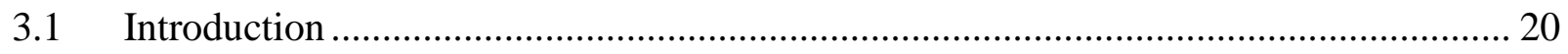

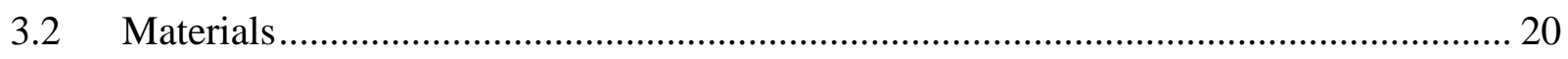

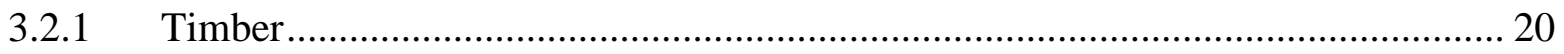

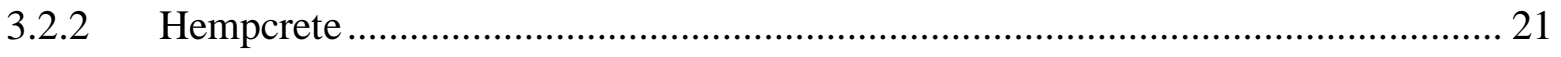

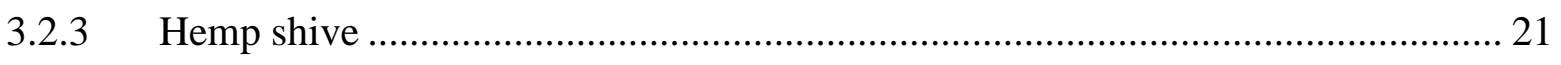

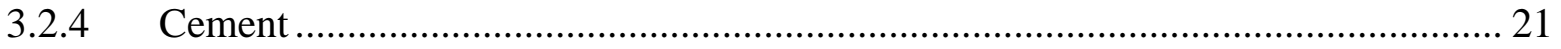

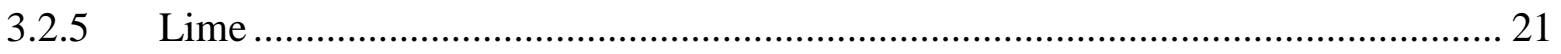

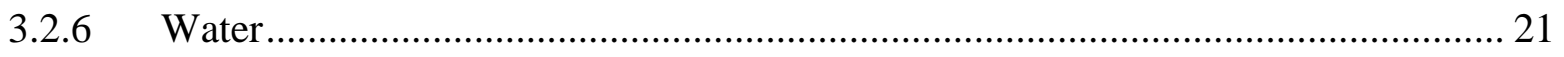




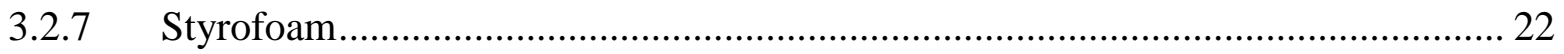

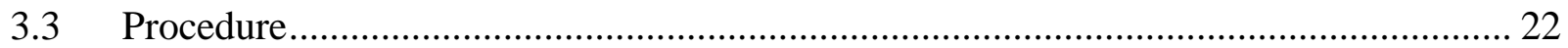

3.3.1 Hempcrete Mix Preparation.......................................................................... 22

3.3.2 Wall Fabrication.......................................................................................... 23

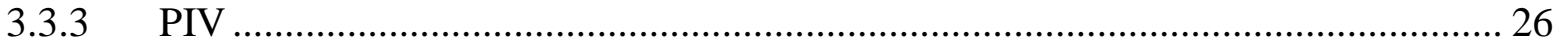

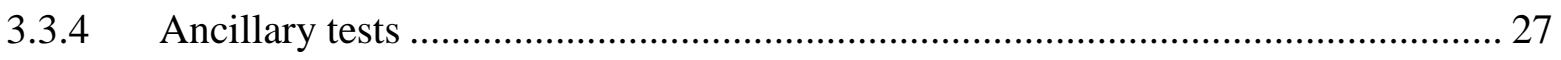

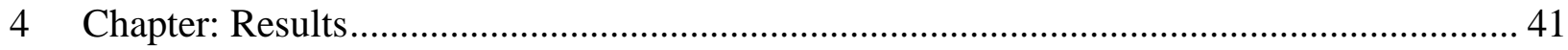

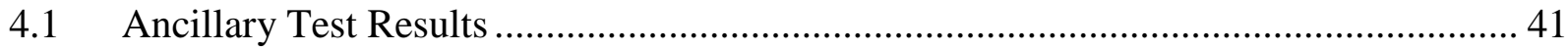

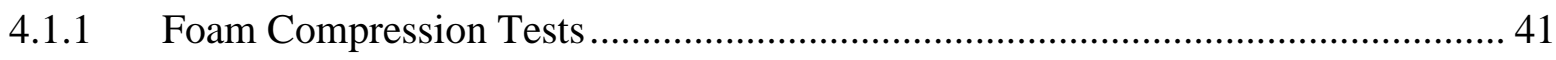

4.1.2 Timber Tests ............................................................................................ 41

4.1.3 Hempcrete Compression Tests ....................................................................... 42

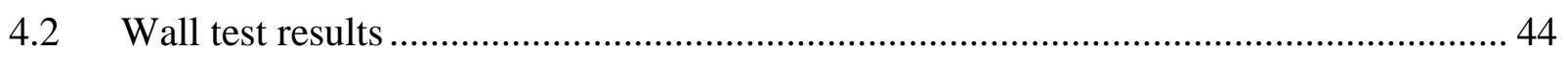

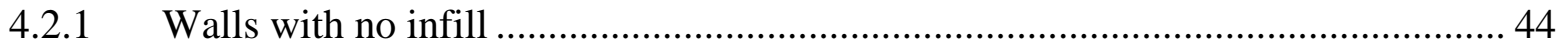

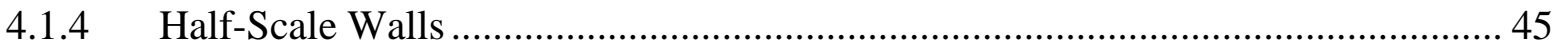

4.1.5 Full-Scale Walls................................................................................. 46

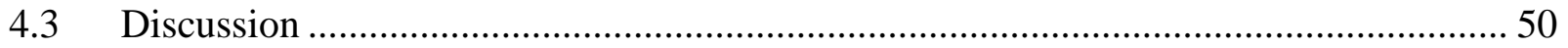

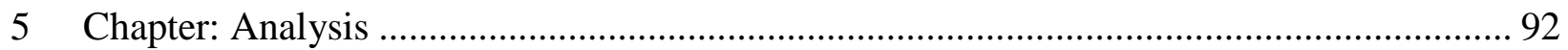

5.1 Calculation of Failure Loads According to CSA- O86-01........................................ 93

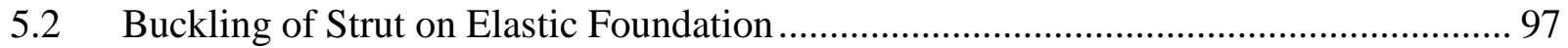

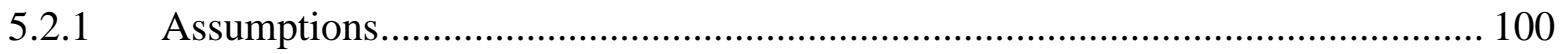

5.3 Discussion on the calculated values and actual results ......................................... 102

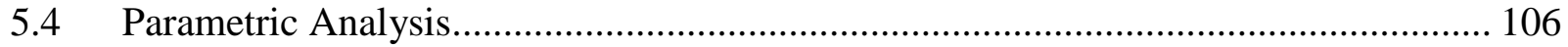

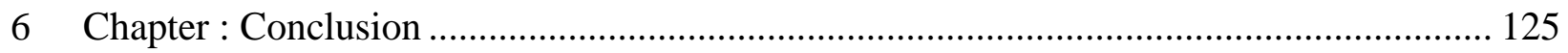

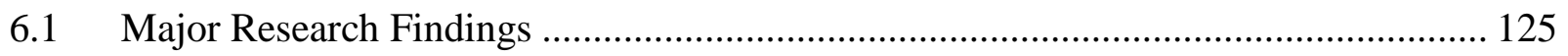

6.1.1 Discussion on Parametric Analysis............................................................... 127

6.2 Recommendations for future work..................................................................... 128

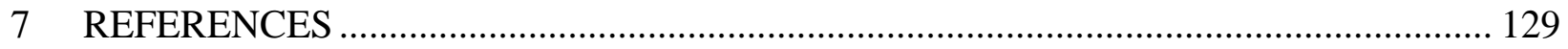




\section{Table of figures}

Figure 2 . 1The usual construction of straw bale walls....................................................... 14

Figure 2 . 2 Plaster being applied on straw bale wall. ....................................................... 15

Figure 2 . 3 A building being constructed with rammed earth bricks in Coberg Ontario. ........... 16

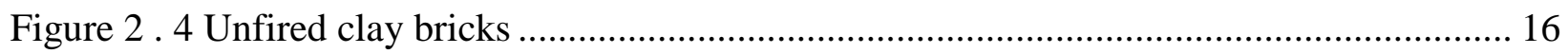

Figure 2 . 5 Harvesting of hemp plants............................................................................. 17

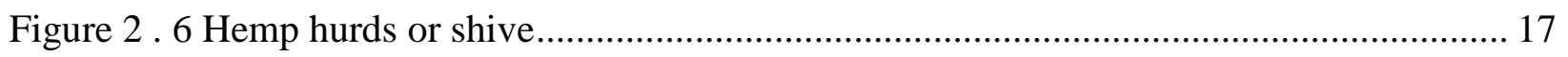

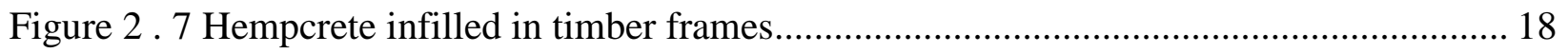

Figure 2 . 8 Spraying hempcrete into walls ( projection process). ........................................ 19

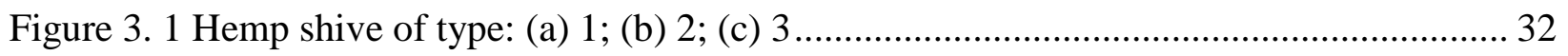

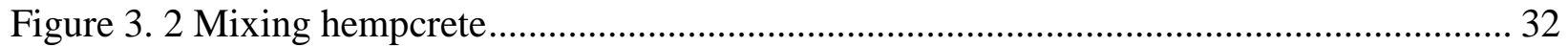

Figure 3. 3 (a) Tamping hempcrete into the wall frame (b) Wall laid on the ground with a plastic sheet at the bottom face being infilled with hempcrete. ...................................................... 33

Figure 3. 4 General structures of the walls tested and the point of application of load P marked. The dimensions $\mathrm{X}$ and $\mathrm{Y}$ of different walls are listed in Table 3.2 ......................................... 34 Figure 3. 5 (a) Instrumentation details Wall 2 and 3; (b) Section A-A details; (c) Typical

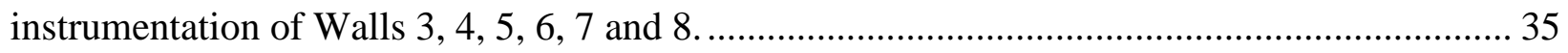

Figure 3. 6 Instrumentation and set up of the shorter walls.............................................. 36

Figure 3. 7 Typical instrumentation and set up of the larger frames $(2133 \mathrm{~mm})$....................... 37

Figure 3. 8 Compression testing hempcrete cylinders ...................................................... 38

Figure 3. 9 Compression testing timber parallel to grain.................................................. 39

Figure 3. 10 Compression testing timber perpendicular to grain............................................ 39

Figure 3. 11 Compression testing of Styrofoam ................................................................ 40

Figure 4. 1 Compressive failure of Styrofoam................................................................... 56

Figure 4. 2 Stress strain curve of Styrofoam tested in compression ........................................ 56

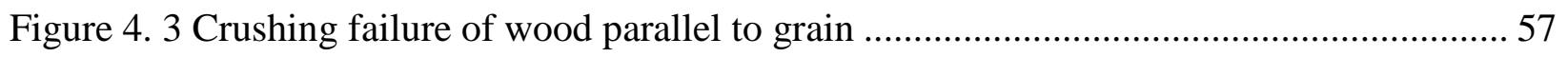

Figure 4. 4 Brooming failure of wood parallel to grain .......................................................... 58

Figure 4. 5 Splitting failure of wood parallel to grain ........................................................ 58 
Figure 4. 6 Typical stress-strain plots for wood parallel to grain: (a) 38x235mm sample; (b) 38x89mm sample. Maximum compressive strength indicated by cross................................... 59

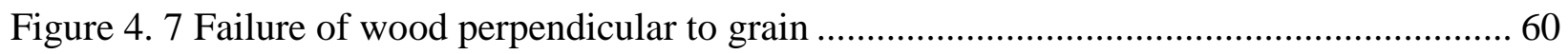

Figure 4. 8 Stress strain graph of wood perpendicular to grain. Maximum compressive strength

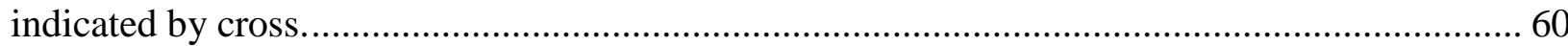

Figure 4. 9 Failure of hempcrete cylinder mix M1 ......................................................... 61

Figure 4. 10 Stress strain graph of hempcrete cylinder mix M1. Maximum compressive strength

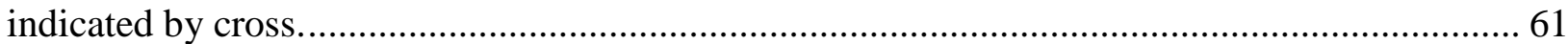

Figure 4. 11 Failure of hempcrete cylinder mix M2 ....................................................... 62

Figure 4. 12 Stress strain graph of hempcrete cylinder mix M2. Maximum compressive strength

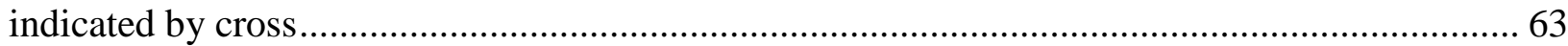

Figure 4. 13 Failure of hempcrete cylinder mix M3 ........................................................... 63

Figure 4. 14 Stress strain graph of hempcrete cylinder mix M3. Maximum compressive strength

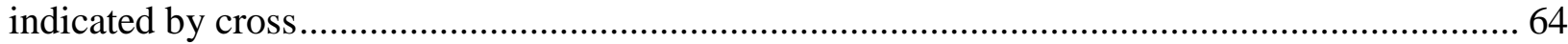

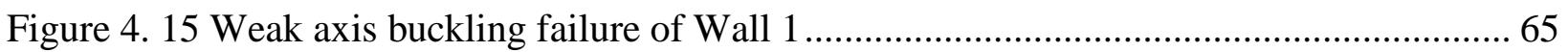

Figure 4. 16 Load versus vertical displacement response of Wall 1 during compressive testing 65 Figure 4. 17 Weak axis buckling failure of 39x235mm timber column (Wall 6) ...................... 66

Figure 4. 18 Load versus vertical deflection of Wall 6.......................................................... 67

Figure 4. 19 Load versus horizontal displacement in direction of buckling obtained from LPs on the middle column wall 6. This clearly depicts a buckling behaviour....................................... 68

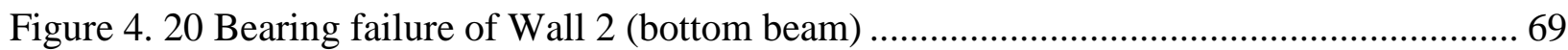

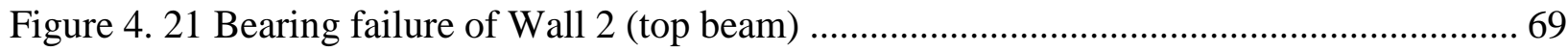

Figure 4. 22 Load versus vertical displacement response of Wall 2 ....................................... 70

Figure 4. 23 Failure of Wall 3: (a) Strong axis buckling of columns. Hempcrete failing in shear planes is highlighted; (b) Side view of the failed wall 3 showing the middle column buckling out of the plane of wall (strong axis) and failed hempcrete falling out of the wall.......................... 72 Figure 4. 24 Load versus lateral displacement for Wall 3. LP 6 and LP5 were placed at about 300mm and $900 \mathrm{~mm}$ below the top of middle column respectively........................................ 73

Figure 4. 25 Load vs Vertical displacements of the LPs on the top beam of wall 3. LP1\&LP2 were on the same side and LP3 and LP4 on the other side of the steel beam (longitudinally) .... 74 Figure 4. 26 Strong axis buckling failure of middle column of Wall 4 ................................... 75 
Figure 4. 27 Cracks in hempcrete of Wall 4 76

Figure 4. 28 Load versus horizontal displacement in direction of buckling obtained from LPs on

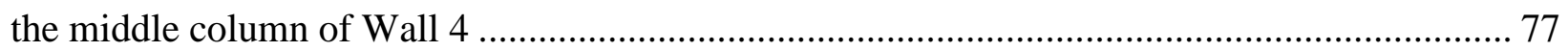

Figure 4. 29 Load versus vertical displacements of the LPs on the top beam of Wall 4............ 78

Figure 4. 30 Strong axis buckling failure of the middle column of Wall 5 ............................. 79

Figure 4. 31 Strong axis buckling failure of the middle column of Wall 5. Failed hempcrete is

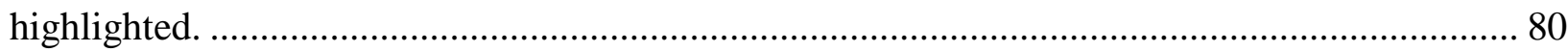

Figure 4. 32 Load versus horizontal displacement in direction of buckling for Wall 5 .............. 81

Figure 4. 33 Load versus vertical displacement of the LPs on the top beam of Wall 5 .............. 82

Figure 4. 34 (a) Bearing failure of middle top beam in wall 7 (b) subsequent failure of hempcrete

Figure 4. 35 Load versus vertical displacement of the LPs on the top beam of Wall 7 ............. 84

Figure 4. 36 Load Vs Horizontal displacement of middle column.......................................... 85

Figure 4. 37 Weak axis buckling failure of the middle column of Wall 8 ............................... 86

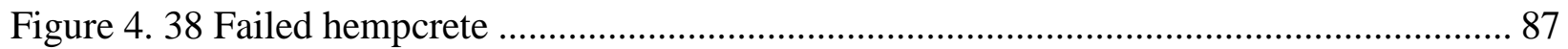

Figure 4. 39 Load versus vertical displacements of the LPs on the top of Wall 8 .................... 88

Figure 4. 40 Load versus horizontal displacement in direction of buckling obtained from LPs on

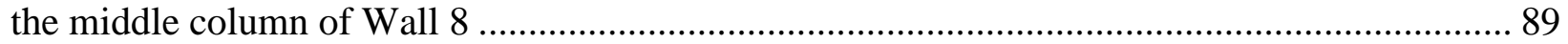

Figure 4. 41 Buckled shape of middle column at different loads (curves obtained from PIV

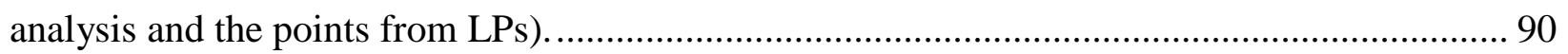

Figure 4. 42 Comparison of the load deflection graphs of wall 6,7 and 8. This depicts the increase in wall strength due to hempcrete infill. 91

Figure5. 1 The comparison of load versus vertical deflection graph of Wall tests 6, 7, 8. Wall 6 had weak axis buckling without any infill, Wall 7 had a hempcrete infill and underwent bearing Failure, Wall 8 had hempcrete infill and it underwent weak axis buckling. ........................... 115 Figure5. 2 The model of column on elastic foundation (bed of springs)................................. 116 Figure5. 3 The analogous situation of the column on elastic foundation with wall 8 . Hempcrete acts as the elastic medium. $\beta$ is calculated by force required to cause unit deflection in hempcrete per unit length of column (Table5.5). 117 
Figure5. 4 The compatibility of deflections of the top steel beam of Wall 3. Tilting of the top steel beam created a moment $\mathrm{P}^{*}$ e about the strong axis, lowering the buckling load about strong axis.

Figure5. 5 The initial buckling mode of column of Wall 3 obtained from PIV analysis. 119 Figure5. 6 The initial buckling mode of two half sine waves from the actual picture during the wall test. 120

Figure5. 7 The final buckled configuration of the central timber column of Wall 8. 121 Figure5. 8 The final buckled curve obtained from PIV analysis. 122 Figure5. 9 The approximate relationship between the density and modulus of elasticity of hempcrete.

Figure5. 10 The variation of strength of timber hempcrete composite wood stud wall with $38 \mathrm{x}$ $140 \mathrm{~mm}$ columns with the density of hempcrete. 124

\section{Table of Tables.}

Table 3. 1 Mix proportions 30

Table 3. 2 Frame dimensions - refer to Figure 3.4 ...................................................................... 30

Table 3. 3 Details of the walls tested. .......................................................................................... 31

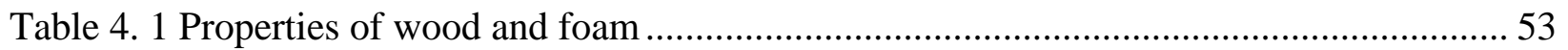

Table 4. 2 Properties of Hempcrete .................................................................................... 54

Table 4. 3 Summary of all Wall test results.................................................................................... 55

Table 5. 1 The compressive resistance of wood parallel to grain with different factors and

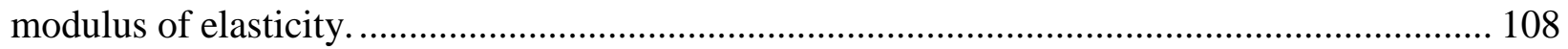

Table 5. 2 Predicted weak axis buckling strength of walls without any infill............................ 108

Table 5. 3 Predicted strong axis buckling strength of all the walls ............................................. 109

Table 5. 4 Predicted bearing strength for each wall..................................................................... 110 
Table 5. 5 Calculation of $\beta$ and equivalent unsupported length for the walls according to the

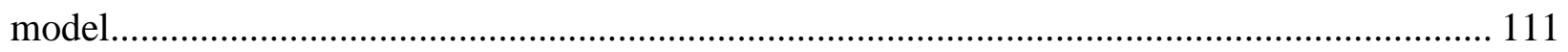

Table 5. 6 Predicted weak axis buckling load of the walls with hempcrete infill support. ........ 112 Table 5. 7 The calculated and actual failure loads of walls without hempcrete infill compared.113 Table 5. 8 The calculated failure loads of different failure modes of walls infilled with hempcrete compared with actual failure loads. . 114 


\section{CHAPTER: INTRODUCTION}

With concern growing in regards to global warming, climate change and the depletion of the Earth's resources, a new focus on environmental sustainability has arisen throughout the world.

Sustainability is "the maintenance of ecosystem components and functions for future generations" and sustainable development is "development that meets the needs of the present without compromising the ability of future generations to meet their own needs” (Meadows 2004). Thus a sustainable building material can be defined as a material that is harvested, produced, or manipulated to a usable building form in such a way as to have no negative impact on future generations during the material's life cycle and disposal.

The building and construction industry accounts for up to $40 \%$ of the world's energy usage (Lippiatt 1999) and approximately $40 \%$ of its raw material usage (Meadows 2004). More sustainable building materials therefore have the potential to have a large impact on global environmental problems.

Steel, concrete, and timber have been tested and approved as the mainstay materials for the building and construction industry. However, each of these materials must be extracted or harvested at one or several sites, transported to a different location for processing, and transported again to the construction site for installation. The amount of energy required for these operations and the material's disposal is called embodied energy. For each of these steps, energy is used and waste is produced, albeit at varying levels depending on which material is harvested. Timber is generally recognized as the material with the least embodied energy of the three (Swan et al 2011). 
More sustainable building materials, such as straw bale and earth, have substantially less embodied energy than processed materials.

\subsection{Natural Building Materials}

Natural building materials, including straw bale construction, rammed earth construction and hempcrete (hemp lime concrete), are gaining importance as low embodied energy and carbon alternatives to conventional building materials. Other benefits of many natural materials include their ability to passively regulate humidity in a building, reduced toxicity, high thermal mass, and biodegradability at the end of life (Walker2006).

Natural fibers such as straw and hemp are annually renewable, with production requiring low degrees of industrialization, at low cost and low fossil fuel consumption. Similarly rammed earth (or unfired clay bricks) is a low embodied energy building material as it can be made from the earth near the construction site (no transportation cost/energy) and does not require a great amount of energy to produce (unfired).

There remain many hurdles to the use of natural building materials in the mainstream construction industry, including a lack of scientific data to quantify their true performance Woolley (2006) and lack of experience in the mainstream construction industry in using these materials. This leads to the perception that these materials are low tech and have poor performance. This perception, however, is changing. There is a growing body of research that is quantifying the performance of natural building materials and showing that they can compete with conventional building materials. There are also some excellent recent examples of the integration of natural building materials in mainstream construction projects. 
This thesis addresses the above research need to scientifically investigate the structural behavior (benefits) of hempcrete when used in a composite timber frame and quantify its strength and structural performance as a building material.

\subsubsection{WHAT IS HEMPCRETE?}

Hemp is a fast growing annual crop (1.5 - 4m height) which is mainly grown for its high tensile strength natural fibre which grows in the stem around the woody core of the plant. This woody core of the plant is chopped up into small sizes (5-25mm) (hurd/shive) and mixed with lime, water and a small quantity of cement (to accelerate setting time) to form a bio-composite mix called hempcrete.

Due to the low density and high porosity of the hemp shive, the combination of hemp and a cementitious binder creates a building material with mechanical, thermal and acoustic properties that differ from those of conventional concrete. It has a lower density, a lower thermal conductivity, and better acoustic insulation properties (Bruijin et al. 2009).

Hempcrete is usually placed in formwork between the structural framing to act as the insulation and cladding material for the walls. The frame is typically timber, but could be cold-formed steel

studs or concrete. The hempcrete is typically covered with a lime plaster, to protect it from exposure to the elements. 


\subsection{OBJECTIVES}

In this thesis, it is hypothesized that the hempcrete infill in timber stud walls can resist weak axis buckling of the timber columns under compressive load and thus add structural strength to such walls by acting as lateral bracing. The main objective of this thesis is to investigate this hypothesis through structural testing of timber walls in-filled with hempcrete. Previous research has mainly focused on investigating the mechanical and thermal properties of hempcrete alone and the effect of variation of different components. Such investigations have shown that hempcrete is not suitable as load bearing material due to its low compressive strength and low elastic modulus (Bruijin et al. 2009).

A series of experiments were carried out to investigate this hypothesis. Several full scale and half scale hempcrete infilled walls were tested. The effect of the density of the hempcrete is also investigated.

A second objective was to investigate analytical methods for predicting the strength of hempcrete in-filled timber walls in compression.

The specific objectives are:

- To experimentally investigate if weak axis buckling of timber column in a frame can be prevented by high density hempcrete $\left(715 \mathrm{~kg} / \mathrm{m}^{3}\right.$ ) by testing $1200 \mathrm{~mm}$ (half scale) high hempcrete infilled timber walls in compression.

- To experimentally investigate if weak axis buckling of timber column in a frame can be prevented by low density hempcrete $\left(313 \mathrm{~kg} / \mathrm{m}^{3}\right)$ by testing $1200 \mathrm{~mm}$ (half scale) high hempcrete infilled timber walls in compression. 
- To investigate experimentally the governing modes of failure for hempcrete infilled walls.

- To test full scale hempcrete infilled timber walls to investigate scale effects on the results.

- To quantify the failure loads of hempcrete in-filled timber walls using timber design equations (CSA O86-01) and column buckling with lateral continuous elastic support solutions.

- To carry out a parametric analysis to investigate the range of density of hempcrete that is likely to be beneficial in providing lateral bracing for standard wood stud walls.

\subsection{Thesis OUTLINE}

The following chapters compose this thesis:

Chapter 2 is the literature review which briefly describes the relevant previous research on hempcrete's mechanical and thermal properties and some research on the compressive strength of timber columns.

Chapter 3 describes the materials and procedure. It lists the details of all the materials used in this research, the procedure in which the walls were fabricated and the instrumentation and the test procedure of the experiments.

Chapter 4 describes the experimental results. It lists the results of wall tests and material property tests including the load deflection and stress strain graphs. It discusses the different failure modes of walls and reasons for particular experimental outcomes.

Chapter 5 is a discussion of the results. Here timber design equations (CSA O86-01) are used to predict the failure loads of the different experiments. These are compared to the actual 
failure loads and different factors for deviations, if any, are discussed. This chapter also describes an analytical model of a strut on an elastic foundation and its analogy to the present walls. This model is used to obtain an equivalent unsupported length for columns having lateral hempcrete support. This length is used in timber design equations (CSA O86-01) to predict the practical failure loads of walls. Chapter 5 also describes a parametric analysis which investigates the density range of hempcrete which will provide lateral support for standard wood stud walls. Chapter 6 summarizes the major findings and conclusions from the research. 


\section{CHAPTER: LITERATURE REVIEW}

\subsection{INTRODUCTION}

Sustainability is fast becoming a significant concern for the Canadian engineering and construction ("E\&C") industry. Companies have to comply with more complex green building standards, improve their environment health and safety records, and manage issues of waste disposal.

Buildings account for thirty-eight percent of the $\mathrm{CO}_{2}$ emissions in North America (according to U.S green building council) (Lippiatt 1999).

To comply with the environmental regulations, the demand for carbon negative and/or zero footprint buildings is at an all-time high.

Natural building materials can be defined as materials that are harvested, produced, or manipulated to a usable building form in such a way as to have no negative impact on future generations during the material's lifecycle and disposal (Swan et al 2011). Some examples are straw bale, hempcrete and rammed earth bricks.

Though these natural building materials have been used traditionally for hundreds or even thousands of years, few building standard guidelines exist to confirm usability and structural adequacy. In Canada, certification of a structure's safety is a requirement. If the building's construction does not follow that of a standard building code, its certification must come in another form. An alternative form of certification is a professional engineer's approval and often involves third-party testing to evaluate the structural integrity of the building's design. This 
method of approval is not cost effective and hinders the progress of new construction using natural building materials. The body of scientific knowledge must be further developed in order to develop a building standard, which will allow natural building structures to be erected and certified more freely.

\subsection{STRAW BALE CONSTRUCTION}

Straw bale construction is not a new idea (MacDougall et al 2007). For approximately 100 years, straw bales have been stacked and plastered (Figure 2.1) to create single storey buildings such as the 4Cs building in Haliburton, Ontario (Vardy et al. 2006). There are several hundred of these structures in Canada and the United States. Straw bale construction offers many advantages, but traditional straw bale construction also has disadvantages that make it difficult to integrate with modern construction. Wall thicknesses and heights are highly variable, making it difficult to obtain level walls and straight corners. Bales must be protected during construction to ensure they do not become wet. Figure 2.2 shows the application of plaster on a straw bale wall.

\subsection{RAMMED EARTH CONSTRUCTION}

Unfired clay bricks and rammed earth are two more ancient technologies that are finding increasing use in modern sustainable buildings. Clay and sand are mixed with water and then placed in formwork to either form bricks, or walls or columns. Often soil from the building site is used, resulting in an extremely low embodied energy structural element with high thermal mass. Conventional fired clay bricks require large amounts of energy for their production and result in the release of large amounts of carbon dioxide (MacDougall 2007).Unfired clay and rammed earth must be protected from exposure to the elements, so in most cases they are only 
used for interior elements. Figure 2.3 shows a building under construction with rammed earth brick walls. Figure 2.4 shows rammed unfired earth bricks.

\subsection{HEMPCRETE}

Hemp is a rapidly growing, annually renewable plant (Figure 2.5). Hempcrete is a biocomposite material made from hemp, lime and water.

It is purported that there is more CO2 locked-up in the process of growing and harvesting of the hemp than is released in the production of the lime binder Harris et al (2009). The woody core of the hemp stalk, called hurd or shive (Figure 2.6), is milled to particles of about10-15 mm in length, and excess fiber and dust is removed. The lime is typically combined with a small amount of cement to reduce the curing time. This lightweight mixture has proven to have good insulation properties, as indicated by recent research. Arnaud and Samri (2007) indicated that the insulation value of hempcrete, although a function of the relative humidity and density, is similar to that of aerated autoclaved concrete. The thermal conductivities of hempcrete of densities 548 $\mathrm{kg} / \mathrm{m} 3$ and $245 \mathrm{~kg} / \mathrm{m} 3$ are $0.114 \mathrm{~W} /(\mathrm{mK})$ and $0.071 \mathrm{~W} /(\mathrm{mK})$, respectively. The thermal conductivity of aerated concrete $(500 \mathrm{~kg} / \mathrm{m} 3)$ is $0.12 \mathrm{~W} /(\mathrm{mK})$ while the thermal conductivity of fiber board insulation is $0.048 \mathrm{~W} /(\mathrm{mK})$.

It is typically cast as an in-fill material in a structural frame (Figure 2.7), however it can be used in an array of applications from roof insulation to wall construction to flooring. Hempcrete does not rot [when used above ground due to presence of lime] and is mostly biodegradable. 


\subsubsection{HEMPCRETE RESEARCH}

This section gives a brief review of research undertaken on hempcrete to date. The research mainly concentrates on the thermal and mechanical material properties of hempcrete and how it varies with density and proportions of binder to hemp shive in the hempcrete mix

(Arnaud et al 2000) studied the mechanical and thermal properties of hemp mortars and wools using experimental and theoretical approaches. Compressive strength tests were carried on hempcrete cylinders of various formulations of hemp mortar and age. It was found that compressive resistance increases with increase in binder percentage and age of the sample. A theoretical model was proposed which predicted the conductivity of bulk hemp or hemp mortar as a function of density and formulations of mortar and it was found to be in good agreement with lab results. It indicated that the conductivity of hempcrete increases with increase of density and binder content of hempcrete. (For densities $550 \mathrm{~kg} / \mathrm{m} 3$ Compressive strength $\sigma \mathrm{max}-0.22 \mathrm{Mpa}$ Elastic modulus E-29Mpa). Thus there is a trade-off between the insulation capability and structural strength. These must be balanced so that hempcrete can be used as a suitable building material.

(Bruijin et al. 2009) examined the effect of using different binding agents in combination with hemp shive and fibres. Contemporary hempcrete only uses the woody core part of the hemp, the shive. However, using both hemp shive and fibers may improve the mechanical strength, eliminating the need for a fiber separation process. The investigation looked into the feasibility of using the entire fragmented hemp stalk, and also studied some important material properties such as compressive strength, splitting tensile strength, water sorption and frost 
resistance. Varying proportions of the lime-based binders were tested, as were five mixes using the binding agents hydrated lime, hydraulic lime, and cement. Specimens were cured for 12 weeks at room temperature and 40 days in a carbonation room (4.5 vol\% CO2). Using both shive and fibers in hempcrete may be advantageous for countries such as Sweden where facilities for separating hemp from shive are not commercially available.

(Bruijin et al. 2009) found out using a hemp material that includes both shive and fibers does not appear to create a mechanically stronger hempcrete compared to only using shive. Compressive strength values in combination with the low Young's modulus of the hempcrete mixtures tested indicate that the material in its present form cannot be used as a load bearing material. More rigidity and higher compressive strength are needed. However, it can be used in combination with other structural material to form load bearing structures.

Hemp shives have a highly porous structure and strong capillarity effects. Hemp is able to absorb large amounts of water (up to five times its own weight). For this reason, the manufacture of lime and hemp concrete by a conventional mixing and casting technique always requires a significant excess of water with respect to what is needed to slake the lime. This results in setting and drying times lasting several months, which is unacceptable in industry. Another concern with hempcrete is that its density largely depends upon the degree of compaction. It is difficult to maintain the same degree of compaction for casting hempcrete in large quantities.

Elfordy et al. (2007) studied the mechanical and thermal properties of hempcrete manufactured by the projection process (Figure 2.8). It consists in the projection, either directly on a wall formwork or in a block mould, of a mixture of lime, shive and water. A dry premix of 
lime and shive is conducted by air through a hose, and water is added just before the hose outlet. The degree of compaction can easily be controlled by varying the distance of projection. They carried out an experimental research program to find the relationship of sprayed hempcrete's density with its compressive strength, modulus of rigidity, toughness, and bending strength. They determined the lime carbonation kinetics by x-ray diffraction. They also proposed models of predicting thermal conductivity, and different mechanical strengths (compressive strength, modulus of rigidity, toughness, and bending strength). Their experimental data agrees well with their model.

\subsubsection{LACK OF STRUCTURAL RESEARCH ON HEMPCRETE}

It has been established from the above research that hempcrete cannot be directly used as a structural material due to its low compressive strength and elastic modulus. Most of the research undertaken on hempcrete concentrates on the material properties. No significant research is available, which studies the composite structural behavior of hempcrete as infill in timber frame walls (the common application of hempcrete in buildings). Comprehensive structural research on hempcrete infill walls can find out if it can have any indirect structural benefits which can increase the load carrying capacity of such walls. If such research can predict the increase of wall strength due to hempcrete infill, then proper scientific design procedures can be established. 


\subsection{TIMBER}

This thesis studies (experimentally and analytically) timber stud walls infilled with hempcrete. To design the experiments, understand the results and predict the wall strengths, it is very important to understand the behavior of timber columns. Various timber construction standards (for example, CSA-O86-01) provide guidelines for timber columns. To understand the implications of the guidelines and apply them correctly to predict the ultimate strength of the timber stud walls the following research was reviewed.

Buchanan et al. (1985) summarize the findings of a comprehensive investigation into the behavior of lumber subjected to eccentric axial loading, which was carried out at two Canadian universities. The study included analytical modeling and an extensive experimental program using full-size lumber. The results of the investigation have been used in to propose improved design methods, using design charts and approximate formulae for in-plane behavior. The discussion was extended to general loading cases and biaxial behavior. Input information required for the design process is also discussed. These methods are based on the results of experimental and analytical studies into the strength of lumber under eccentric axial loading. The proposed design methods reflect the behavior of real materials more accurately than existing methods. They offer potential for more efficient and economical design of certain types of timber structures.

Johns (1991) discusses how historical timber design methods were based on studies carried out on clear wood samples, and are no longer appropriate because they do not recognize that wood with defects behaves in compression as a nonlinear ductile material and in tension as an elastic brittle material subject to size effects. Timber column design methods now take account 
of a body of research work on timber properties from in-grade tests and on strength considerations using notions of stressed volume. The cubic Rankine-Gordon Neubauer(1973) column curve is deemed to be simple to use and sufficiently close both to experimental results and to other more rigorous, but less convenient, formulations. A factor to adjust compression strength for the length of columns is proposed (size factor Kzc ), justified by both experimental and numerical studies. The new Canadian code formulation for timber columns is based on the above considerations, with some quite conservative choices for certain parameters based on engineering judgement.

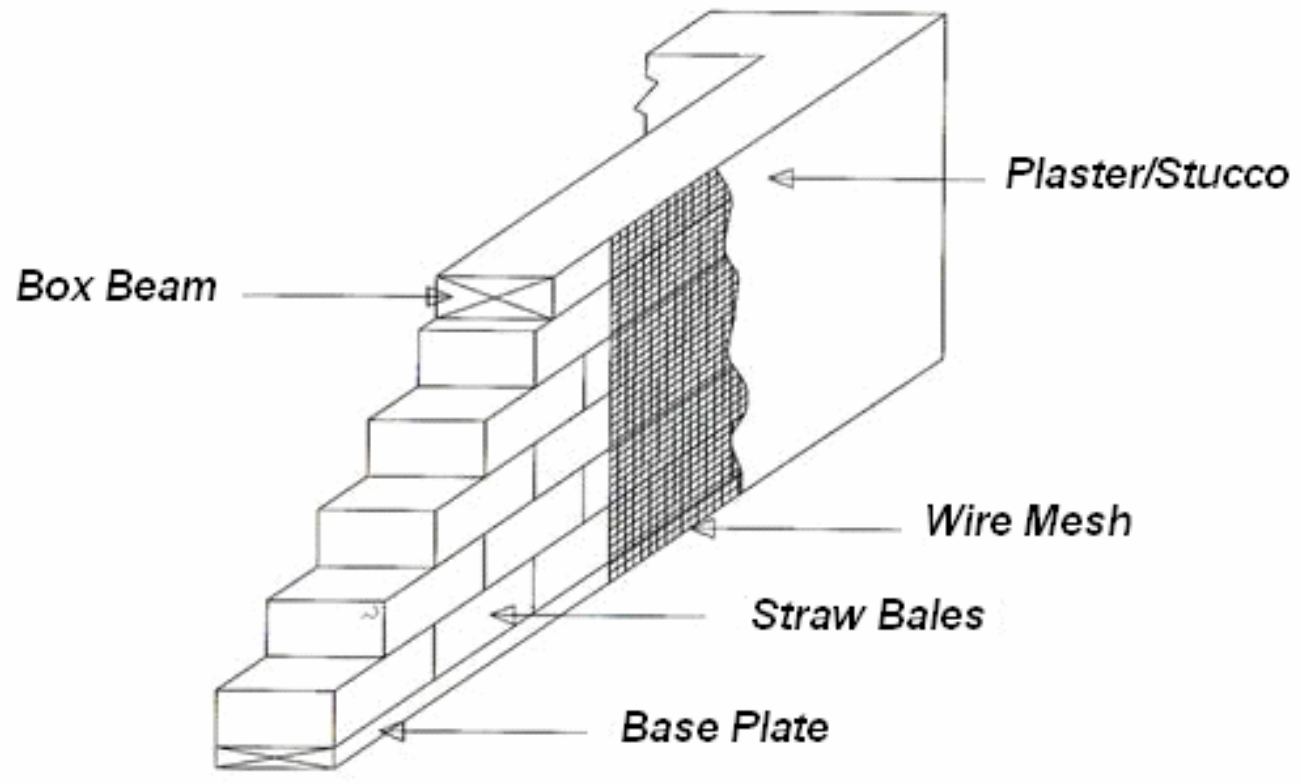

Figure 2.1The usual construction of straw bale walls 


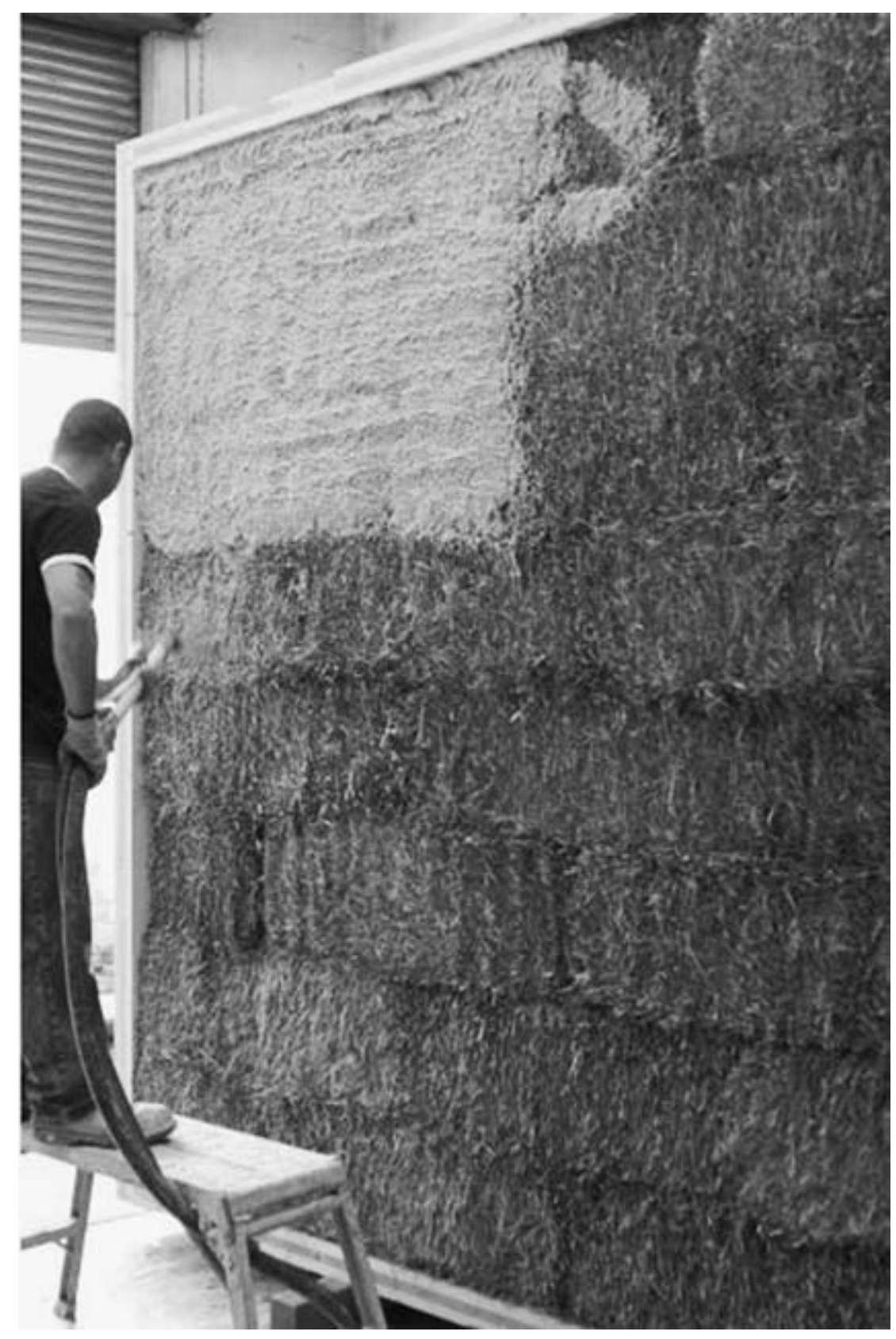

Figure 2.2 Plaster being applied on straw bale wall. 


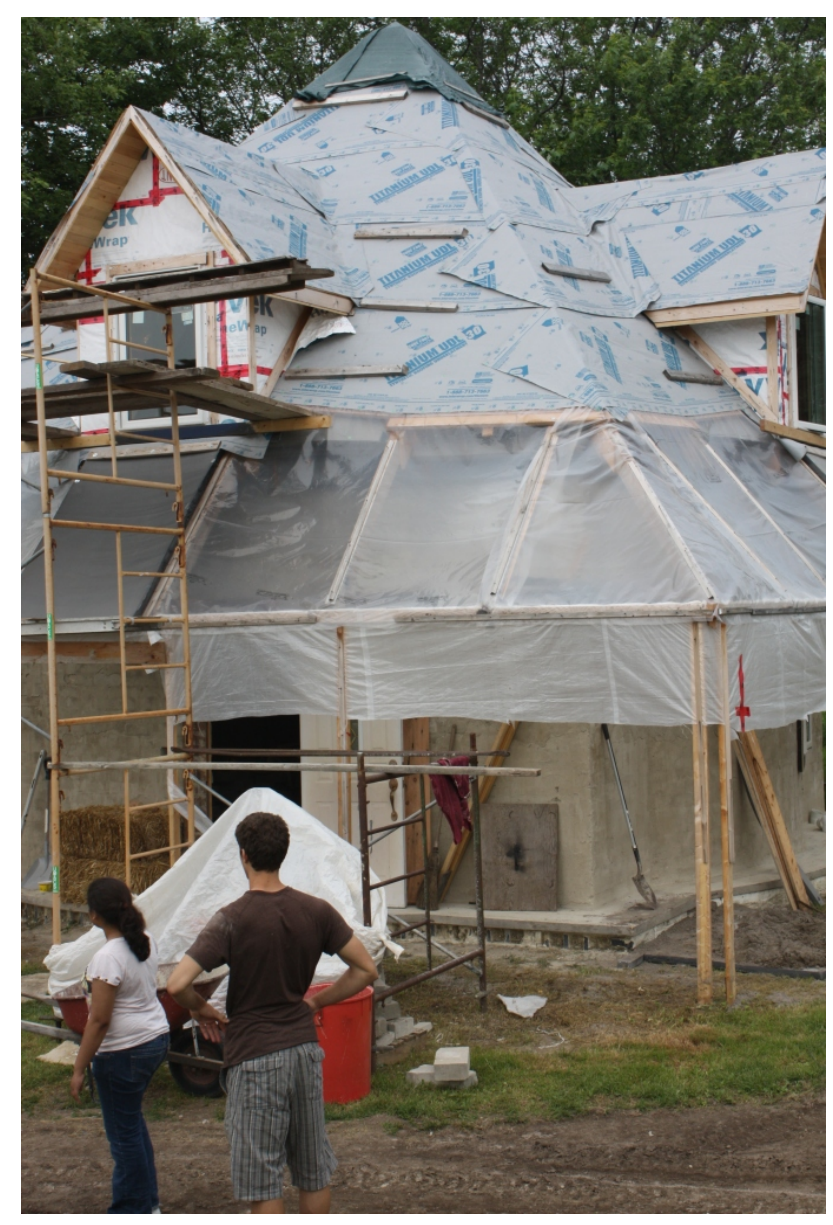

Figure 2.3 A building being constructed with rammed earth bricks in Coberg Ontario.

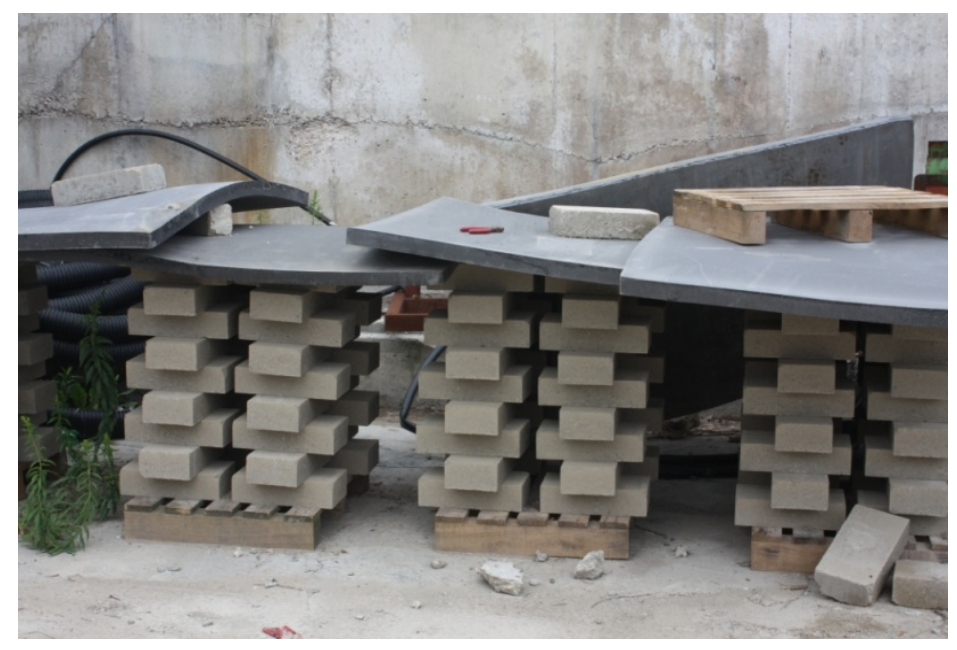

Figure 2.4 Unfired clay bricks 


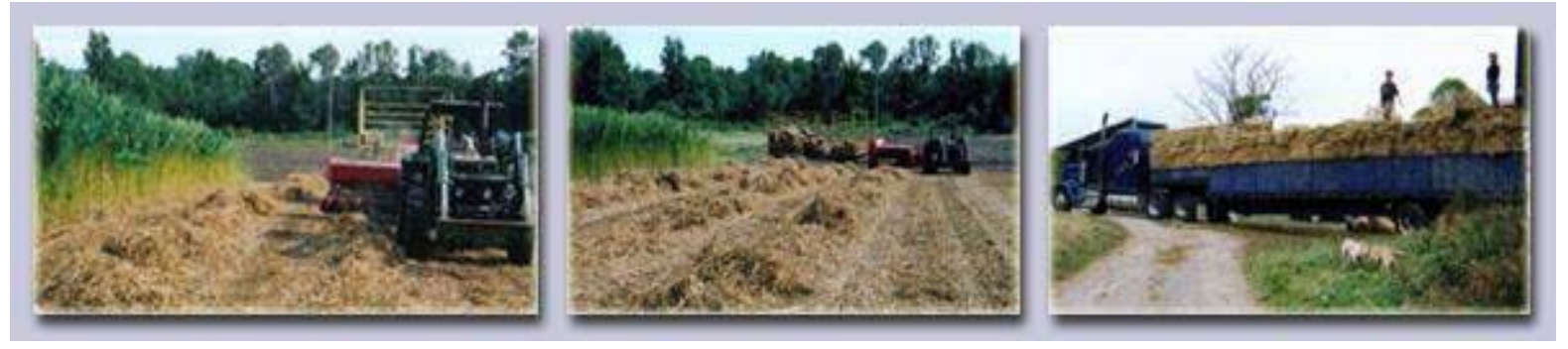

Figure 2.5 Harvesting of hemp plants

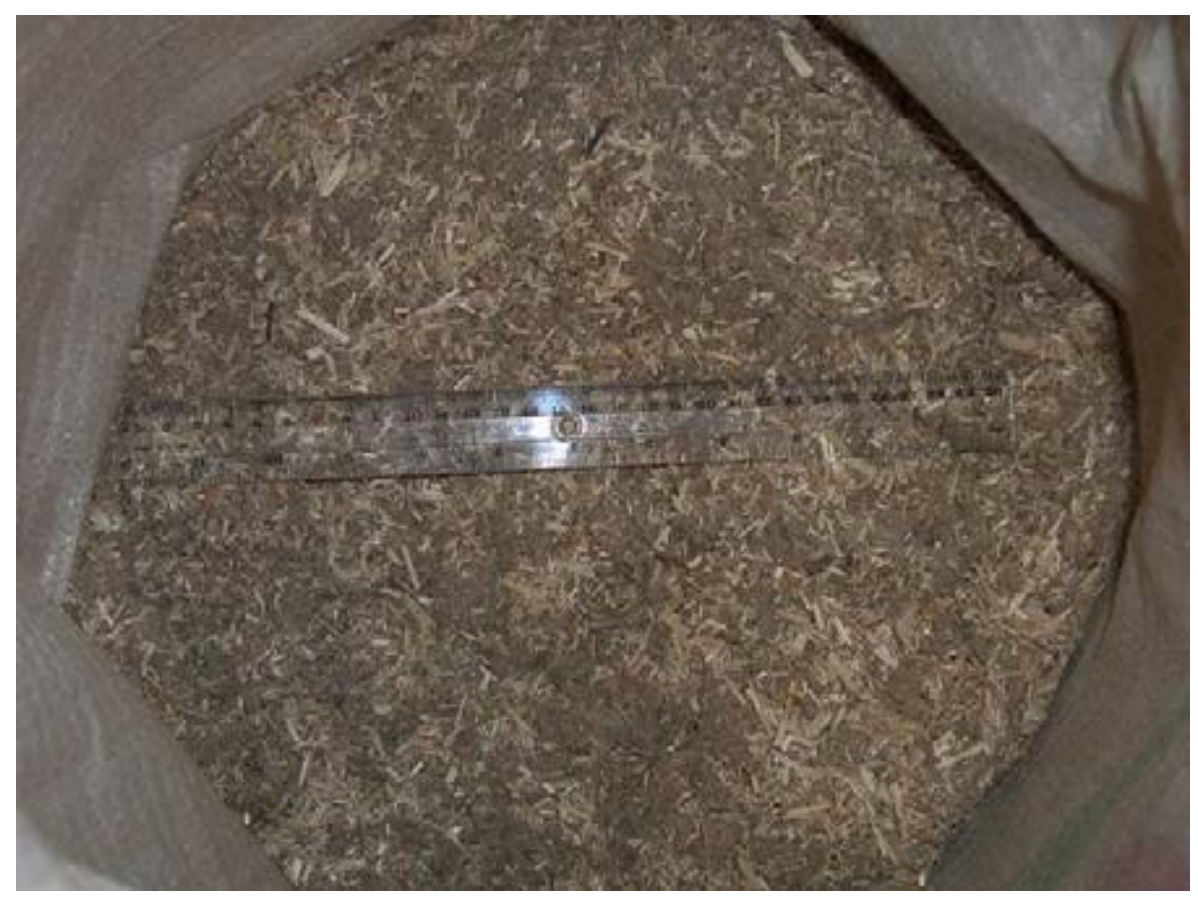

Figure 2.6 Hemp hurds or shive 


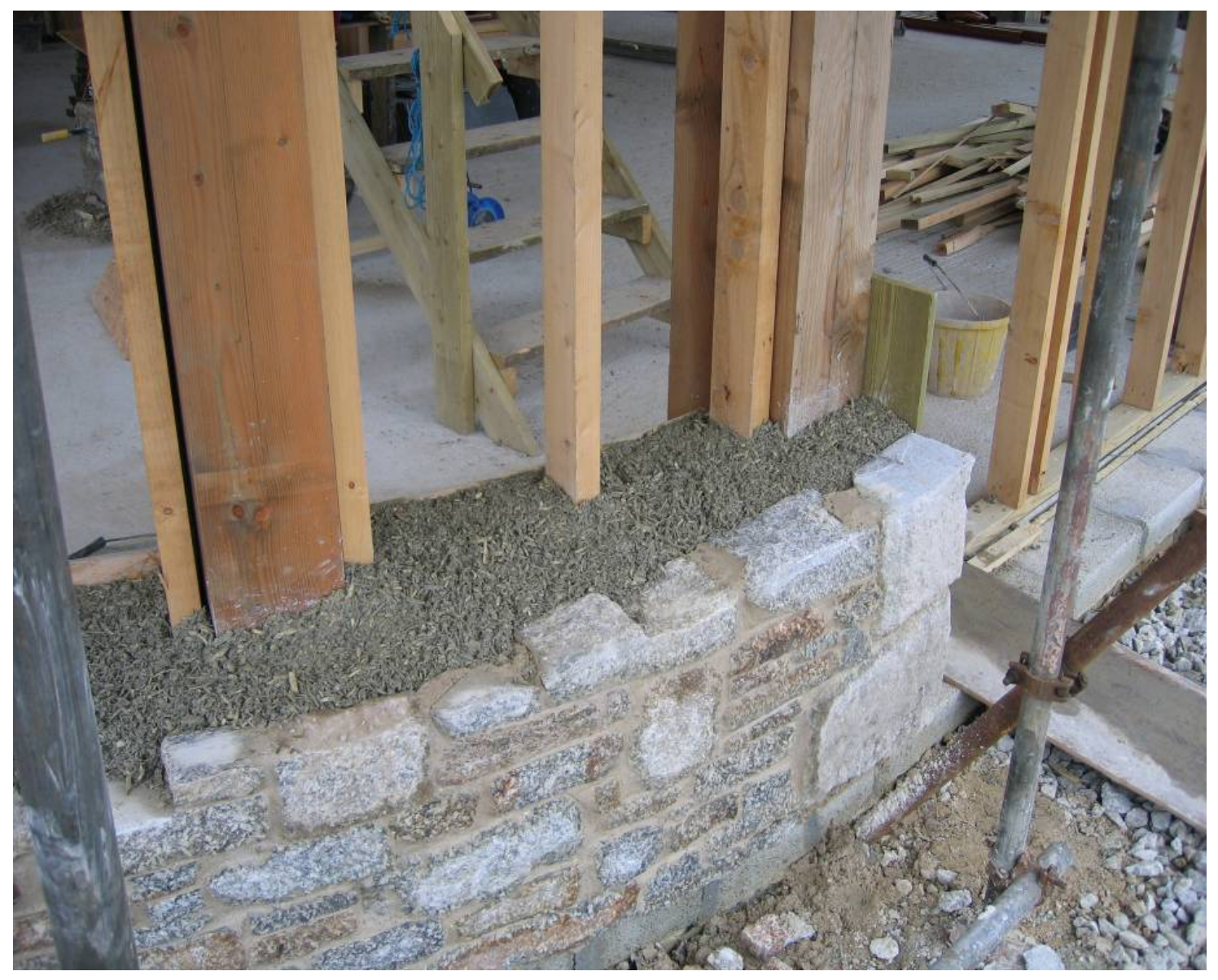

Figure 2.7 Hempcrete infilled in timber frames 


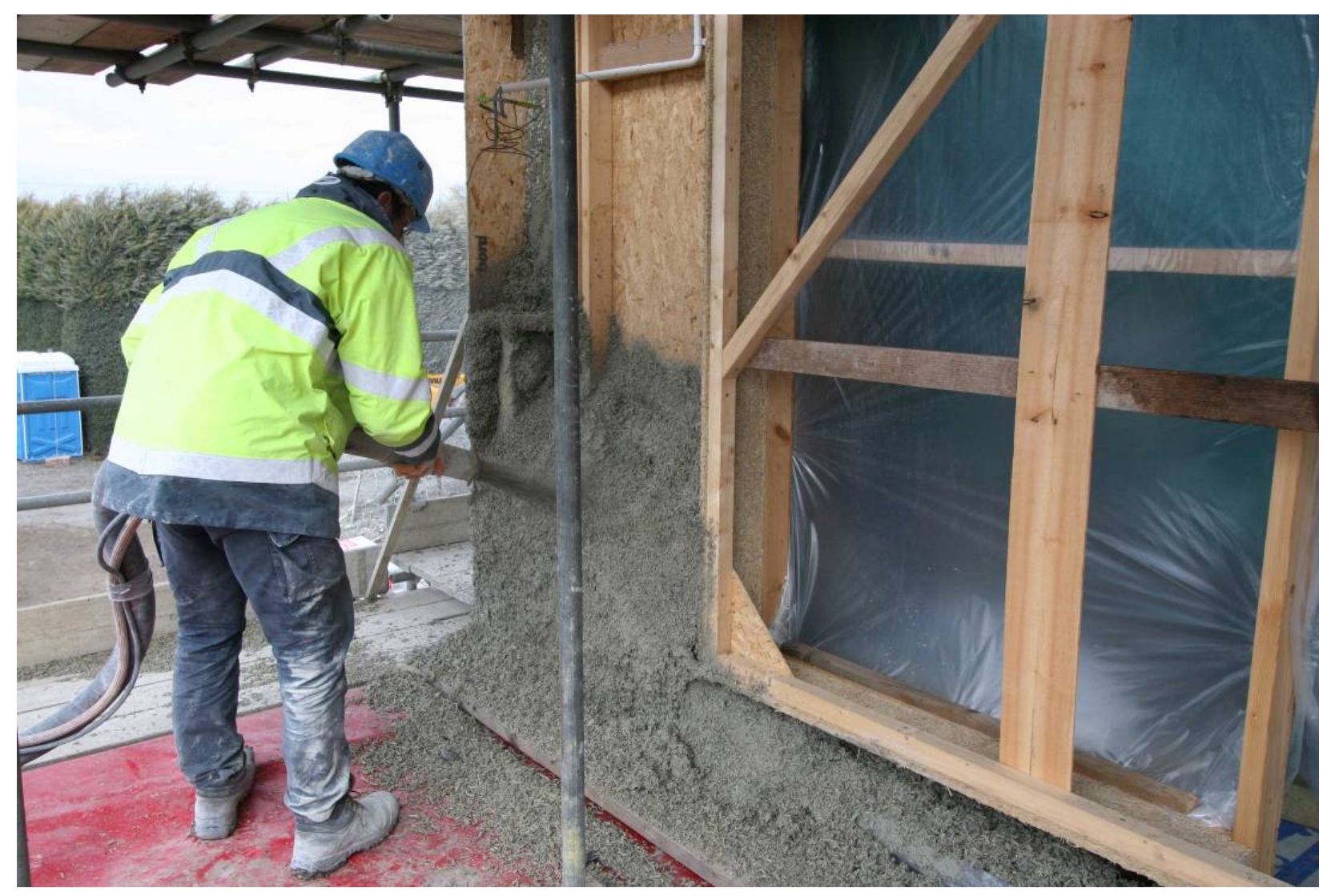

Figure 2.8 Spraying hempcrete into walls ( projection process). 


\section{CHAPTER: MATERIALS AND PROCEDURES}

\subsection{INTRODUCTION}

This chapter gives the details of the materials used, the fabrication of the test sample walls, and the testing procedure used to experimentally study the structural behaviour of hempcrete timber composite walls. Timber-only walls were also tested to provide a baseline for comparison. The details of all the constituents of hempcrete, including hemp shive, cement and hydrated lime, are provided. The process of making hempcrete is discussed. The procedure for fabricating the composite walls is dealt with in detail. This chapter also describes the procedure used for the structural compressive testing of these walls along with the instrumentation and test setup.

\subsection{MATERiALS}

Eight timber frames were built for the wall specimens. Six of the walls were in-filled with hempcrete. Two walls were not in-filled and were the control specimens intended to simulate conventional construction practice. One frame had "rigid" styrofoam as infill on one side and hempcrete for the other. This was done to "force" the column to buckle by pushing into the weaker hempcrete. The following is a brief description of the different materials used in this study.

\subsubsection{TIMBER}

Five walls were constructed of 38 x 89mm Spruce-Pine-Fir (S-P-F) dry select stud grade wood as per CSA O141-05 and the remaining walls were constructed from 38 x 235mm S-P-F 
select stud grade wood as per CSA O141-05. This is the standard commercial grade timber used for building construction in Canada.

\subsubsection{HEMPCRETE}

Hempcrete is a bio-composite mix of hemp shive, Portland cement, and hydrated lime. Hempcretes of different densities were prepared by using different sizes of the shive (allowing for different degrees of compaction) and by varying the binder content, i.e. the proportion of cement and lime.

\subsubsection{HEMP SHIVE}

Hemp shive are from the chopped woody core of a hemp plant stalk. In this research, three types of shive were used (Figure 3.1). Type 1 shive had an average size of $8 \mathrm{~mm}$ and had hemp fibers mixed with it. Type 2 shive were of about 30mm average in length and did not have any fibers in them. Type 3 shive were of $20 \mathrm{~mm}$ average size and had very fine woody particles in them. This hemp was produced by Hempline Inc. of Canada.

\subsubsection{CEMENT}

The cement used was general purpose Type 10 Portland cement, produced as per ASTM C150M-09.

\subsubsection{LIME}

The lime was hydrated lime, produced as per ASTM C207-06 under the trade name "Bondcrete Mason’s \& Stucco Lime”.

\subsubsection{WATER}

The mixing water used for the hempcrete was potable water. 


\subsubsection{STYROFOAM}

The Styrofoam used was Type IV XP5 extruded polystyrene produced by Dow Chemicals.

\subsection{Procedure}

\subsubsection{HEMPCRETE MiX PREPARATION}

Table 1 provides the mix proportions for the hempcrete mixtures used. The general procedure was to first combine the hemp and binders in a horizontally rotating mixing drum (Figure 3.2). This allows for clumps to be broken down and binding powder to be dispersed evenly throughout the dry hemp. The water was next added in incremental steps. Once all the water had been added, the mixing continued for several minutes afterwards. This ensured that the water was not just soaked up by the hemp. Hemp is an extremely porous material and can soak up large amounts of water through capillary action.

The hempcrete produced was then either poured into cylinders (for ancillary compression testing of the hempcrete) in layers and compacted or was packed in a timber frame for the wall tests (Figure 3.3). Due to the light weight of hemp, almost no compaction was possible under self weight. The larger hemp shive sizes create larger voids and hence a lower density and lower strength. However, the degree of compaction can greatly impact the density of dried hempcrete.

To ensure equal compaction for the cylinder tests, 25 tamps were performed on each layer of hempcrete. Tamping was done with minor force to remove voids and fill in gaps between consecutive layers. The hempcrete was cured in moulds in normal room conditions for two days before it was taken out of the moulds and dried in air for about three weeks. 
It was found from preliminary research that hydration during curing had a detrimental effect on strength of hempcrete due to hemp soaking up water and preventing curing of the binder. Drying the specimens in air reduced setting time and increased the compressive strength of the cylinders.

\subsubsection{WALL FABRICATION}

\subsubsection{Description of Frames Tested}

The details of the frames are illustrated in Figures 3.4 and 3.5. Standard \#8, $50 \mathrm{~mm}$ long steel screws were used to assemble each frame. For each frame, the middle column was the member being tested. The hempcrete was in-filled around this column, thus supporting the weak axis of the column. Side columns were use to hold the hempcrete in place but did not carry any of the applied loads. To ensure this, the middle column was screwed to the top and bottom beams; while the side columns were only screwed to the bottom beam. To keep the hempcrete and side timber column from falling apart during testing a ratcheting strap was put around the wall (Figure 3.6).

Wall 8 had one side infilled with stiff styrofoam layers and the other side in-filled with hempcrete. This was to ensure that the column would buckle in the direction of the hempcrete (determining the direction of buckling ensured appropriate instrumentation attachment and positioning of camera for PIV monitoring of deformations). The styrofoam layers were inserted in the gap between the outer and central timber columns. Styrofoam sheets were cut according to the dimensions of the gaps in the frame. Three styrofoam layers, each about $50 \mathrm{~mm}$ thick, were inserted in the gap. 
The dimensions of each of 8 the frames tested are listed in Table 3.2.

The middle column was either $1220 \mathrm{~mm}$, or 2133mm tall, except for Frame 2 which was $1050 \mathrm{~mm}$ tall (shorter height was to accommodate the Steel I beam on the top in the space available in the Riehle Testing Machine). The dimension of the taller frames was selected to approximate the full height of a timber column in residential construction (typically $2400 \mathrm{~mm}$ long). The columns needed to be slightly shorter (i.e. $2133 \mathrm{~mm}$ ) so that they could be accommodated in the available testing frame. Despite the reduced length, global buckling can be expected for a timber column of this unbraced length. The shorter length columns (i.e. $1220 \mathrm{~mm}$ and $1050 \mathrm{~mm}$ ) were selected to be approximately half the typical timber column height to examine the effect of height on the behaviour of the wall.

There are some differences in the details of the walls as listed in Table 3.3. For Walls 1, 4, 5 and 7, the columns were connected at top and bottom with timber beams, which is similar to typical construction practice.

For Walls 3, 4 and 8, different top and bottom beams were used to eliminate the possibility of the timber beams undergoing bearing failure at the connection to the column. The timber beams were replaced with stiff steel or aluminum beams (Table 3.3). Holes were drilled in the aluminum and steel beams to accommodate the screws for the timber

After the frames were assembled, they were in-filled with hempcrete. A large sheet of plastic was nailed, with small finishing nails, to the back of the wall frame and the frame was laid, plastic side down, on the floor. After each batch of hempcrete was mixed, it was tamped into the frame in small sections to ensure better compaction and elimination of voids (Figure 
3.3). This procedure was used for packing hempcrete infill instead of usual practice of formwork so that the walls could dry faster. It also ensured uniform compaction.

For each frame, three cylinders of hempcrete were prepared to obtain the compressive strength and density. The walls were made to stand upright and the plastic sheet was removed after the initial setting time of about 15 days. The walls were then allowed to air cure for 1.5 to 3 months depending on the thickness and height of the wall until the hempcrete was dry to touch.

\subsubsection{WALl Instrumentation and Test Setup}

The walls were craned into the testing frames. The point of application of load was positioned to be the top beam just above the middle column.

Walls 1, 2 and 3 were tested in compression until failure in a Riehle universal testing machine (Figure 3.6) at a stroke rate of $0.75 \mathrm{~mm} / \mathrm{min}$. Linear potentiometers (LPs) were used to measure the vertical deformation of the frames. Three LPs were placed on the top beam to measure vertical deflection of the frames as shown in Figure 3.5.

Horizontal deformation of the middle column along the strong and weak axes were measured using three horizontal LPs depending upon the expected direction of buckling.

The LPs were placed at different heights to measure the horizontal deflection at those levels (Figure 3.5).

Walls 4 to 8 were tested in a large structural testing frame. Figure 3.6 shows a picture of the typical instrumentation of the large frames. A hand operated hydraulic ram manufactured by Enerpac was used to apply the compressive load at the middle of the top beam above the middle 
column. The walls were tested in compression until failure was observed either by buckling or bearing. A load cell at the point of application was used to measure the load.

For the large walls, three LPs were attached to the top beam to measure vertical deflections and to the middle column for horizontal displacement as shown in Figure 3.7.

A System 5000 data acquisition system (Intertechnology Inc.) was used to record the load and deflection data from the LPs, the load cells and the load and stroke from the Riehle Testing machine and the Unite-O-Matic (the material property testing-wood, styrofoam, hempcrete) testing machine. The scan rate of the data acquisition system varied from 5 scans per second to 10 scans per second in different tests.

The LPs were of either $100 \mathrm{~mm}$ or $25 \mathrm{~mm}$ gauge length. They were calibrated using a micrometer screw gauge with 10 points on a calibration curve, as recorded using the data acquisition system.

For Walls 4, 5 and 6 a 100kN capacity load cell was used while for Walls 7 and 8 the capacity of the load cell was $200 \mathrm{kN}$. The load cell was calibrated using the Riehle testing machine with the data acquisition system.

\subsubsection{PIV}

In addition to the above mentioned instrumentation, the deformations were also monitored through Particle Image Velocimetry (PIV) which was adapted to measure or track displacements in a solid during an ongoing test (DIC -Digital image correlation), through GeoPIV 8 (White et al 2003). GeoPIV 8 is a Matlab module which runs in the Matlab command 
line. It operates by tracking the texture (spatial variation of brightness) within the image of the solid whose deformation is being measured. The initial image is divided up into a mesh of patches. To find the displaced position of one particular search zone in a subsequent image, the correlation between the patch extracted from the first image and a larger search zone in the same area of the new image is determined. The area of the larger search zone in the new image which gives the highest correlation is the new position of the first image patch.

When the new position of the patch is determined, the positional difference of the initial patch and the new patch is the deformation of that part (point) of the structure in terms of pixels. The pixel to actual length conversion is calculated by comparing a known length of an object in the picture and the number of pixels that form that object in the picture for the object.

The precision and accuracy of this technique depends on the size of the patch and texture of the image. Hempcrete has a highly textured surface and so is suitable for using this technique to measure deformations at different parts of the wall. The timber parts of the wall were marked with black crosses to improve their texture. Pictures of the ongoing experiment were taken at regular intervals of 3 seconds. Geopiv8 (White et al 2003) was used to track the deformation of different parts of the tested wall composite from the initial picture at the beginning of the test to the final image at the end. These deformations were compared with the deformations obtained by the LPs.

\subsubsection{ANCILLARY TESTS}

\subsubsection{HEMPCRETE CYLINDER TESTS}

Hempcrete cylinders (100 diameter and 200mm high) were made from the mixes made for the walls. These cylinders were taken out of the moulds after a week. They were left to air 
cure for another week, until dry to touch. The hempcrete cylinders were then tested in compression to failure in a Unite-o-Matic universal testing machine (Figure 3.8). The hempcrete cylinders could not be capped as they are extremely low in strength.

Each hempcrete cylinder was placed concentrically within the loading disc of the machine. The testing machine was equipped with a spherical bearing to ensure uniform distribution of load over the ends of the specimen. The cylinders were compressed at a loading rate of $0.5 \mathrm{~mm} / \mathrm{min}$.

The load and stroke data of the Unite-o-Matic machine was recorded in the data acquisition system from which the load deflection graphs were obtained. Types of failure of the cylinders were noted.

\subsubsection{TIMBER TESTS}

Timber samples were made and tested in compression parallel and perpendicular to the grain in the Unite-o-Matic testing machine according to ASTM D143 - 09 (Figure 3.9).

\subsubsection{COMPRESSION TEST PARALLEL TO GRAIN.}

Compression parallel-to-grain tests were done on $37.5 \mathrm{~mm}$ by $37.5 \mathrm{~mm}$ by $150 \mathrm{~mm}$ timber specimens. Care was taken to make the end surfaces parallel and to ensure that the end grain surfaces were parallel to each other and at right angles to the longitudinal axis of the specimen.

The testing machine was equipped with a spherical head to obtain uniform distribution of load over the ends of the specimen. The specimen was loaded on a 37.5 x $37.5 \mathrm{~mm}$ surface. The load was applied continuously at a stroke rate of $0.5 \mathrm{~mm} / \mathrm{min}$ (Figure 3.9). 
The load and stroke data from the Unite-o-Matic was acquired by the data acquisition system.

\subsubsection{COMPRESSiON TEST PERPENDICUlar tO GRAin}

The compression-perpendicular to-grain tests were performed on $37.5 \mathrm{~mm}$ by $37.5 \mathrm{~mm}$ by 150mm timber samples. Each was loaded through a metal bearing plate of the same width, placed across the upper surface of the specimen at equal distances from the ends and at right angles to the length. The specimens were placed so that the load was applied through the bearing plate to a radial surface. The load was applied continuously throughout the test at a stroke rate of $0.305 \mathrm{~mm} / \mathrm{min}$ (Figure 3.10). This would help us measure the bearing strength of timber when a wooden beam undergoes bearing failure due to load from the stud which is in aperpendicular direction to the grain of wood.

\subsubsection{FOAM TESTS}

Styrofoam specimens of $45 \mathrm{~mm}$ by $45 \mathrm{~mm}$ by $45 \mathrm{~mm}$ were obtained. The foam samples were cut according to the above dimensions using an electric saw. This ensured that the edges remained at right angles. These specimens were loaded in compression in the Unite-o-Matic testing machine (Figure 3.11).

The longitudinal axis of the foam was perpendicular to the loading axis of the machine. The load was applied continuously at a stroke rate of $0.5 \mathrm{~mm} / \mathrm{min}$. 
Table 3. 1 Mix proportions

\begin{tabular}{|l|c|c|c|}
\hline Mixes & M1 & M2 & M3 \\
\hline Units & $(\mathrm{kg})$ & $(\mathrm{kg})$ & $(\mathrm{kg})$ \\
\hline Cement & 2.06 & 1.37 & 1.37 \\
\hline Lime & 1.24 & 0.825 & 0.825 \\
\hline Shiv-1(5mm) & 1.24 & & \\
\hline Shiv-2(20mm) & & 1.24 & \\
\hline Shiv-3(12mm) & & & 1.24 \\
\hline Water & 4.05 & 2.7 & 2.7 \\
\hline
\end{tabular}

Table 3. 2 Frame dimensions - refer to Figure 3.4

\begin{tabular}{|l|l|l|l|l|l|l|l|l|}
\hline $\begin{array}{l}\text { Frame } \\
\text { no. }\end{array}$ & 1 & 2 & 3 & 4 & 5 & 6 & 7 & 8 \\
\hline $\mathbf{X ~ m m}$ & 300 & 600 & 550 & 550 & 550 & -- & 550 & 550 \\
\hline $\mathbf{Y ~ m m}$ & 1220 & 1220 & 1050 & 2133 & 2133 & 2133 & 2083 & 2083 \\
\hline
\end{tabular}


Table 3. 3 Details of the walls tested.

\begin{tabular}{|c|c|c|c|c|c|c|}
\hline Wall & $\begin{array}{c}\text { Height of } \\
\text { wall(mm) }\end{array}$ & $\begin{array}{c}\text { column } \\
\text { dimension } \\
\mathbf{( m m}\end{array}$ & $\begin{array}{c}\text { Hempcrete } \\
\text { in-filled? }\end{array}$ & $\begin{array}{c}\text { Density of } \\
\text { hempcrete } \\
\mathbf{k g} / \mathbf{m}^{\mathbf{3}}\end{array}$ & Top beam & $\begin{array}{c}\text { Bottom } \\
\text { beam }\end{array}$ \\
\hline 1 & 1220 & $39 \times 89$ & no & & wood & wood \\
\hline 2 & 1220 & $39 \times 89$ & yes & 715 & wood & wood \\
\hline 3 & 1050 & $39 \times 89$ & Yes & 313 & $\begin{array}{c}\text { steel I } \\
\text { section }\end{array}$ & $\begin{array}{c}\text { aluminum } \\
\text { plate }\end{array}$ \\
\hline 4 & 2133 & $39 \times 89$ & Yes & 313 & wood & wood \\
\hline 5 & 2133 & $39 \times 89$ & yes & 313 & wood & $\begin{array}{c}\text { aluminum } \\
\text { bottom plate }\end{array}$ \\
\hline 6 & 2133 & $39 \times 235$ & no & & $\begin{array}{c}\text { aluminum } \\
\text { plate }\end{array}$ & $\begin{array}{c}\text { aluminum } \\
\text { plate }\end{array}$ \\
\hline 7 & 2133 & $39 \times 235$ & Yes & $313 / 415$ & wood & $\begin{array}{c}\text { aluminum } \\
\text { plate }\end{array}$ \\
\hline 8 & 2133 & $39 x 235$ & Yes & foam/415 & steel plate & $\begin{array}{c}\text { aluminum } \\
\text { plate }\end{array}$ \\
\hline
\end{tabular}




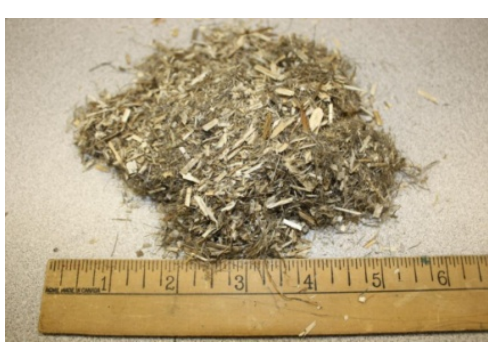

(a)

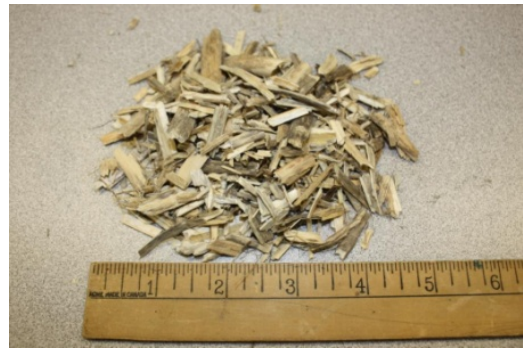

(b)

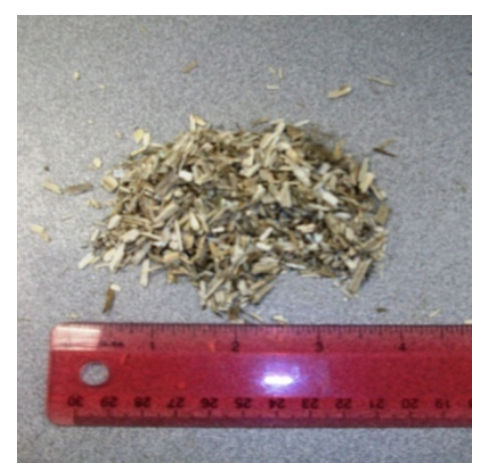

(c)

Figure 3.1 Hemp shive of type: (a) 1; (b) 2; (c) 3

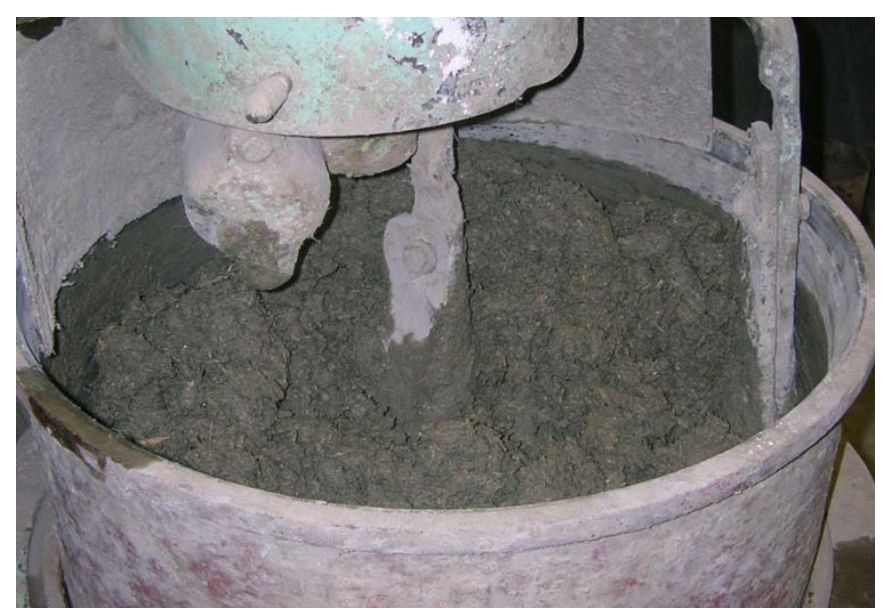

Figure 3.2 Mixing hempcrete 


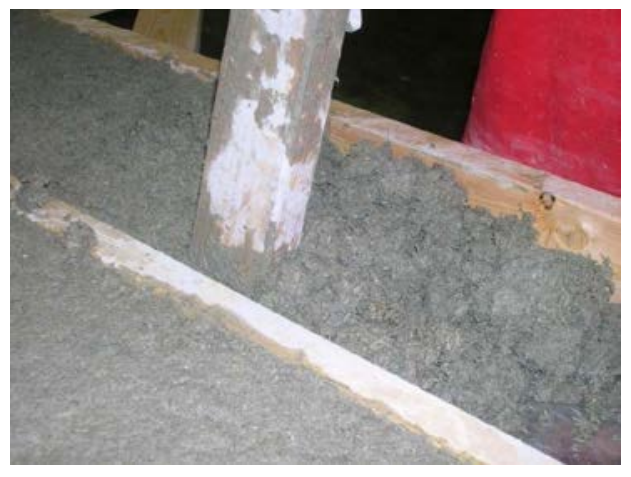

(a)

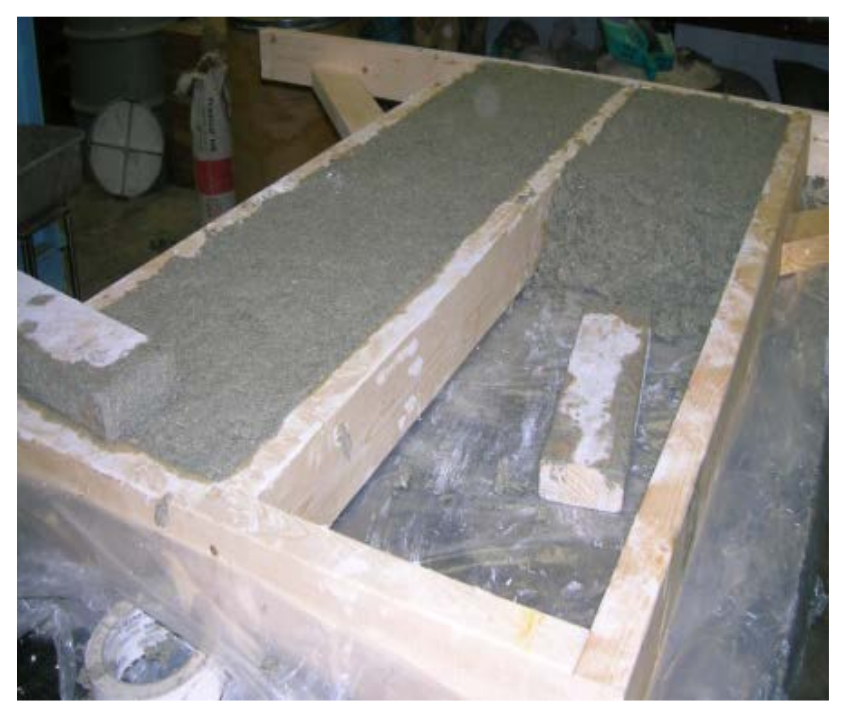

Figure 3.3 (a) Tamping hempcrete into the wall frame (b) Wall laid on the ground with a plastic sheet at the bottom face being infilled with hempcrete. 


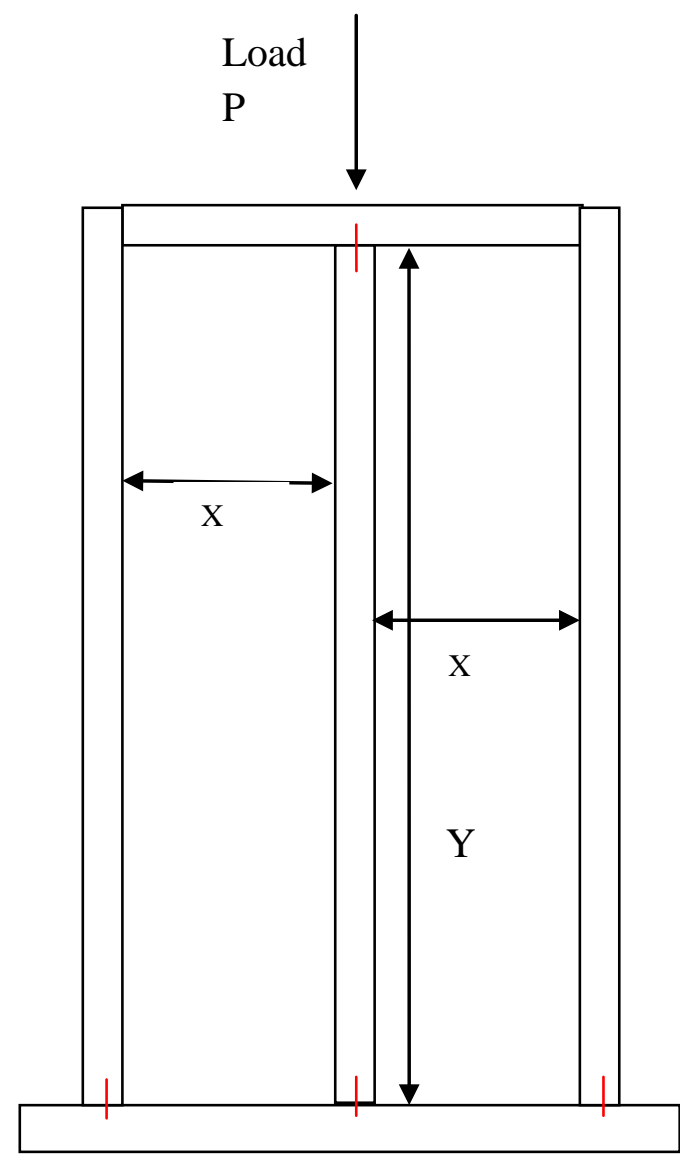

Figure 3.4 General structures of the walls tested and the point of application of load $\mathrm{P}$ marked. The dimensions $\mathrm{X}$ and Y of different walls are listed in Table 3.2 

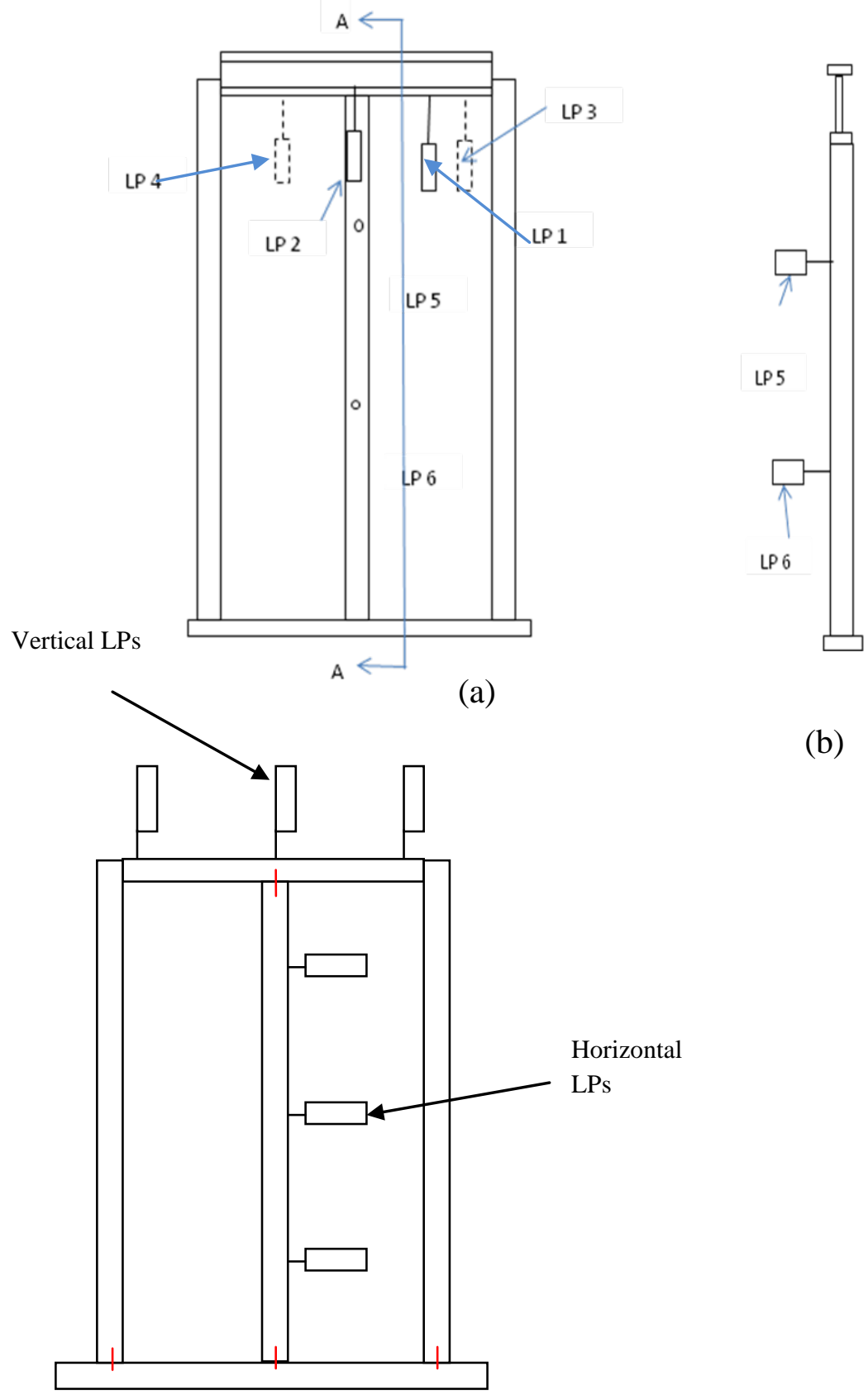

(c)

(b)

Figure 3.5 (a) Instrumentation details Wall 2 and 3; (b) Section A-A details; (c) Typical instrumentation of Walls 3, 4, 5, 6, 7 and 8. 


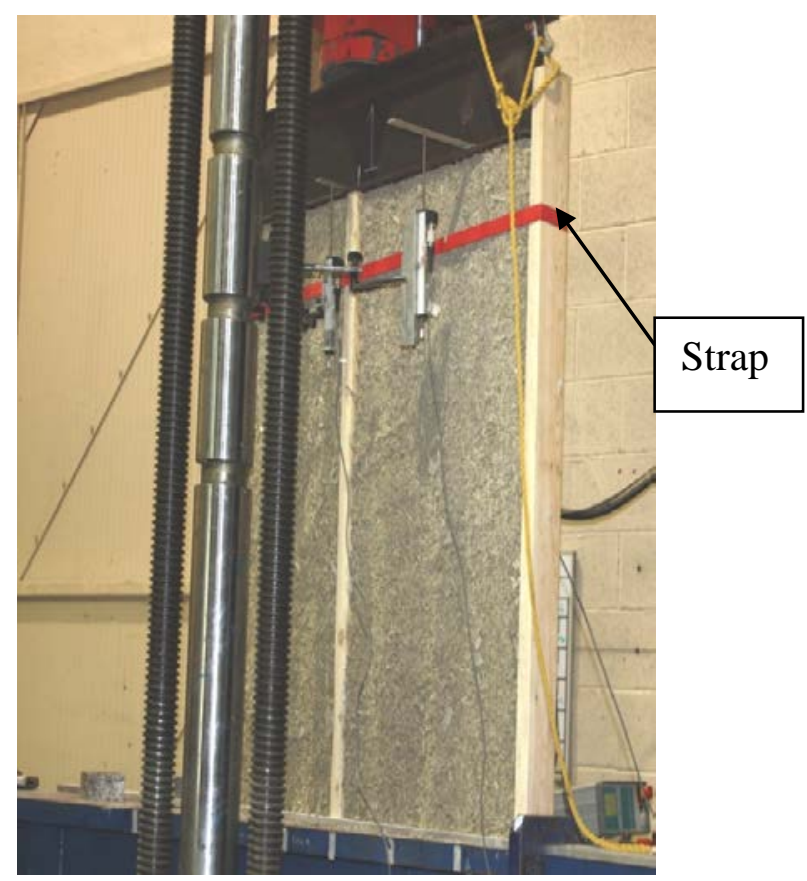

Figure 3.6 Instrumentation and set up of the shorter walls 


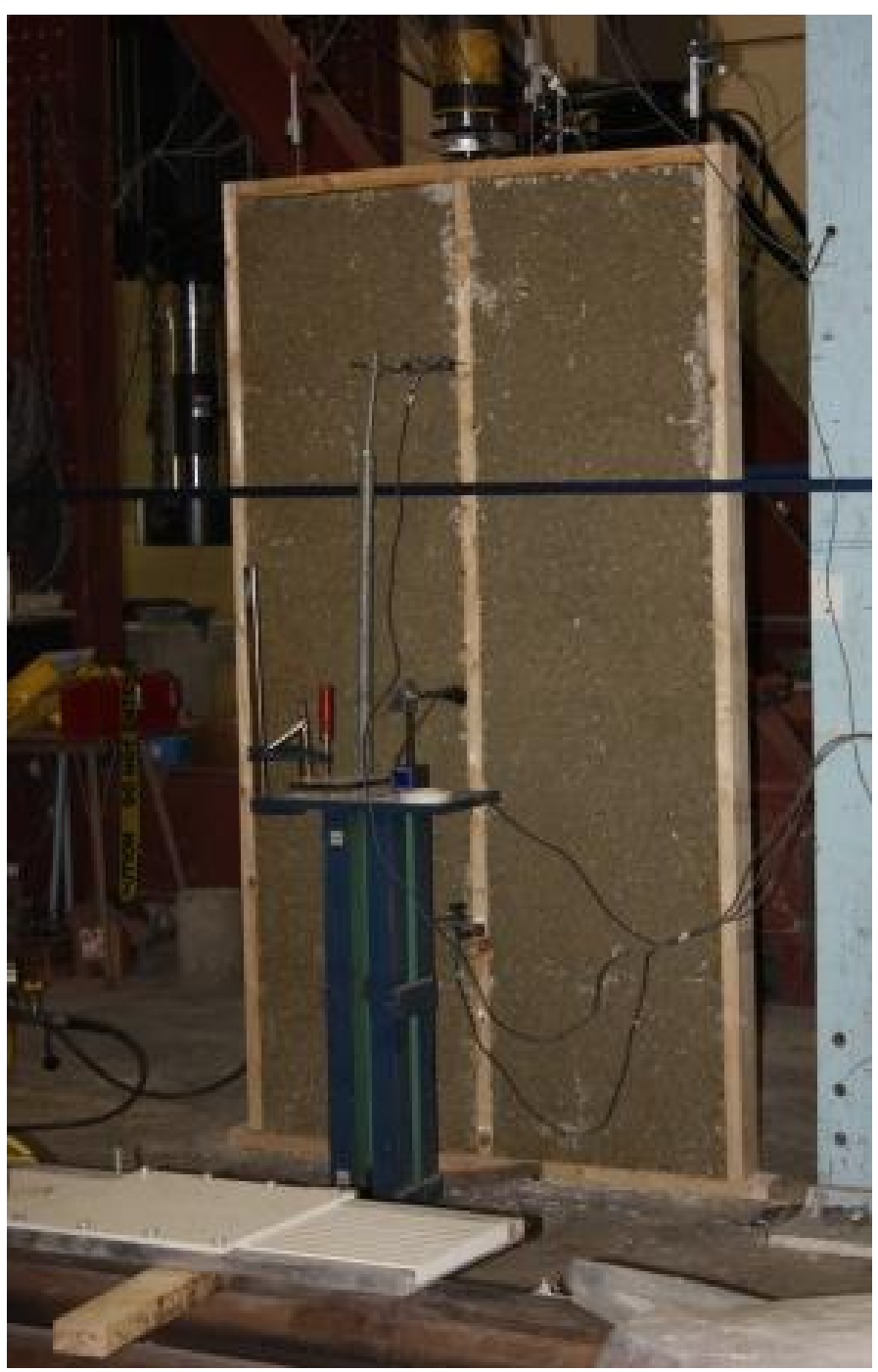

Figure 3.7 Typical instrumentation and set up of the larger frames (2133mm) 


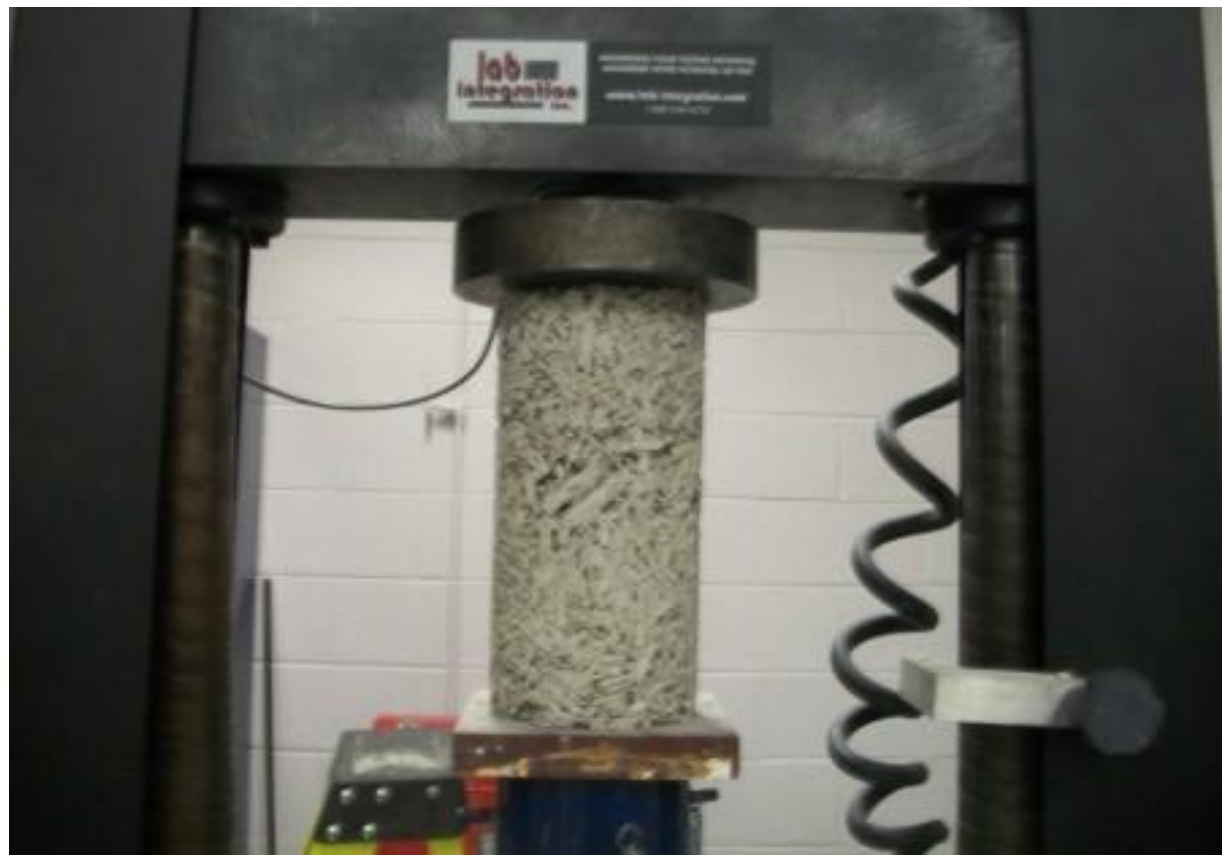

Figure 3.8 Compression testing hempcrete cylinders 


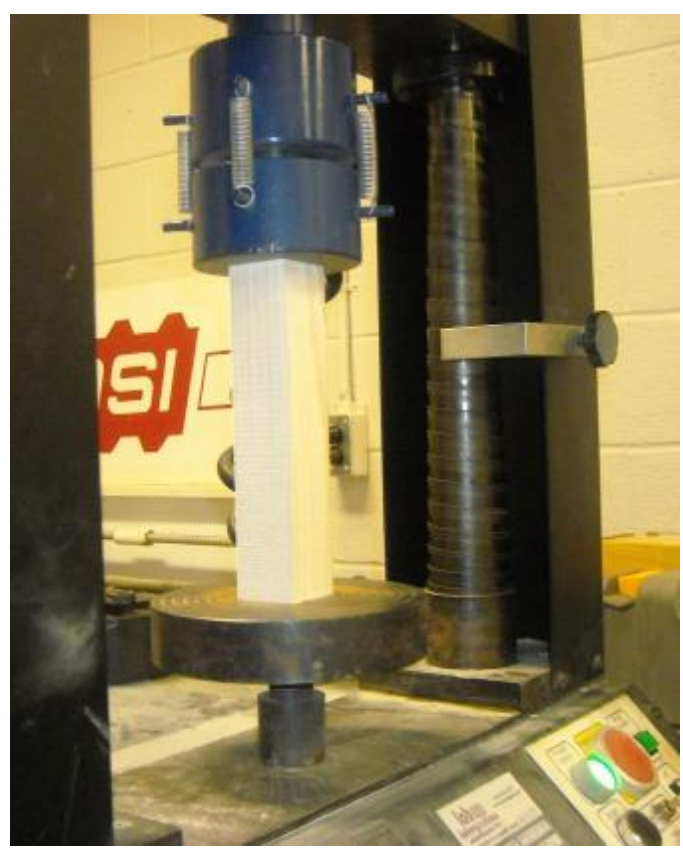

Figure 3.9 Compression testing timber parallel to grain

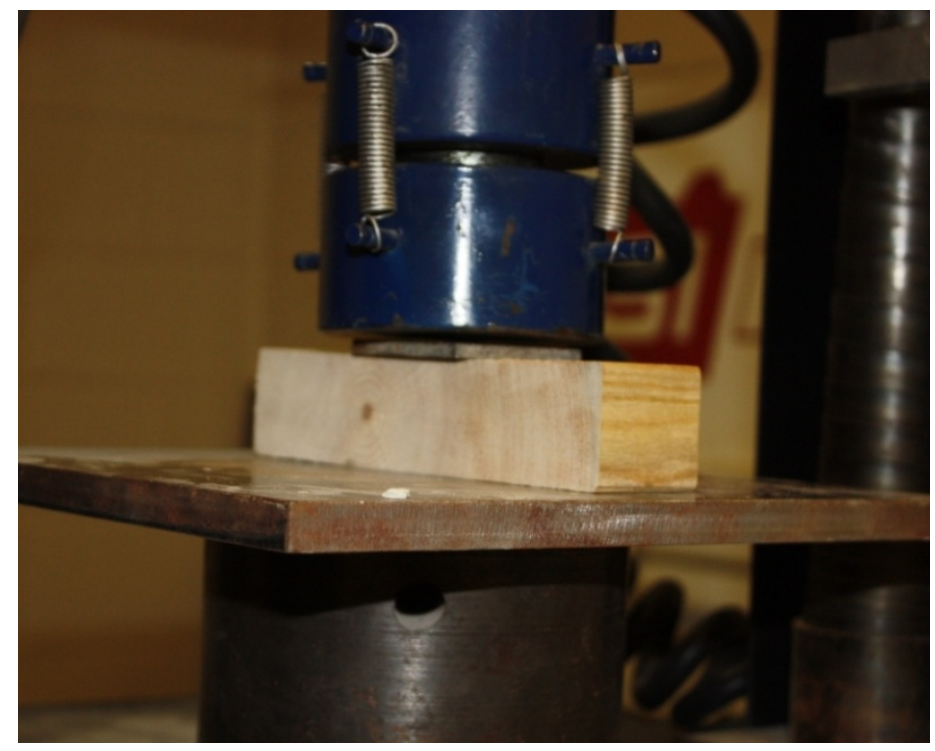

Figure 3.10 Compression testing timber perpendicular to grain 


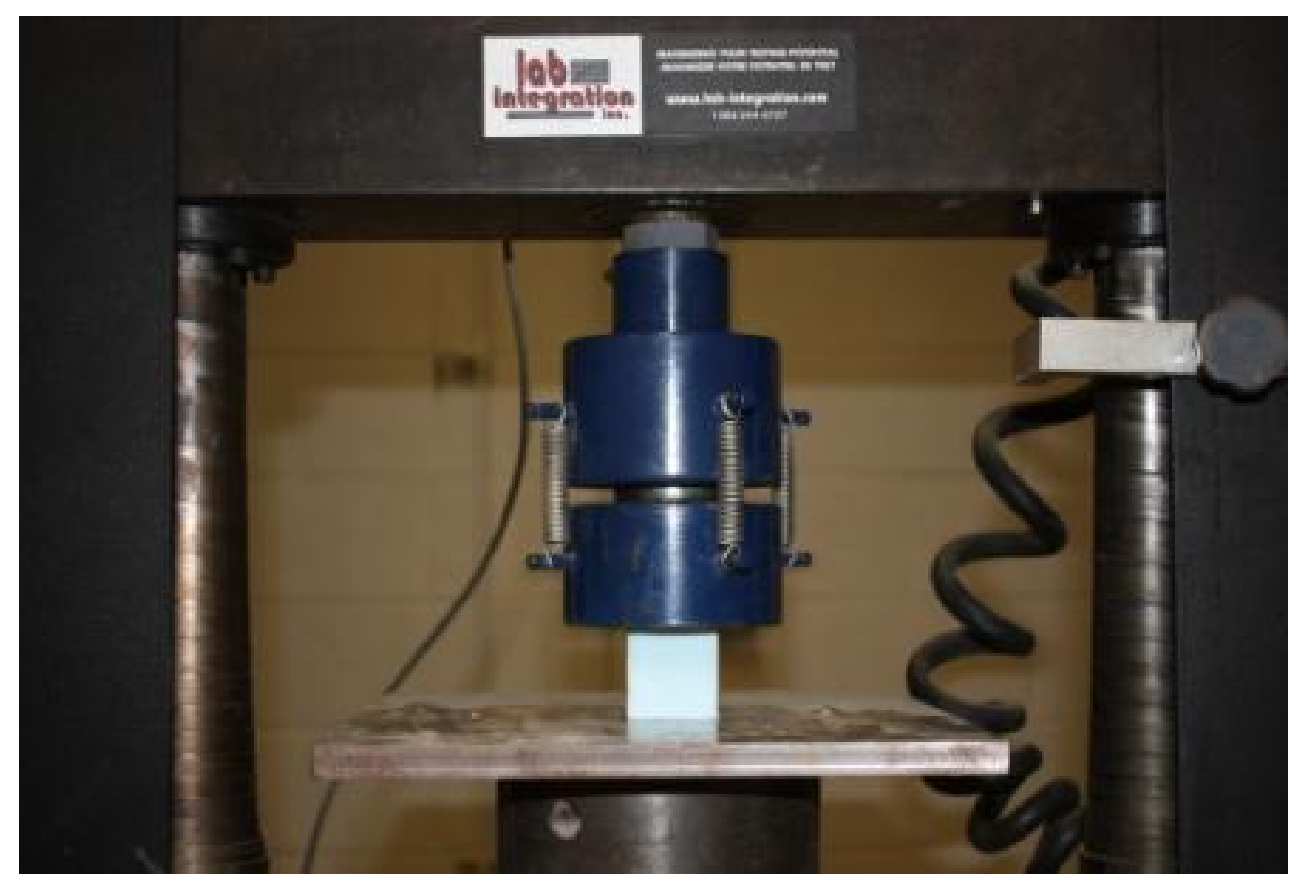

Figure 3.11 Compression testing of Styrofoam 


\section{CHAPTER: RESUltS}

\subsection{AnCillary Test Results}

\subsubsection{FOAM COMPRESSION TESTS}

Three 45mm cube samples of styrofoam were tested in compression (Figure 4.1) in accordance with ASTM D1621 (Standard Test Method for Compressive Properties of Rigid Cellular Plastics). The results are plotted in Figure 4.2. The styrofoam initially showed some linear elastic behavior with the load rising with deformation. At about $1.5 \mathrm{MPa}$, there was increasing strain without an increase in stress. This continued until the voids in the foam were compressed and the cube hardened to form a densified mass (Figure 4.1). At this point the stress increased without appreciable deformation. The maximum compressive strength was determined from the maximum value of stress from the approximate linear elastic portion of the stress strain graph for each sample and the average is presented in Table 4.1.The modulus of elasticity was determined from the slope of the best fit line of the initial approximate linear elastic portion of the graph (0 to 1.5MPa load) and is presented in Table 4.1.

\subsubsection{TIMBER TESTS}

\subsubsection{Compression Parallel to Grain}

Six timber samples (three from the 38x89 mm sections and three from the 38x235mm sections) were tested in compression parallel to the grain in accordance with ASTM D143 - 09. The failure modes observed were: compression crushing (Figure 4.3) with failure planes roughly horizontal; brooming (Figure 4.4); and splitting (Figure 4.5). 
The stress-strain diagrams for typical tests are plotted in Figure 4.6. The modulus of elasticity for timber parallel to grain was obtained by the slope of the best fit line to the linear elastic portion of each stress strain graph. The average of the modulus obtained from different samples is listed in Table 4.1 along with the standard deviation.

The maximum compressive strength parallel to the grain of the timber was determined for each test. The average is summarized in Table 4.1. It was found the samples from the 38x89mm timber had 38\% lower strength than the 38x235 mm samples.

\subsubsection{COMPRESSiOn PERPENDICULAR to Grain}

Three timber samples were tested perpendicular to grain according to ASTM D143 - 09 . The failure of the samples perpendicular to the grain was associated with rupture of the fibers and bearing of the steel plate into the sample (Figure 4.7). A typical stress-strain diagram is plotted in Figure 4.8. The modulus of elasticity perpendicular to grain was obtained by the slope of the best fit line on the linear elastic portion of the stress strain graph. The average of the modulus obtained from different samples is listed in Table 4.1 with the standard deviation. The maximum compressive stress perpendicular to the grain is summarized in Table 4.1.

\subsubsection{HEMPCRETE COMPRESSION TESTS}

A number (Table 4.2) of cylinders were tested for each hempcrete mix. The hempcrete cylinders were fragile due to their low density and some of them broke while taking them out of their moulds. After curing, each hempcrete cylinder was weighed and the density calculated. The average density of the cylinders of different mixes is summarized in Table 4.2. 
Each cylinder was tested in compression until failure. The compression test results are listed in Table 4.2 along with the standard deviation.

The failure mode of the hempcrete cylinders was mainly bulging followed by 45 degree shear cracks. Typical failures of each mix are shown in Figures 4.9, 4.11, and 4.13.

The load and stroke recorded for each test was used to obtain stress strain diagrams (Figures 4.10, 4.12, and 4.14). The modulus of elasticity for each hempcrete mix was obtained by the slope of the best fit line to the linear elastic portion of the stress strain graph. The average of the modulus and compressive strength, along with the standard deviation, obtained for the different mixes is recorded in Table 4.2.

Hempcrete has very low compressive strength and elastic modulus which does not make it suitable as a direct load bearing structural material. In general, the elastic modulus and compressive of hempcrete increases exponentially with density Elfordy et al (2008) as seen in Table 4.1 for M1 and M2. An exception was seen with M2 and M3 where the compressive strength and modulus of M2 (lower density hempcrete) was higher than M3. This can be mainly attributed to the fact that the shive used for M3 had a lot of dust particles in it. These particles can absorb water and hinder in the hydration process of the binding materials and thus result in a lower strength.

Another important property of hempcrete observed from the compression tests was the large deformation it can undergo after reaching the ultimate load (Figure 4.10 and Figure 4.12). This shows hempcrete has a quasi-ductile behavior unlike the sudden brittle failure associated with concrete. 


\subsection{WALL TEST RESULTS}

\subsubsection{WALLS WITH NO INFILL}

\subsubsection{WALL 1}

The wall had a middle column of $39 \mathrm{~mm}$ x $89 \mathrm{~mm}$. The vertical deflection of the wall was measured by the three LPs placed at different points on the top beam. The average deflection obtained from the LPs at each load level was plotted versus load in Figure 4.16. This wall, when tested in compression, failed by the weak axis buckling of the middle column (Figure 4.15) at a load of $27.9 \mathrm{kN}$. No appreciable lateral deflection was observed until the buckling load was reached. After reaching the buckling load the column continued to bend sideways (in the weak axis direction) and the load dropped until the column cracked and the test was stopped.

\subsubsection{WALL 6}

This wall had a middle column of $39 \mathrm{~mm}$ x $235 \mathrm{~mm}$. One LP was located at the top of the column to measure the vertical deflection and 3 LPs measured horizontal deflections. This column also failed in weak axis buckling as shown in Figure 4.17.

The vertical deflection versus load response is plotted in Figure 4.18. The horizontal deflections, Figure 4.19, were close to zero until the applied load approached the ultimate of $28.8 \mathrm{kN}$. At this point, the load decreased as the lateral deflections continued to increase and the column cracked due to bending. 


\subsubsection{HALF-SCALE WALLS}

Wall 2 had a high density hempcrete infill (M1) and Wall 3 had a low density hempcrete infill (M2). The results of these tests are discussed below.

\subsubsection{WALL 2}

Wall 2 did not exhibit observable buckling at failure. Instead, the bottom beam failed in bearing, and the top beam failed in bending (Figures 4.20, 4.21). The load versus vertical deflection graph was obtained from the deflections recorded by the average of 3 LPs on the top beam (Figure 4.19). Figure 4.19 shows that the load deflection curve reaches a plateau at about $80 \mathrm{kN}$, but no subsequent drop in load was observed. This is likely due to the "bearing" nature of the failure. The top timber beam was not stiff enough to resist the reaction of the compressed hempcrete and it started bending upwards. Non-uniform loading of the hempcrete inadvertently occurred due to the bending of the top beam. Compressive failure of the hempcrete was observed only beside the middle stud.

\subsubsection{WALL 3}

Wall 3 was in-filled with lighter hempcrete $M 2$ and initially failed by buckling about its strong axis (Figure 4.23a) followed by the failure of the hempcrete infill with shear cracks (Figure 4.23b). 
Bearing failure was prevented by an aluminum plate at the bottom of the wall and a stiff steel top beam. No bending of the top beam was observed. The buckling was initiated at the location of a knot in the timber column.

Figure 4.21 shows the lateral deflection response in the direction of the strong axis of the middle column of the wall. Deflections were measured at the top and bottom quarter points of the column. The lateral deflections were close to zero $(0-1 \mathrm{~mm})$ until approaching a load of about $57 \mathrm{kN}$ (the ultimate load) when the lateral deflection started increasing rapidly $(15 \mathrm{~mm})$ and the load began to decrease as the column failed by bending about its strong axis.

Figure 4.22 shows the vertical deflection versus load response of the four LPs placed on the top of the steel I-beam on top of the wall. The deflections recorded by the LPs suggest that the top I-beam tilted about its longitudinal axis when the wall started buckling. As the load was nearing the buckling load, vertical deflections recorded by the LPs 1and 2 started increasing, while the deflections recorded by LPs 3 and 4 on the other side of the beam decreased (though the decrease was much smaller than the increase due to the overall downward deflection of the wall during buckling).

\subsubsection{FULL-SCALE WALLS}

To investigate height effects and also to simulate an actual wall according to present construction practice, Walls 4, 5, 7 and 8 were constructed and tested in compression. The detailed results of each experiment are discussed below. 


\subsubsection{WALL 4}

This wall was $2133 \mathrm{~mm}$ in height, had $39 \mathrm{~mm}$ x $89 \mathrm{~mm}$ columns, wooden top and bottom beams and a light hempcrete infill of M2.

The wall failed by buckling of the strong axis (out of the plane of the wall) of the middle column and was accompanied by bending and cracking of the hempcrete out of the plane of the wall (Figures 4.23, 4.24). No bearing failure was observed in the top or bottom beams. The graph (Figure 4.25) shows the lateral deflections obtained from the LPs which were placed at different heights on the middle column along the strong axis of the column.

The horizontal deflections of the column (measured at three height levels on the middle column) were close to zero until approaching the ultimate load (33.5 kN), at which point bending about the strong axis becomes significant. The load versus vertical deflection plot (Figure 4.26) ( 3 LPs on the top beam -1 near the middle and two toward the two ends of the beam) also exhibits typical buckling behaviour as the load started to drastically decrease after the ultimate load was reached. This was accompanied by substantial vertical deflection due to bending of the middle column.

\subsubsection{WALL 5}

This wall was very similar to Wall 4 except with bottom beam of aluminum plate. Since bearing failure was not seen in the previous test, it served as a test to check the repeatability. This wall when tested in compression also failed in strong axis buckling of the middle column with subsequent failure of the hempcrete (Figures 4.27 and 4.28). LPs measuring the horizontal deflection of the middle columns at different heights clearly exhibit a buckling behavior, i.e. no 
significant lateral deflection is observed before ultimate buckling load (34kN), but after reaching the ultimate load a large lateral deflection was observed with decrease of load (Figure 4.29).

The load versus vertical deflection graph (Figures 4.30) was obtained from 3 LPs placed on the top beam. LP2 gives the vertical deflection at the middle of the beam (approximately the top of the column). LP1 and LP2 were towards the ends of the beam. The top beam (which had the two ends free) had tilted downwards a little at the beginning of the test on the LP2 side thus lifting up on the LP1 side. This tilting is reflected in the load versus vertical deflection of the graph where LP2 has initial large positive (downward deflection) and LP1 has initial large negative (upward) deflection at very low loads. These deflections had the overall downward deflection of the top beam under the compressive load superimposed on it. The initial deflections became insignificant when the overall downward deflection started to increase with load. The load started to decrease after the ultimate buckling load was reached with increasing downward deflection following the typical characteristics of buckling.

\subsubsection{WALL 7}

This wall had timber columns of $39 \mathrm{~mm}$ x $235 \mathrm{~mm}$ and was $2133 \mathrm{~mm}$ in height. The timber frame was in-filled with hempcrete M2 $\left(414 \mathrm{~kg} / \mathrm{m}^{3}\right)$ on one side and M3 $\left(515 \mathrm{~kg} / \mathrm{m}^{3}\right)$ on the other side of the middle column. The bottom of the wall had an aluminum plate and the top had a wooden beam. This wall failed by the column bearing into the top wooden beam (Figure 4.34).

The bearing was followed by tilting of the top beam due to bearing failure in the lighter hempcrete. This resulted in tilting of the top beam (Figure 4.34). This tilting is responsible for 
the differences in vertical deflection of the left and right LPs on the top of the beam. The right side of the wall (M3 infill) did not appear to undergo any significant failure (Figure 4.34).

Failure of the central column was not observed. The vertical deflection graph obtained from the LPs on the top of the beam shows downward deflection of the beam (Figure 4.35). The load vertical deflection curve does not show continuous drop of load until the test was stopped due to failure of hempcrete wall in one side. Instead a continuous load increase with a much lower slope was observed. This is typical of a bearing-type failure.

No appreciable horizontal displacements of the LPs on the central column were observed (Figure 4.36) providing further evidence that failure did not occur as a result of column buckling.

\subsubsection{WALL 8}

Wall 8 was in-filled on one side of the central column with hempcrete M3 and on the other side with styrofoam. The styrofoam $(\mathrm{E}=28.7 \mathrm{MPa})$ was much stiffer than the hempcrete $(\mathrm{E}=1.89 \mathrm{MPa})$ infill.

The wall failed in weak axis buckling by pushing into the hempcrete at an ultimate load of 116.7 $\mathrm{kN}$ (Figure 4.37). Initially the hempcrete failed locally where the column had maximum lateral deformation, and then large shear cracks appeared in the hempcrete infill (Figure 4.38).

Figure 4.39 is the load versus vertical deflection of the wall. The typical buckling behaviour is depicted with the load falling after reaching the maximum load and significant increase of downward displacement . 
Figure 4.40 is the load versus horizontal deflection in the direction of the weak axis at different heights of the column. The topmost horizontal LP was in the region where the column underwent maximum bending and broke into the hempcrete. This topmost LP underwent the maximum deflection after the ultimate buckling load. The load decreased after buckling started but the resistance of the hempcrete to lateral deflection flattened the load deflection curve.

The PIV technique was used to monitor the lateral deformations as the column buckled. The deflections of the column obtained by the PIV analysis at different applied loads as the experiment proceeded (Figure 4.42) are plotted in Figure 4.41. The corresponding deflections obtained from the horizontal LP readings are also plotted.

\subsection{Discussion}

Table 4.3 summarizes the test results. These results clearly show the beneficial effect of hempcrete infill on the strength of a hempcrete timber composite wall.

It is noted that the load spreading system varied between the walls. Wall 2 had a wooden beam which bent up during testing and created non uniform loading on the hempcrete. Wall 3, on the other hand, had a steel beam which created uniform loading. Wall 8 had just a steel plate on top of the column resulting in the hempcrete not being directly loaded at all.

The outer columns did not carry any direct load since they were not physically in contact (Figure 4.26) with the top beam. The confinement of the straps may have contributed to increasing the buckling load of the columns due to arching action through the hempcrete infill. However, such an effect is expected to be small because the hempcrete has a much lower modulus of elasticity compared to wood. In actual walls the outer columns are expected to be confined due to the presence of adjacent in-fill sections. 
Walls 1, 2 and 3 were similar in terms of central column dimensions and height. The strengths of Walls 2 and 3 were 2.9 times and 2.0 times larger, respectively, than Wall 1 . This indicates that even light hempcrete in-fill (M2, Wall 3) can prevent buckling of the weak axis of a timber column.

Hempcrete prevented weak axis buckling for Walls 3, 4, and 5 which forced them to fail in strong axis buckling (next lowest failure load mode). The failure load was very similar for both Walls 4 and 5 (33.5 and 34kN respectively) as both had same central column dimensions and same mode of failure. Unlike in Wall 2, bearing failure of the top and bottom timber beams was not an issue, as the buckling load for the taller columns was now lower than the bearing resistance of the beams. Thus, the aluminum top and bottom beams used for Wall 5 were not necessary to prevent premature bearing failure.

To quantify the maximum amount of strength hempcrete can add to resist weak axis buckling the thicker (39x 235mm columns) were built and tested. This ensured that the middle column failed by weak axis buckling by pushing into the hempcrete as strong axis buckling would theoretically occur at a much higher load. Walls 6, 7, and 8 were designed to have columns which had strong axis buckling loads almost 20 times that of the weak axis. This ensured that the column buckling occurred by buckling about weak axis and pushing into the hempcrete. Wall 6, without hempcrete infill, failed in weak axis buckling as expected. Wall 7 failed due to bearing of the column on the top wooden beam at a load about 4 times that of Wall 6. This was because the buckling strength of this thicker column was higher than the bearing load. 
Wall 8 was designed to measure the maximum load to which hempcrete can resist weak axis buckling for a given density and column configuration. To ensure weak axis buckling of the central column all other modes of failure were prevented. The strong axis buckling strength was 20 times that of weak axis, and the bottom of the column had aluminum plates and load was applied to the wall through a steel bearing plate, directly at the top of the column without any wooden beam to prevent bearing failure. Wall 8 failed by weak axis buckling into the hempcrete infill at a load about 5 times (Table 4.3) that of the Wall 6 (i.e. same column without hempcrete lateral confinement). The increase of load may also have some contributions from the styrofoam since when the column tried to buckle towards styrofoam it was resisted and it buckled towards weaker hempcrete. This effect is not much since deflections of the column towards the stryrofoam was insignificant compared to deflections towards hempcrete.

Figure 4.42 compares the vertical load deflection graphs of Wall 6, 7 and 8 . The presence of hempcrete in-fill has increased the strength and deflection at failure of all the columns. If bearing failure is also prevented, there is an additional increase in strength of the column. 
Table 4.1 Properties of wood and foam

\begin{tabular}{|c|c|c|c|c|c|}
\hline Materials & $\begin{array}{c}\text { No. of } \\
\text { samples }\end{array}$ & $\begin{array}{c}\text { Compressive } \\
\text { strength, } \\
\text { MPa } \\
\text { (average) }\end{array}$ & $\begin{array}{c}\text { Standard } \\
\text { deviation, } \\
\text { MPa for } \\
\text { Compressive } \\
\text { strength. }\end{array}$ & $\begin{array}{l}\text { Modulus } \\
\text { of } \\
\text { elasticity, } \\
\text { MPa } \\
\text { (average) }\end{array}$ & $\begin{array}{l}\text { Standard } \\
\text { deviation, } \\
\text { MPa } \\
\text { Mor } \\
\text { Modulus of } \\
\text { elasticity }\end{array}$ \\
\hline $\begin{array}{c}\text { Wood parallel to } \\
\text { grain(from38x89) }\end{array}$ & 3 & 17.9 & 2.2 & 12500 & 1308 \\
\hline $\begin{array}{c}\text { Wood parallel to } \\
\text { grain (from 38x235) }\end{array}$ & 3 & 28.9 & 3.13 & 13040 & 1104 \\
\hline $\begin{array}{c}\text { Wood perpendicular } \\
\text { to grain }\end{array}$ & 3 & 7.00 & 1.31 & 1268.0 & 166.1 \\
\hline Styrofoam & 3 & 1.50 & 0.11 & 28.7 & 4.34 \\
\hline
\end{tabular}


Table 4.2 Properties of Hempcrete

\begin{tabular}{|c|c|c|c|c|c|c|c|}
\hline $\begin{array}{c}\text { Hempcrete } \\
\text { Mix }\end{array}$ & $\begin{array}{l}\text { No of } \\
\text { cylinders } \\
\text { tested }\end{array}$ & $\begin{array}{l}\text { Density } \\
\left(\mathrm{kg} / \mathrm{m}^{3}\right)\end{array}$ & $\begin{array}{l}\text { Standard } \\
\text { deviation for } \\
\text { density } \\
\left(\mathrm{kg} / \mathrm{m}^{3}\right)\end{array}$ & $\begin{array}{l}\text { Average } \\
\text { compressive } \\
\text { strength } \\
\text { MPa }\end{array}$ & $\begin{array}{l}\text { Standard } \\
\text { deviation of } \\
\text { compressive } \\
\text { strength } \\
\mathrm{MPa}\end{array}$ & $\begin{array}{l}\text { Modulus } \\
\text { of } \\
\text { elasticity } \\
\text { MPa }\end{array}$ & $\begin{array}{l}\text { Standard } \\
\text { deviation } \\
\text { of } \\
\text { Modulus } \\
\text { of } \\
\text { elasticity } \\
\text { MPa }\end{array}$ \\
\hline M1 & 4 & 715 & 17.0 & 0.92 & 0.14 & 20.12 & 3.11 \\
\hline M2 & 9 & 313 & 14.5 & 0.11 & 0.016 & 2.99 & 0.45 \\
\hline M3 & 3 & 415 & 20.0 & 0.092 & 0.018 & 1.89 & 0.41 \\
\hline
\end{tabular}


Table 4.3 Summary of all Wall test results

\begin{tabular}{|c|c|c|c|c|c|c|c|}
\hline $\begin{array}{l}\text { Frame } \\
\text { No. }\end{array}$ & $\begin{array}{l}\text { Height } \\
\text { of wall } \\
\text { (mm) }\end{array}$ & $\begin{array}{l}\text { Column } \\
\text { Dimensions } \\
(\mathbf{m m})\end{array}$ & $\begin{array}{l}\text { Hempcrete } \\
\text { infilled? }\end{array}$ & $\begin{array}{l}\text { Density of } \\
\text { hempcrete } \\
\mathrm{kg} / \mathrm{m}^{3}\end{array}$ & Beams & $\begin{array}{l}\mathbf{P}_{\text {ult }} \exp \\
(\mathbf{k N})\end{array}$ & $\begin{array}{l}\text { Failure } \\
\text { mode }\end{array}$ \\
\hline 1 & 1220 & $39 \times 89$ & no & -- & wood & 27.9 & $\begin{array}{l}\text { Weak axis } \\
\text { buckling }\end{array}$ \\
\hline 2 & 1220 & $39 \times 89$ & yes & 715 & wood & 79.8 & Bearing \\
\hline 3 & 1050 & $39 \times 89$ & yes & 313 & $\begin{array}{l}\text { Top - steel I } \\
\text { section } \\
\text { Bottom- } \\
\text { aluminum } \\
\text { plate }\end{array}$ & 56.0 & $\begin{array}{l}\text { Strong } \\
\text { axis } \\
\text { buckling }\end{array}$ \\
\hline 4 & 2133 & $39 \times 89$ & yes & 313 & wood & 33.5 & $\begin{array}{l}\text { Strong } \\
\text { axis } \\
\text { buckling }\end{array}$ \\
\hline 5 & 2133 & $39 \times 89$ & yes & 313 & $\begin{array}{l}\text { Top - wood } \\
\text { Bottom- } \\
\text { aluminum } \\
\text { plate }\end{array}$ & 34.0 & $\begin{array}{l}\text { Strong } \\
\text { axis } \\
\text { buckling }\end{array}$ \\
\hline 6 & 2133 & $39 \times 235$ & no & & aluminum & 28.8 & $\begin{array}{l}\text { Weak axis } \\
\text { buckling }\end{array}$ \\
\hline 7 & 2133 & $39 \times 235$ & yes & $313 / 430$ & wood & 86.3 & Bearing \\
\hline 8 & 2133 & $39 \times 235$ & yes & foam/430 & steel plate & 117 & $\begin{array}{l}\text { Weak axis } \\
\text { buckling }\end{array}$ \\
\hline
\end{tabular}




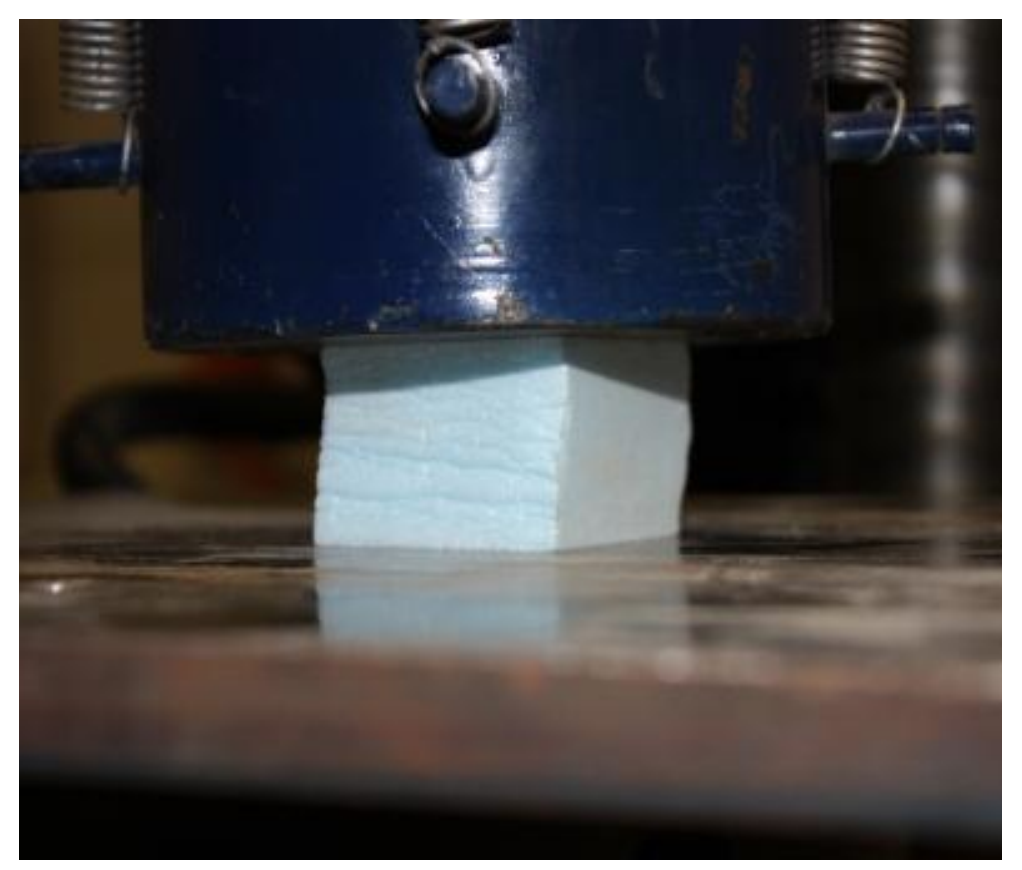

Figure 4.1 Compressive failure of Styrofoam

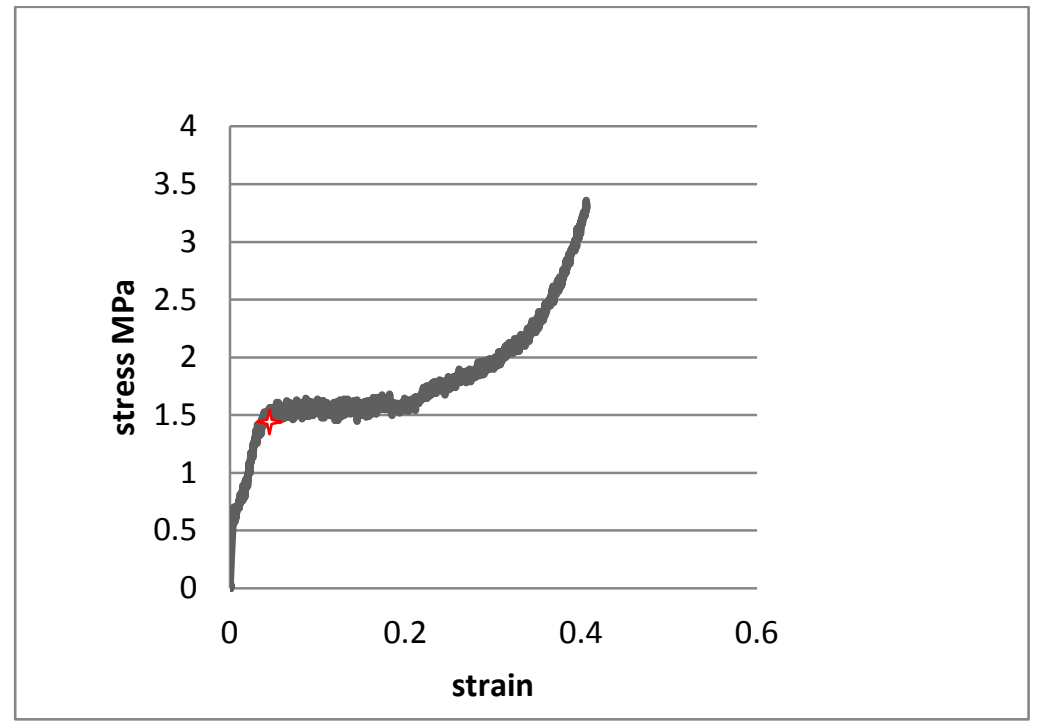

Figure 4.2 Stress strain curve of Styrofoam tested in compression 


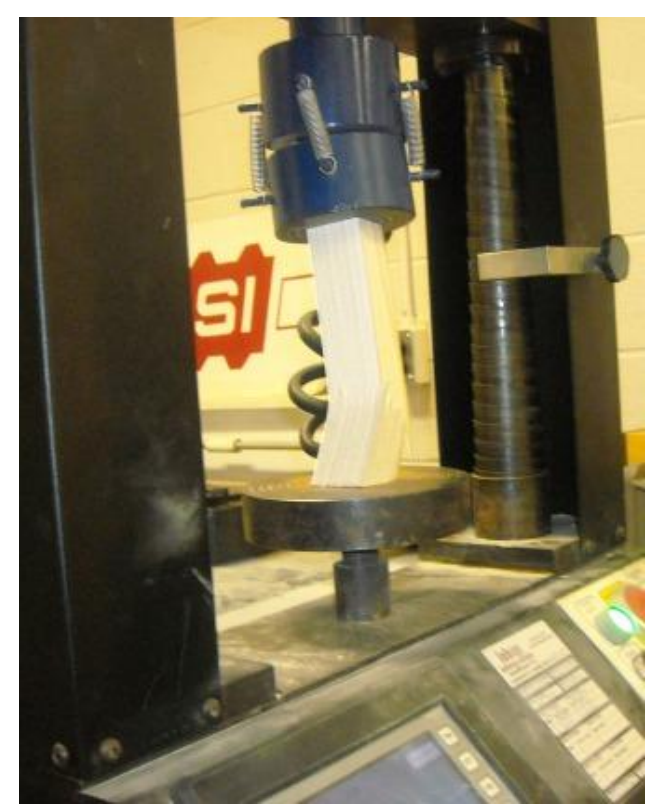

Figure 4.3 Crushing failure of wood parallel to grain 


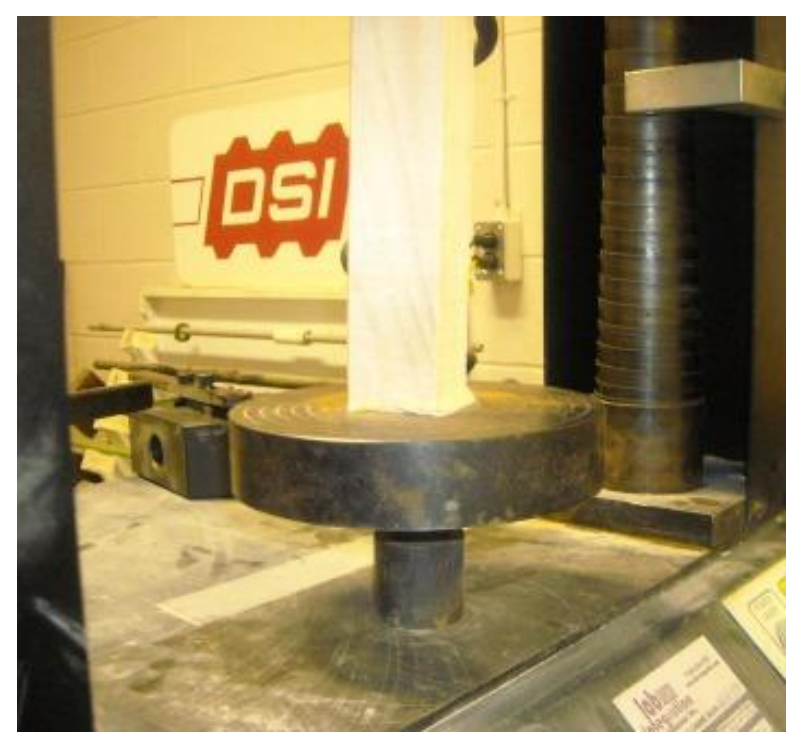

Figure 4.4 Brooming failure of wood parallel to grain

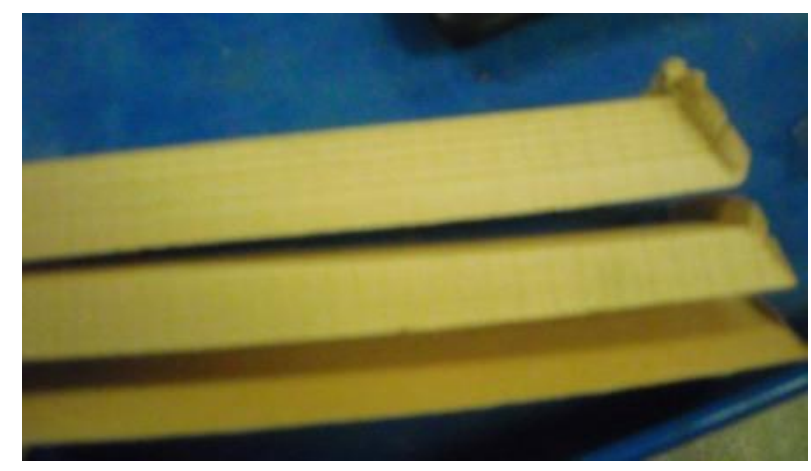

Figure 4.5 Splitting failure of wood parallel to grain 


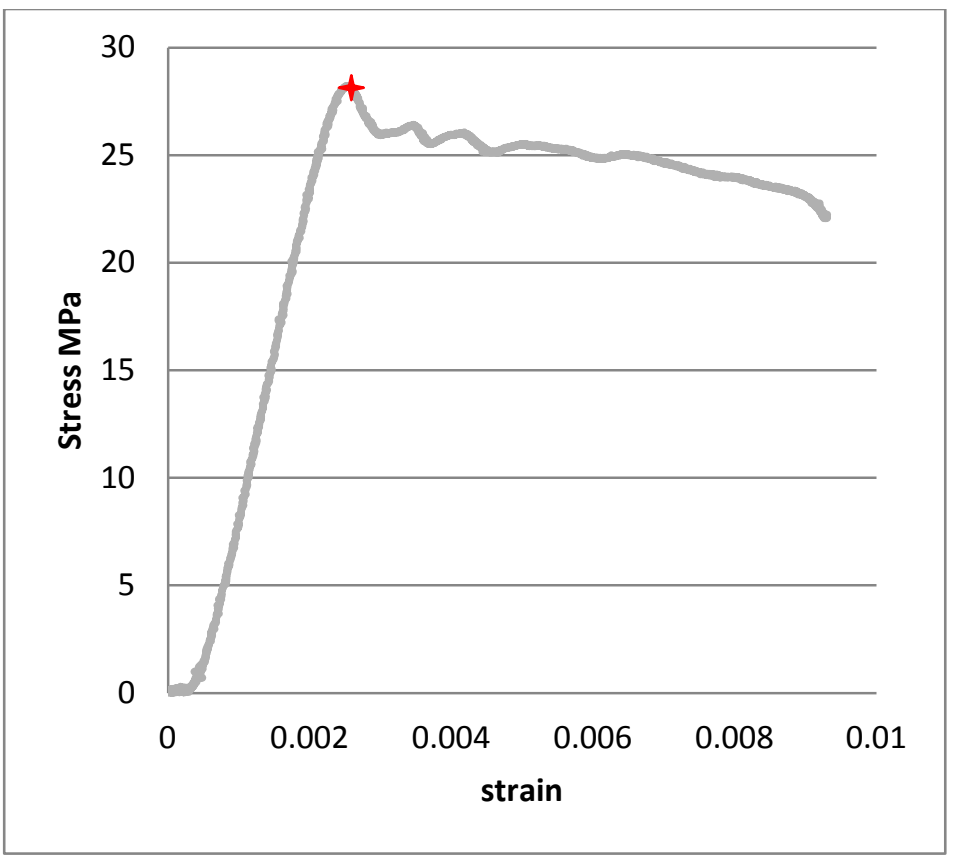

(a)

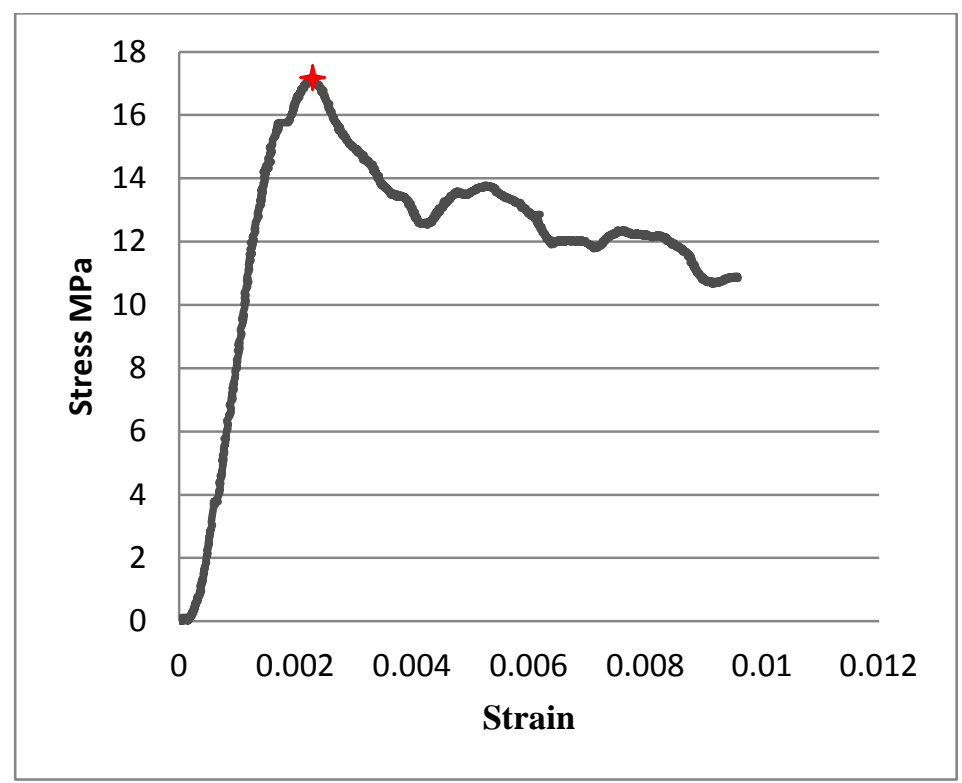

(b)

Figure 4. 6 Typical stress-strain plots for wood parallel to grain: (a) (38X38X150mm) cross section from $38 x 235 \mathrm{~mm}$ timber columns ; (b) (38X38X150mm) cross section from 38x89mm timber columns. Maximum compressive strength indicated by cross. 


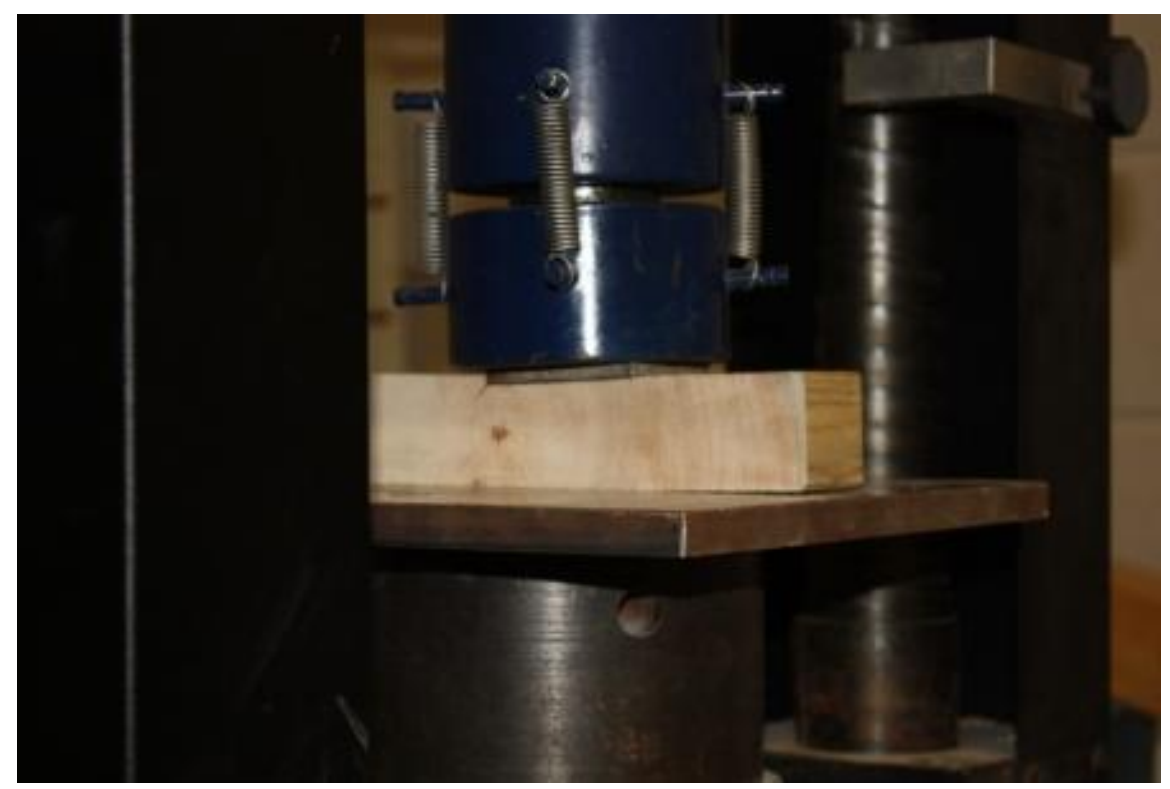

Figure 4. 7 Failure of wood perpendicular to grain

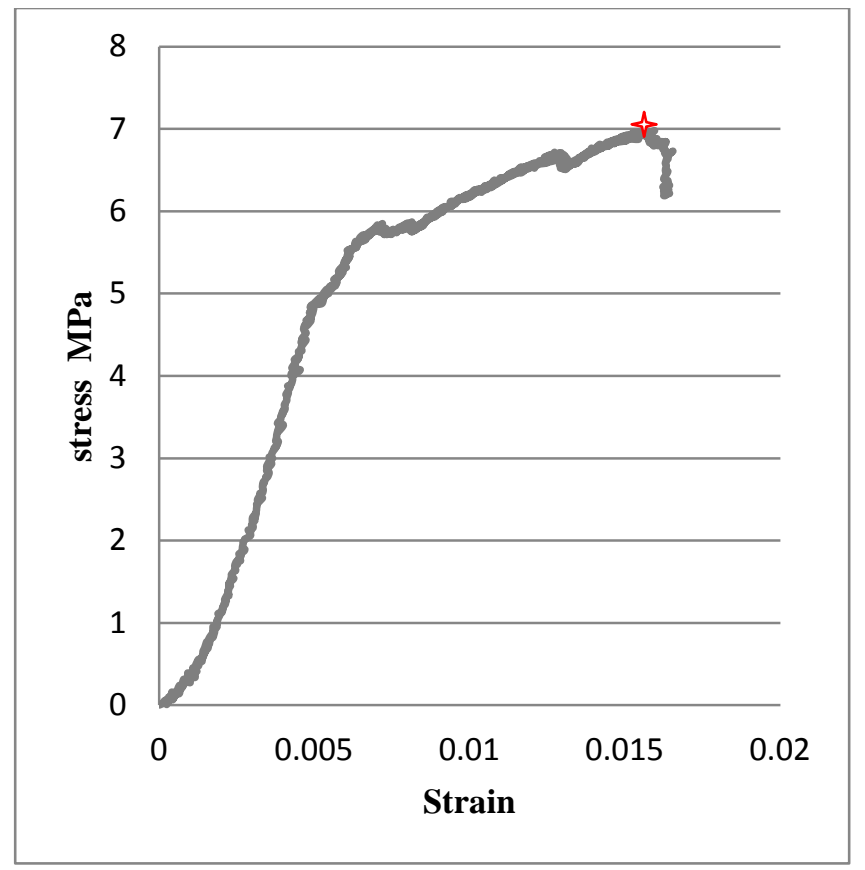

Figure 4. 8 Stress strain graph of wood perpendicular to grain. Maximum compressive strength indicated by cross. 


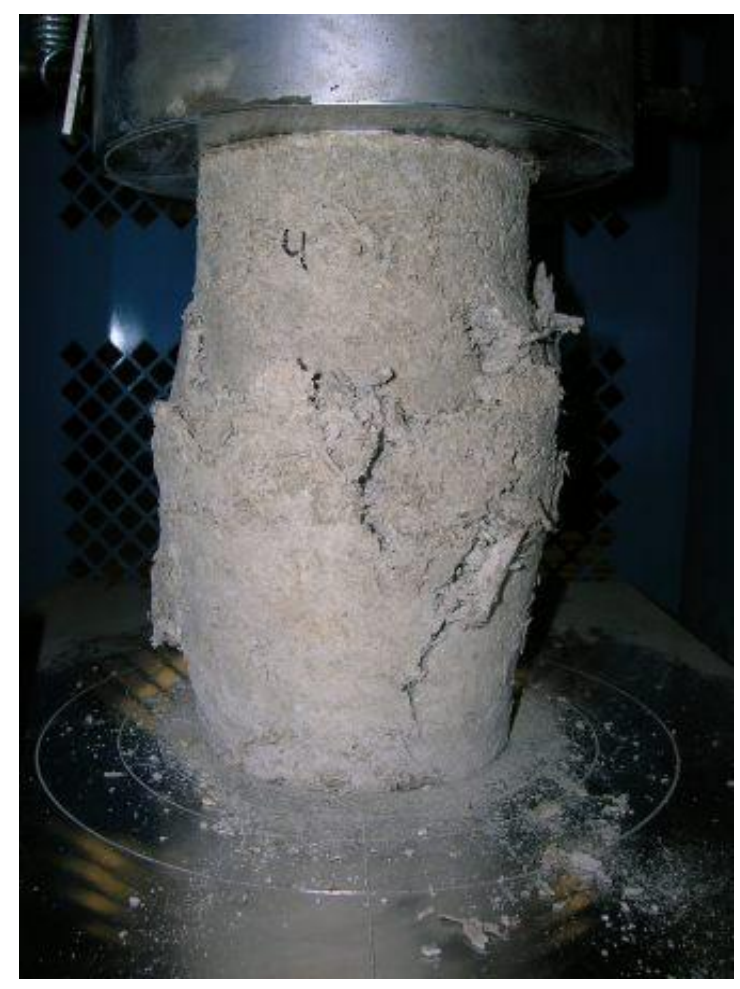

Figure 4. 9 Failure of hempcrete cylinder mix M1

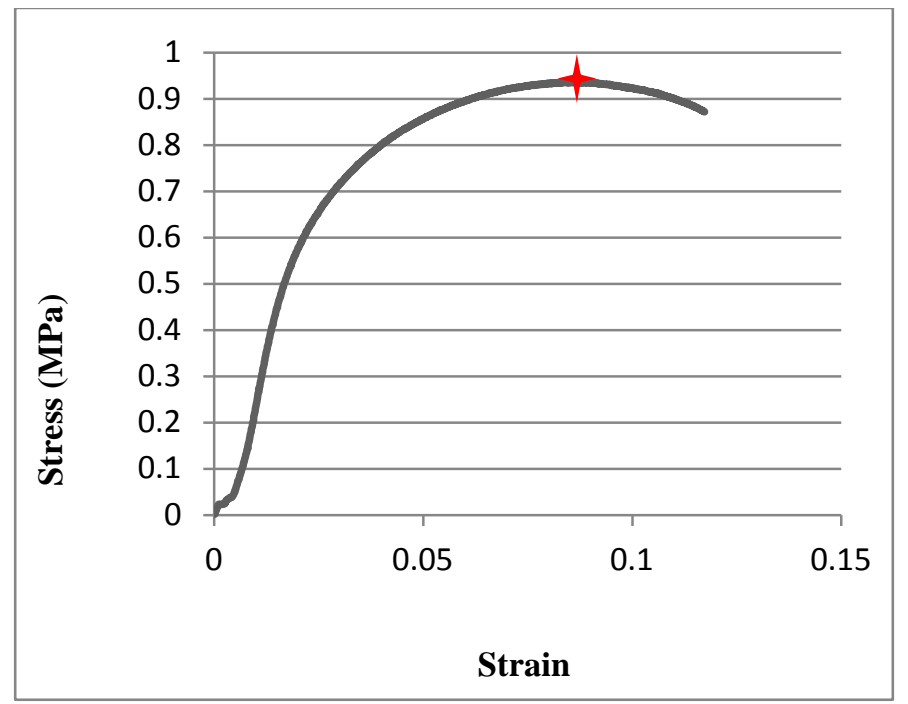

Figure 4. 10 Stress strain graph of hempcrete cylinder mix M1. Maximum compressive strength indicated by cross. 


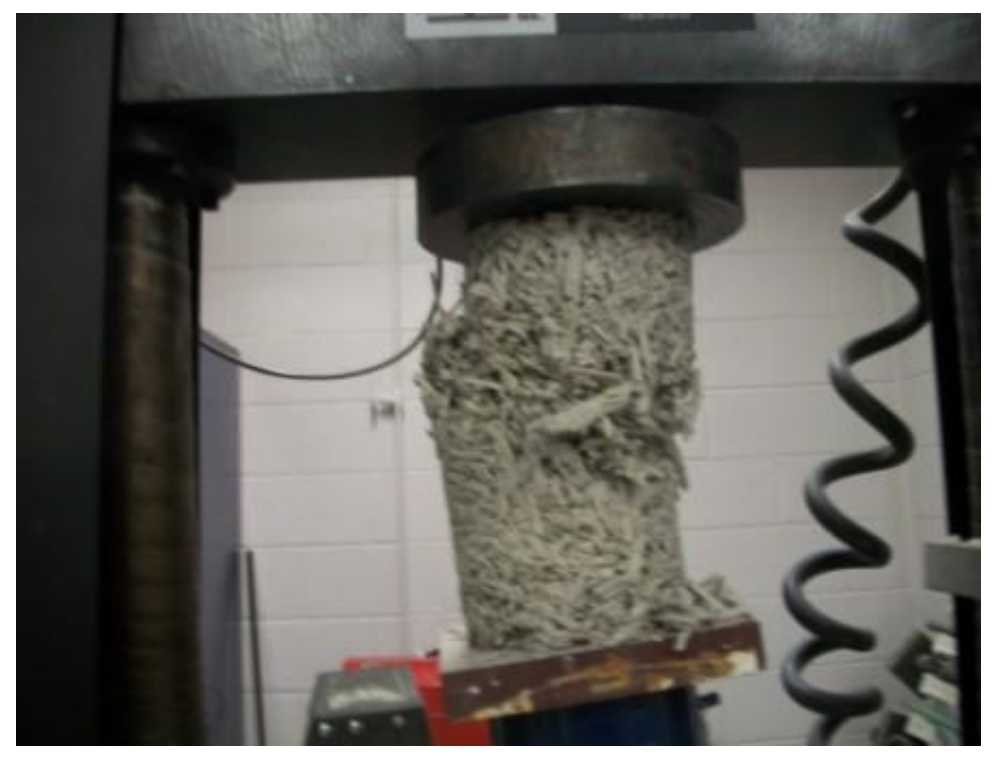

Figure 4.11 Failure of hempcrete cylinder mix M2 


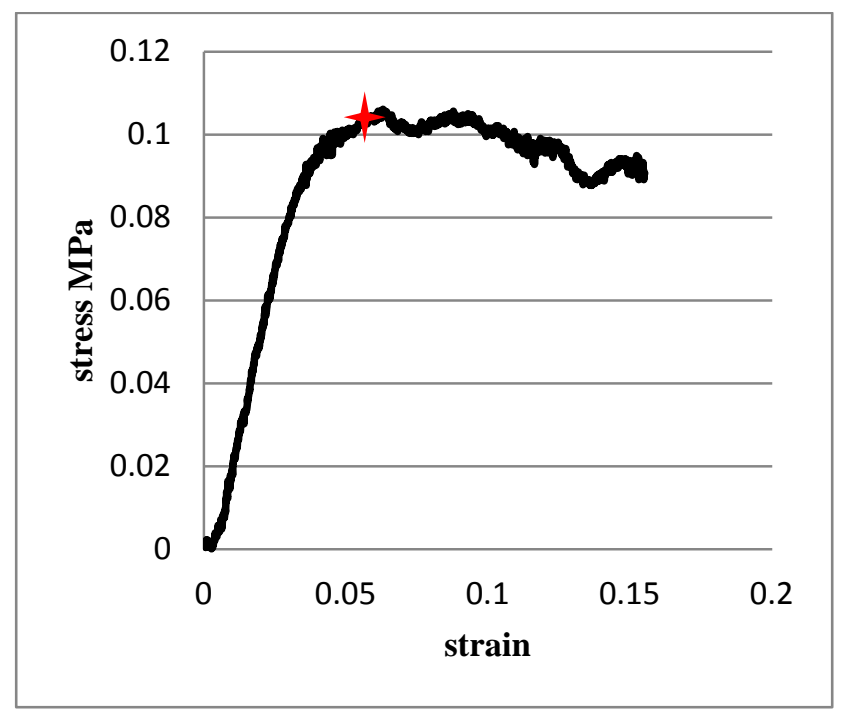

Figure 4.12 Stress strain graph of hempcrete cylinder mix M2. Maximum compressive strength indicated by cross

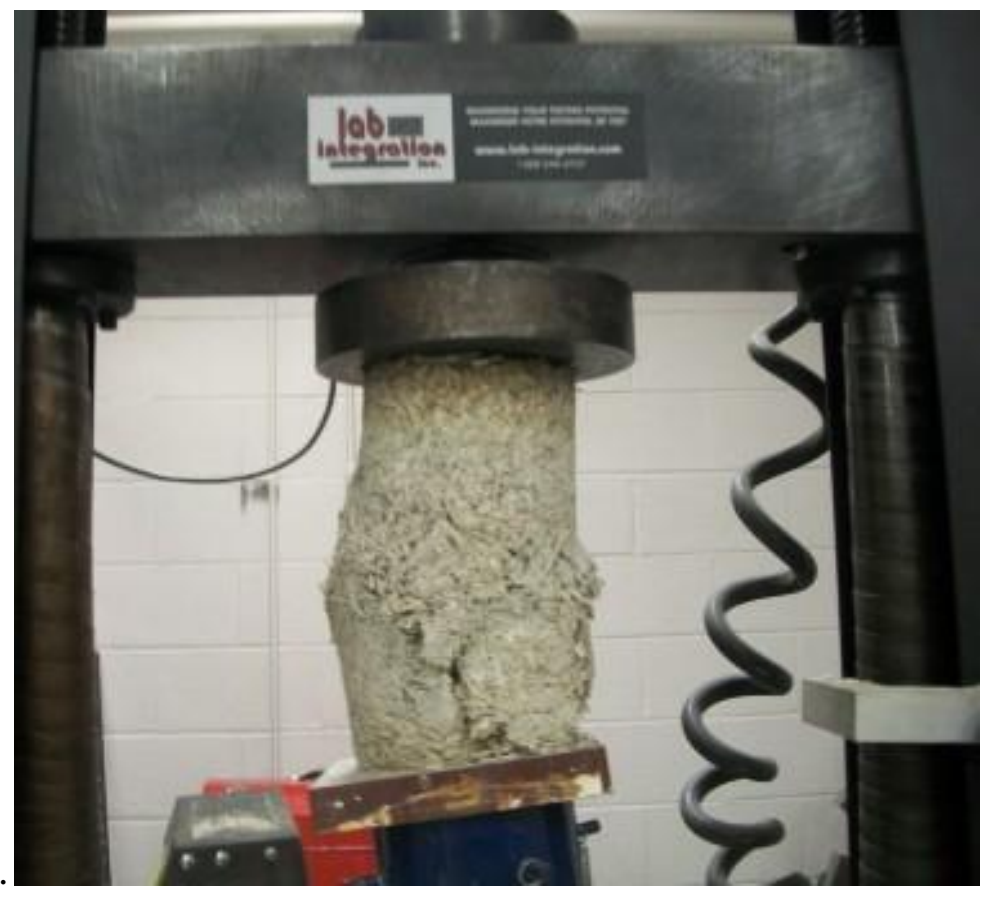

Figure 4.13 Failure of hempcrete cylinder mix M3 


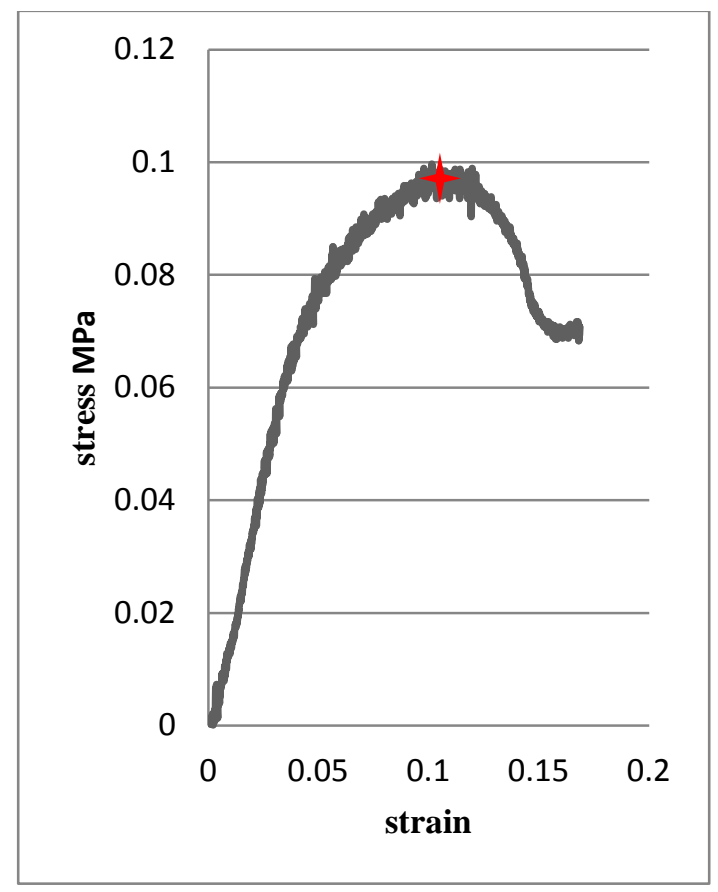

Figure 4.14 Stress strain graph of hempcrete cylinder mix M3. Maximum compressive strength indicated by cross 


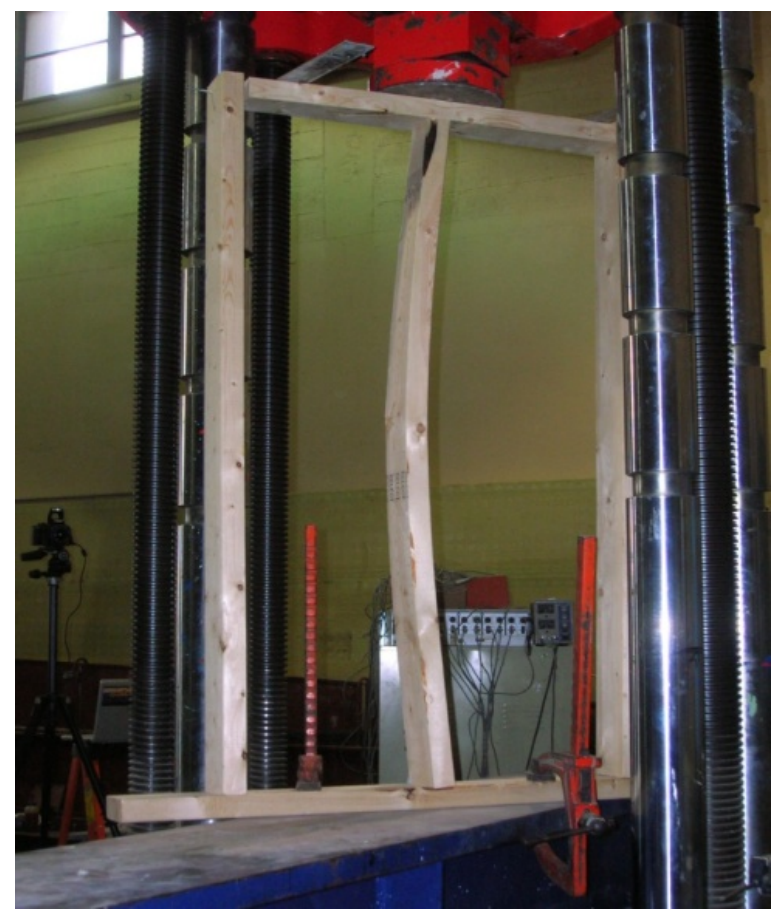

Figure 4.15 Weak axis buckling failure of Wall 1

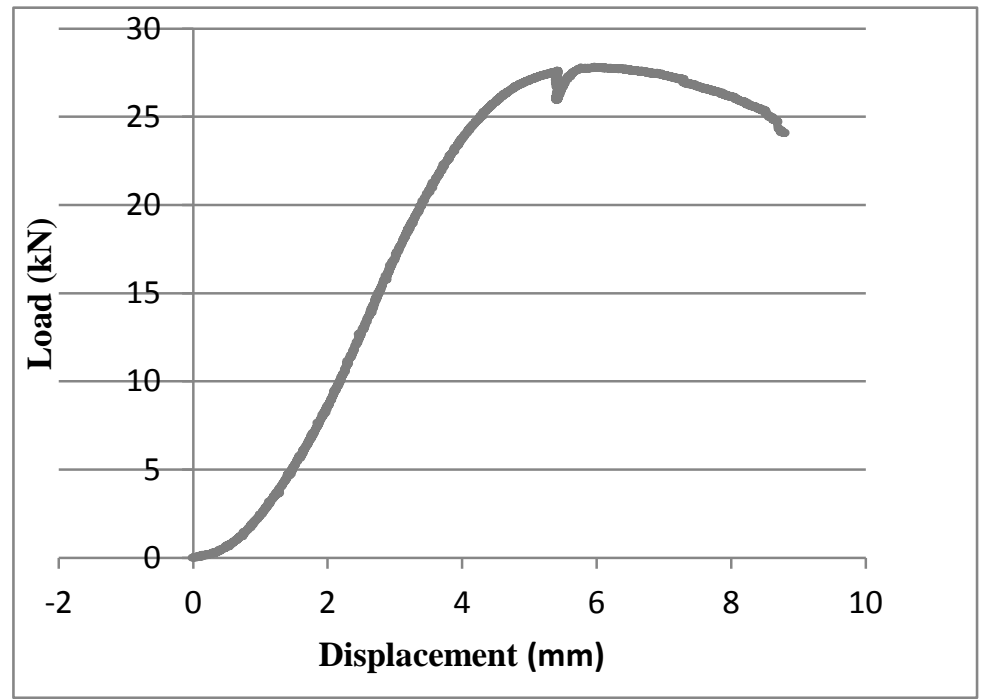

Figure 4.16 Load versus vertical displacement response of Wall 1 during compressive testing 


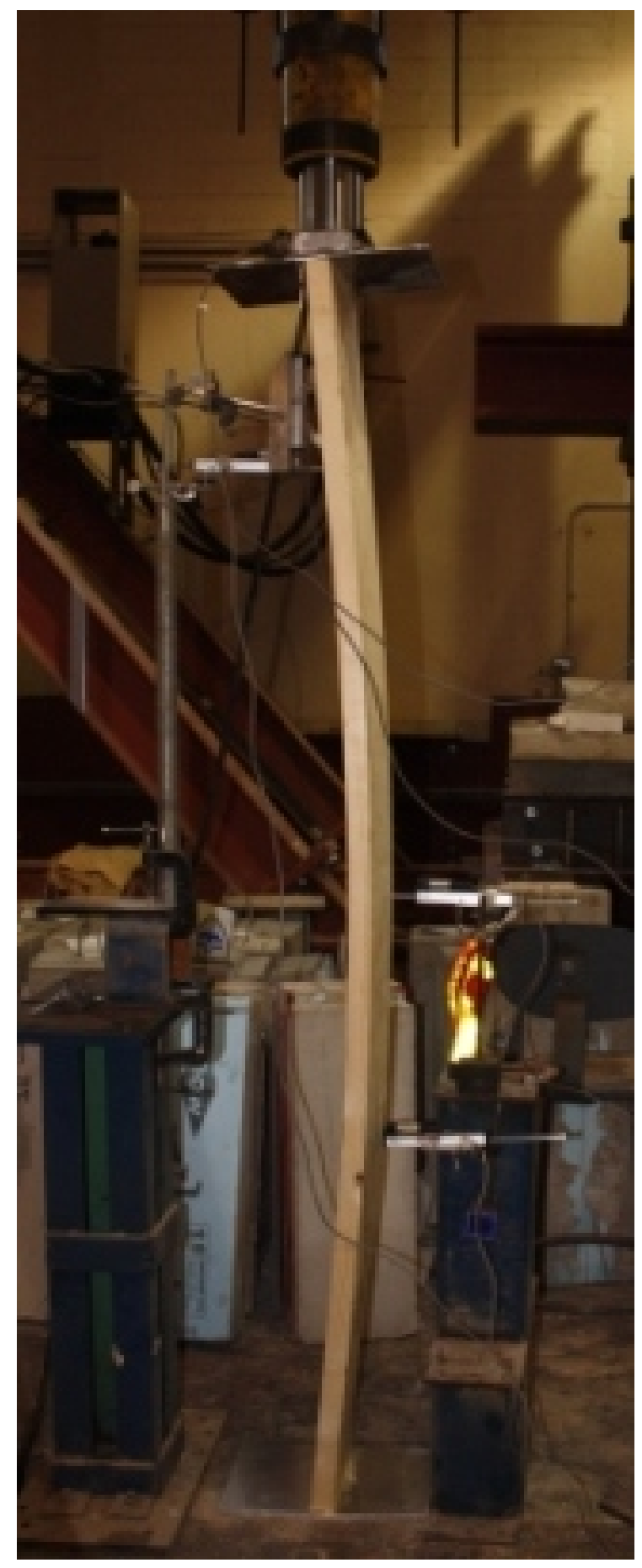

Figure 4.17 Weak axis buckling failure of 39x235mm timber column (Wall 6) 


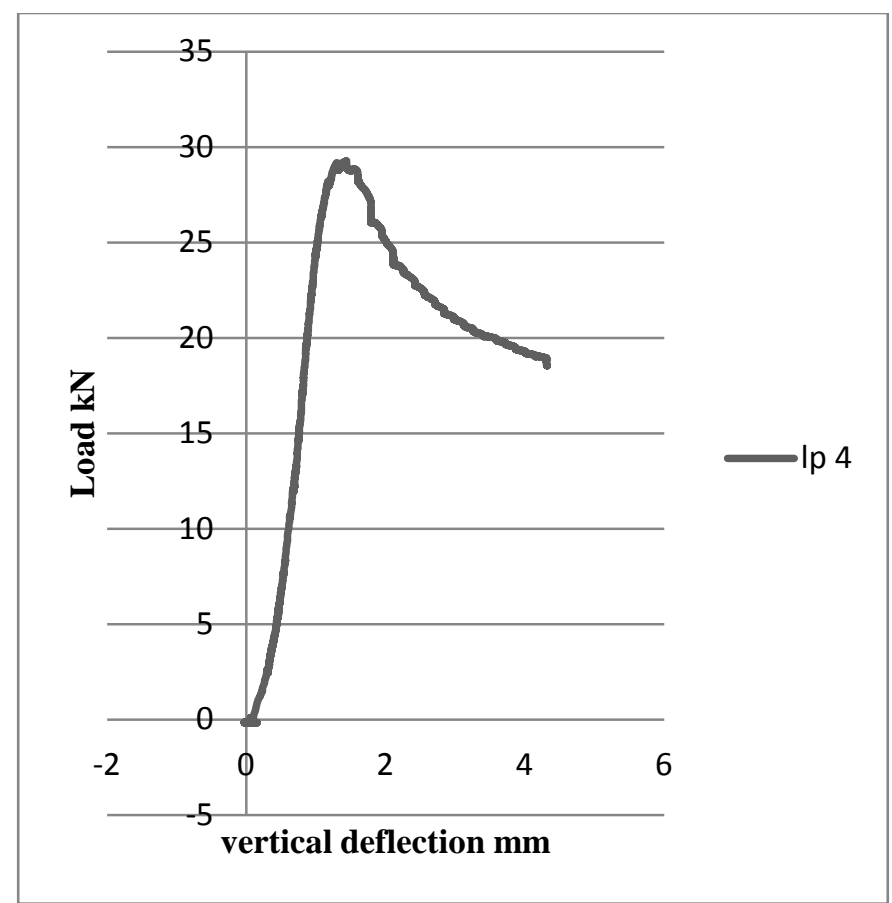

Figure 4.18 Load versus vertical deflection of Wall 6 

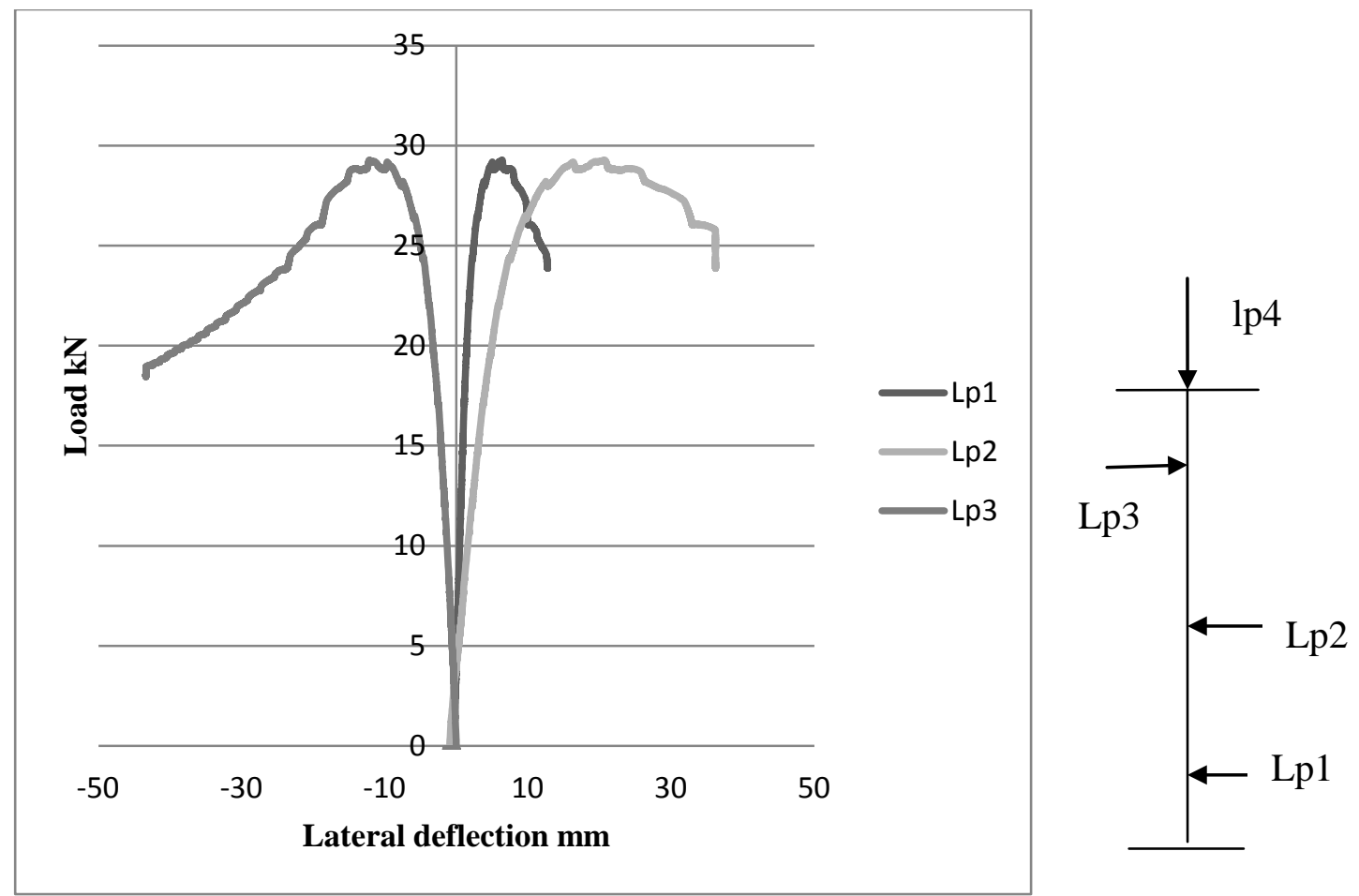

Figure 4.19 Load versus horizontal displacement in direction of buckling obtained from LPs on the middle column wall 6 . This clearly depicts a buckling behavior. 


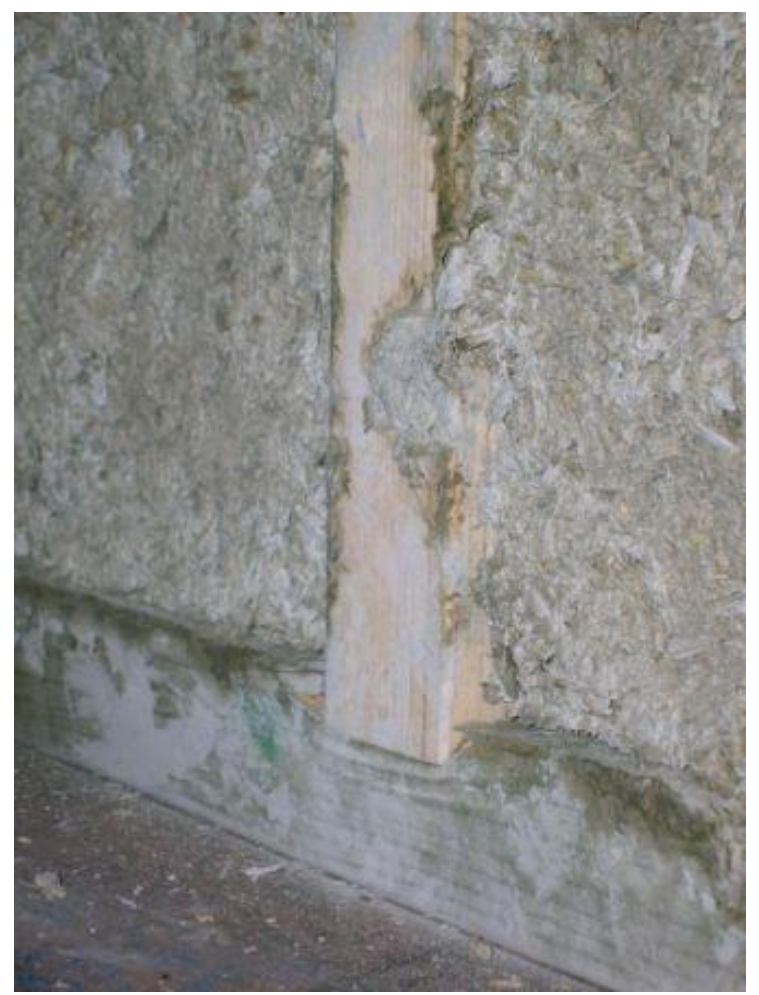

Figure 4.20 Bearing failure of Wall 2 (bottom beam)

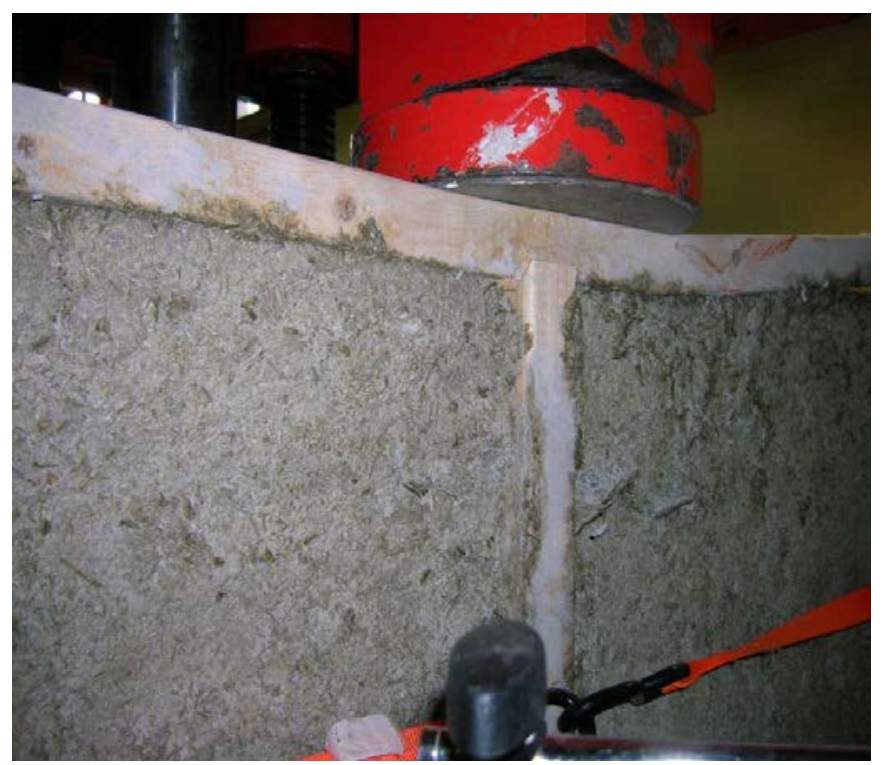

Figure 4.21 Bearing failure of Wall 2 (top beam) 


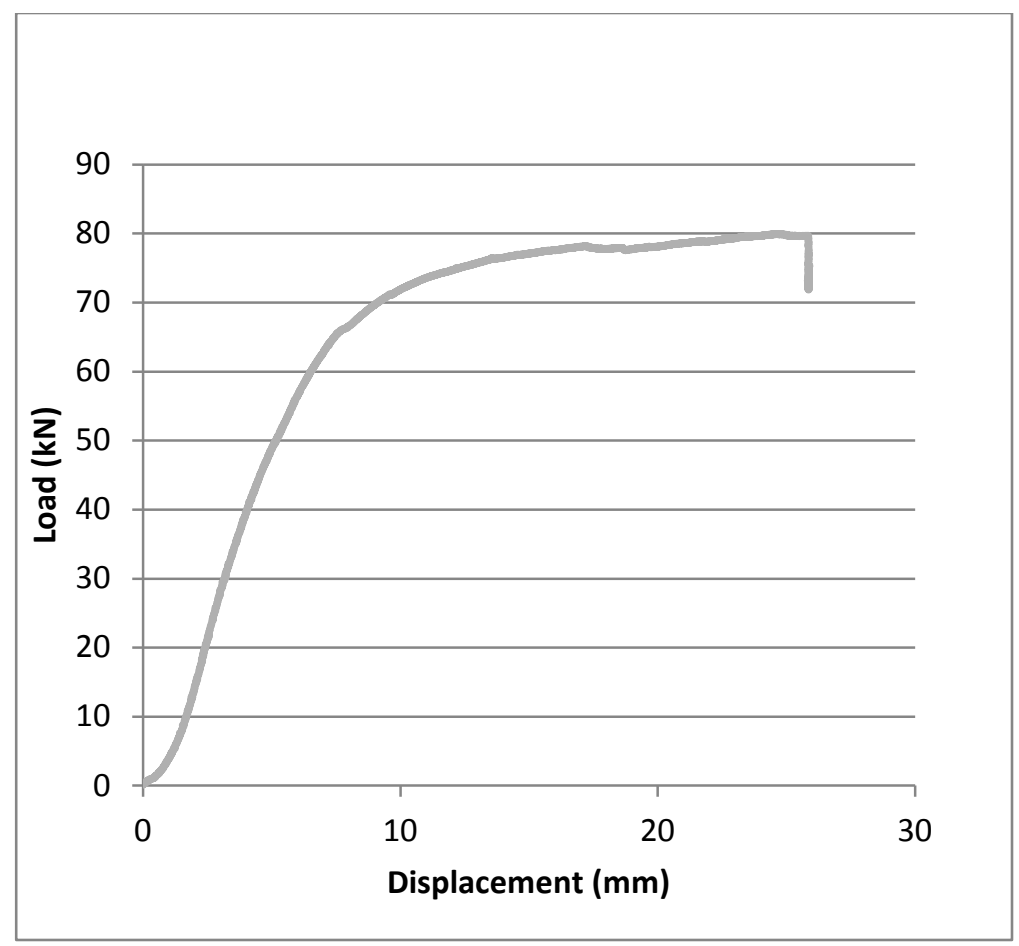

Figure 4.22 Load versus vertical displacement response of Wall 2 


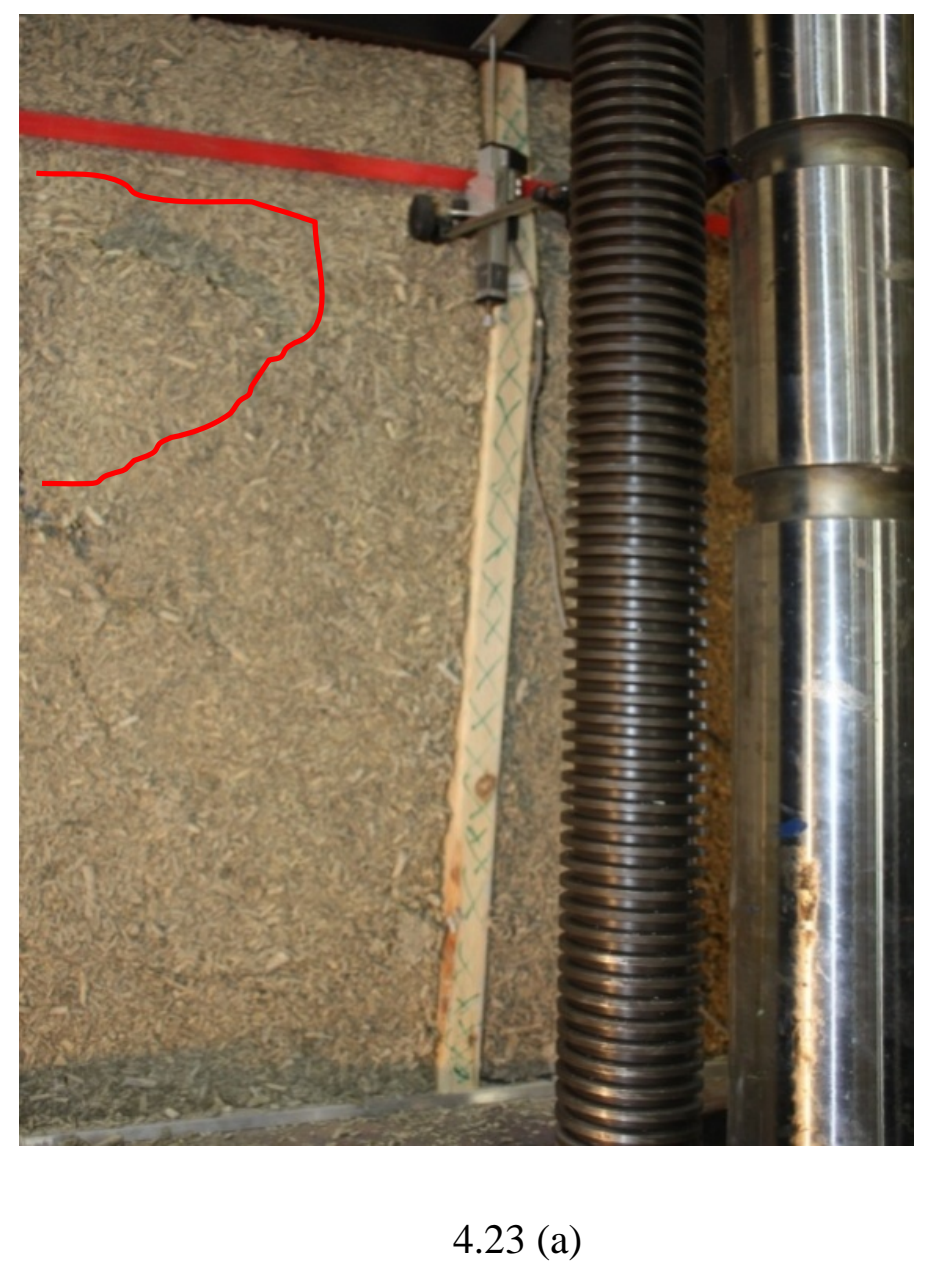




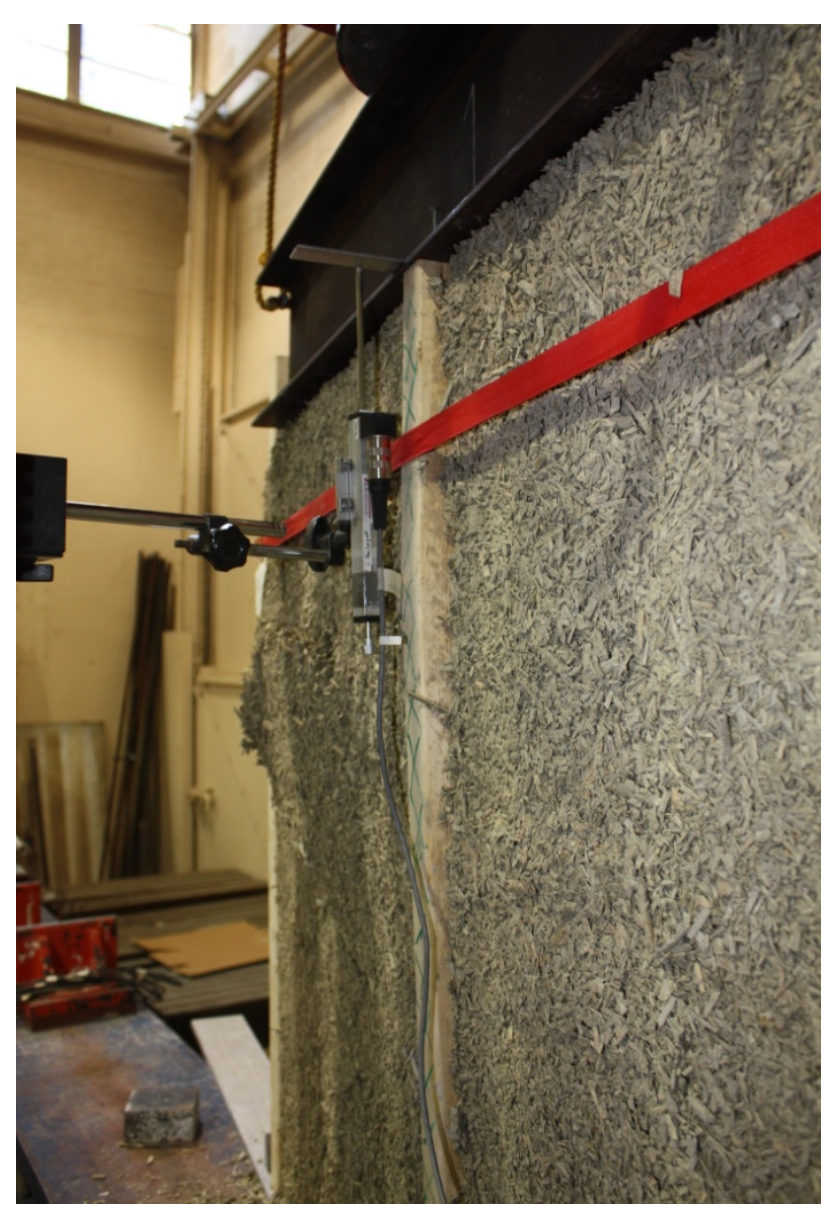

4.23 (b)

Figure 4.23 Failure of Wall 3: (a) Strong axis buckling of columns. Hempcrete failing in shear planes is highlighted; (b) Side view of the failed wall 3 showing the middle column buckling out of the plane of wall (strong axis) and failed hempcrete falling out of the wall. 


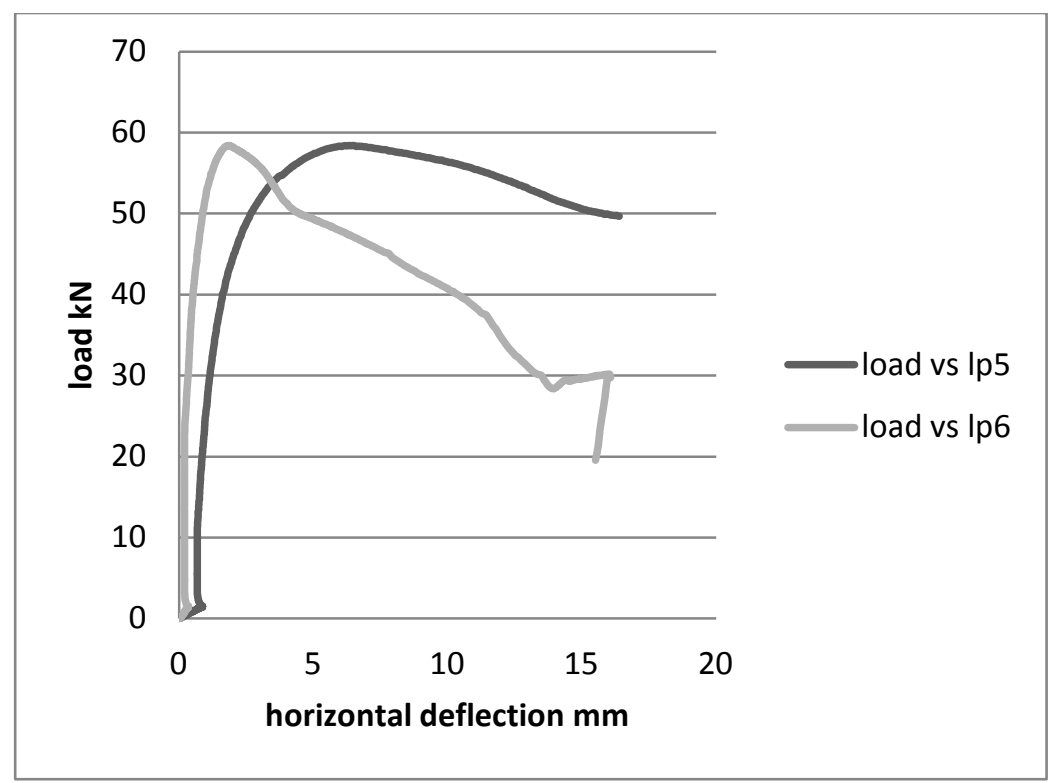

Figure 4.24 Load versus lateral displacement for Wall 3. LP 6 and LP5 were placed at about 300mm and $900 \mathrm{~mm}$ below the top of middle column respectively.

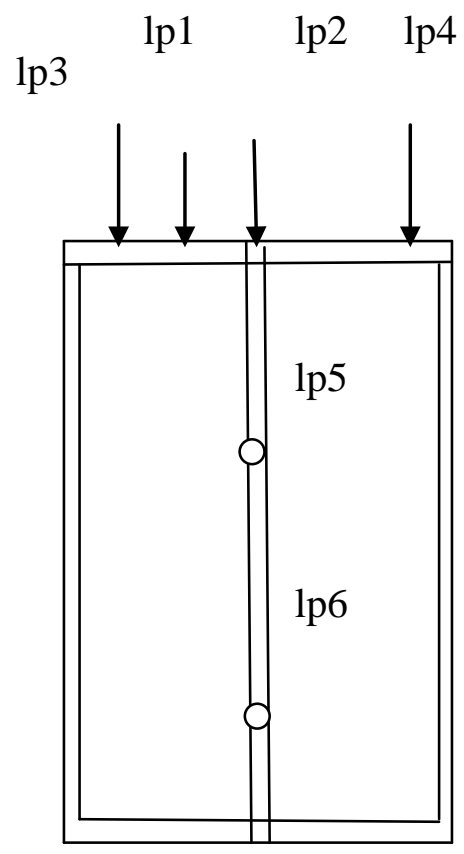




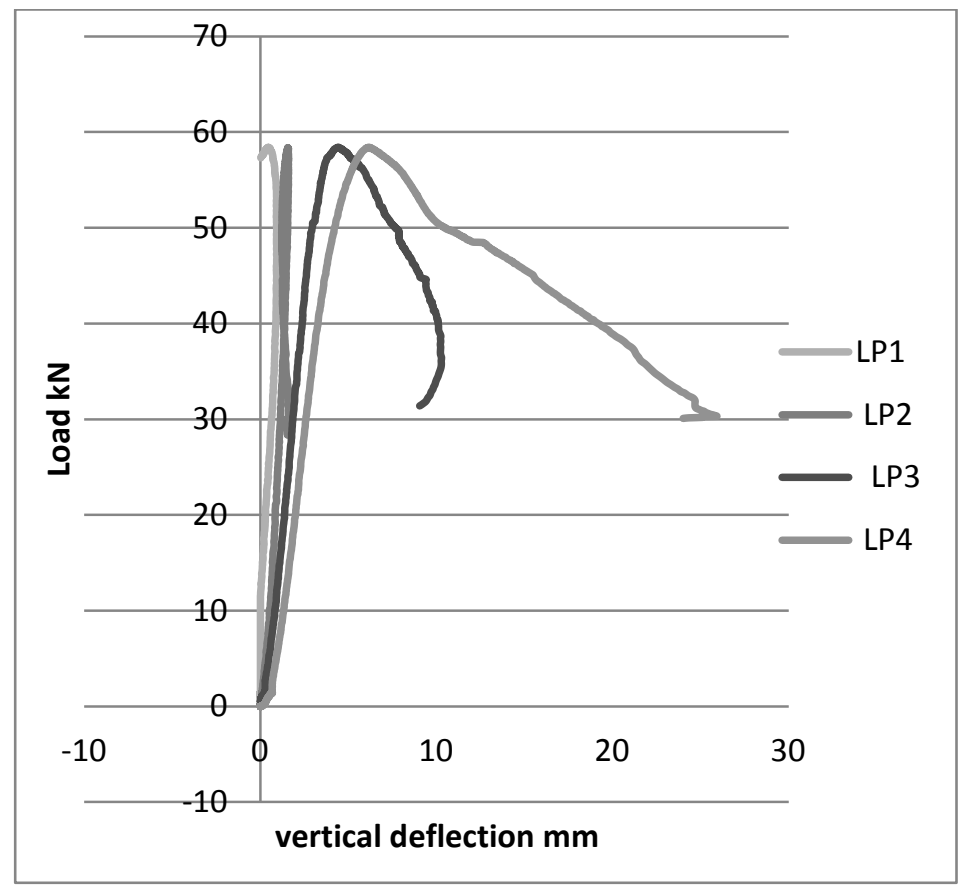

Figure 4.25 Load vs Vertical displacements of the LPs on the top beam of wall 3. LP1\&LP2 were on the same side and LP3 and LP4 on the other side of the steel beam (longitudinally) 


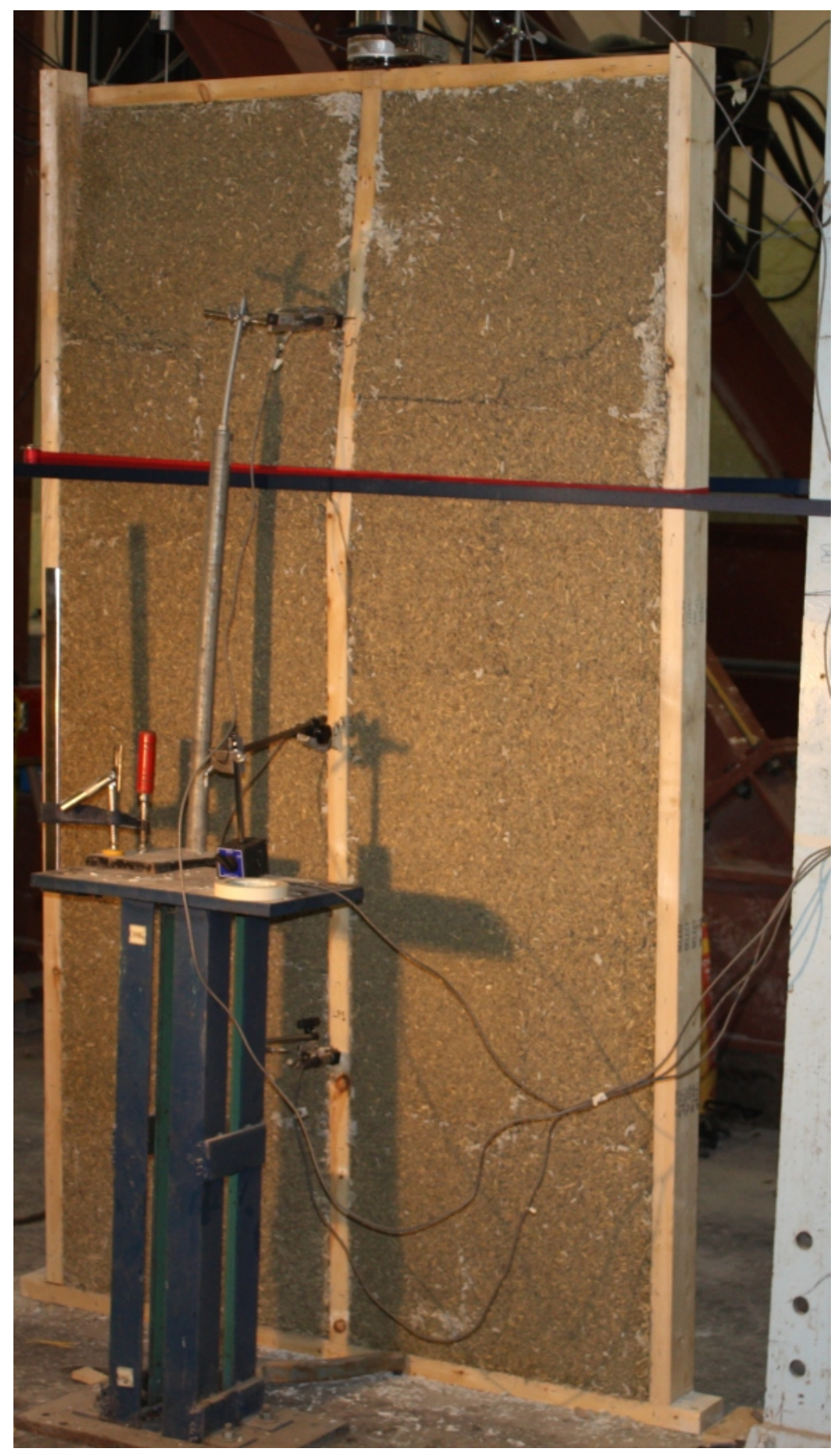

Figure 4. 26 Strong axis buckling failure of middle column of Wall 4 


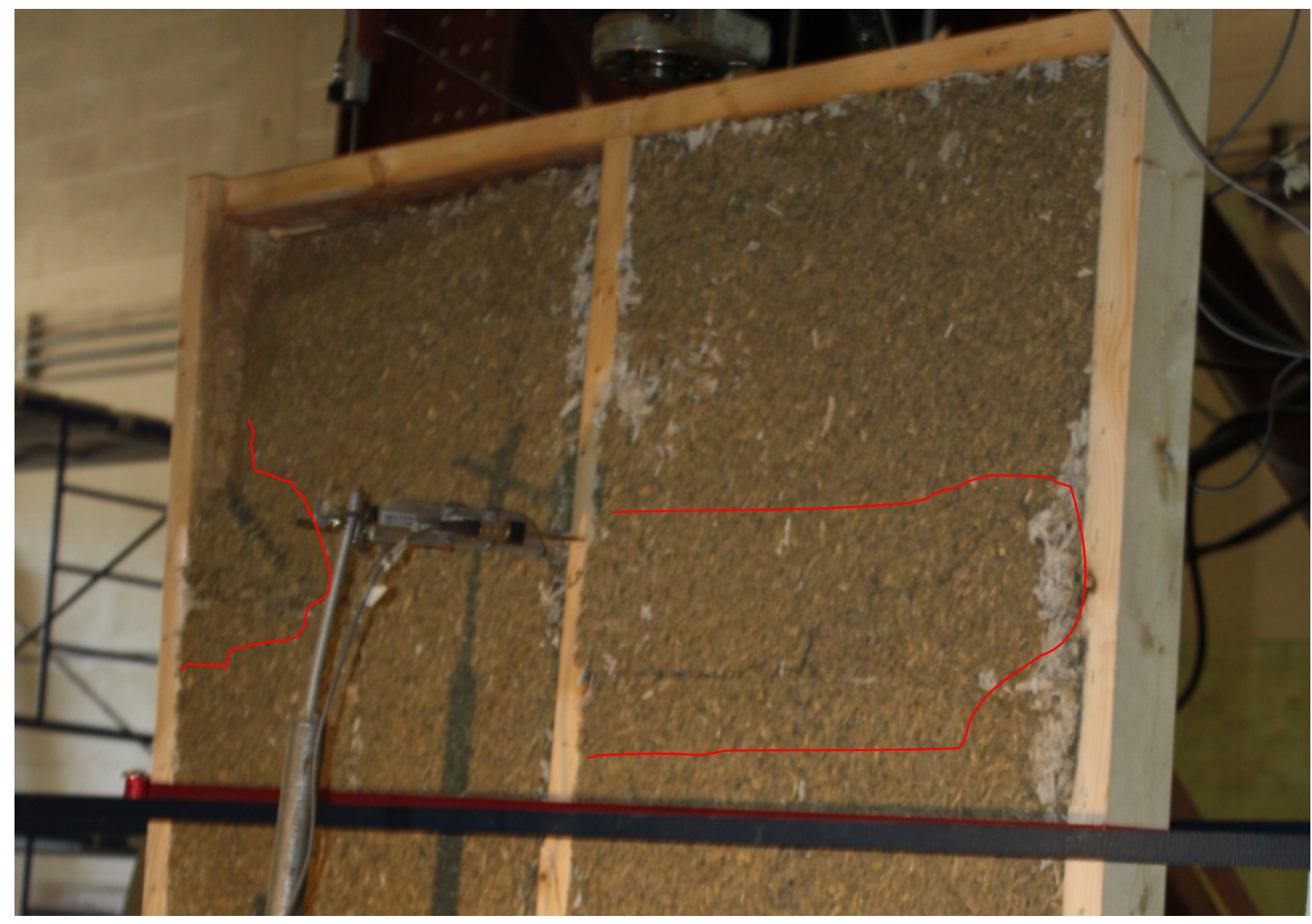

Figure 4. 27 Cracks in hempcrete of Wall 4 


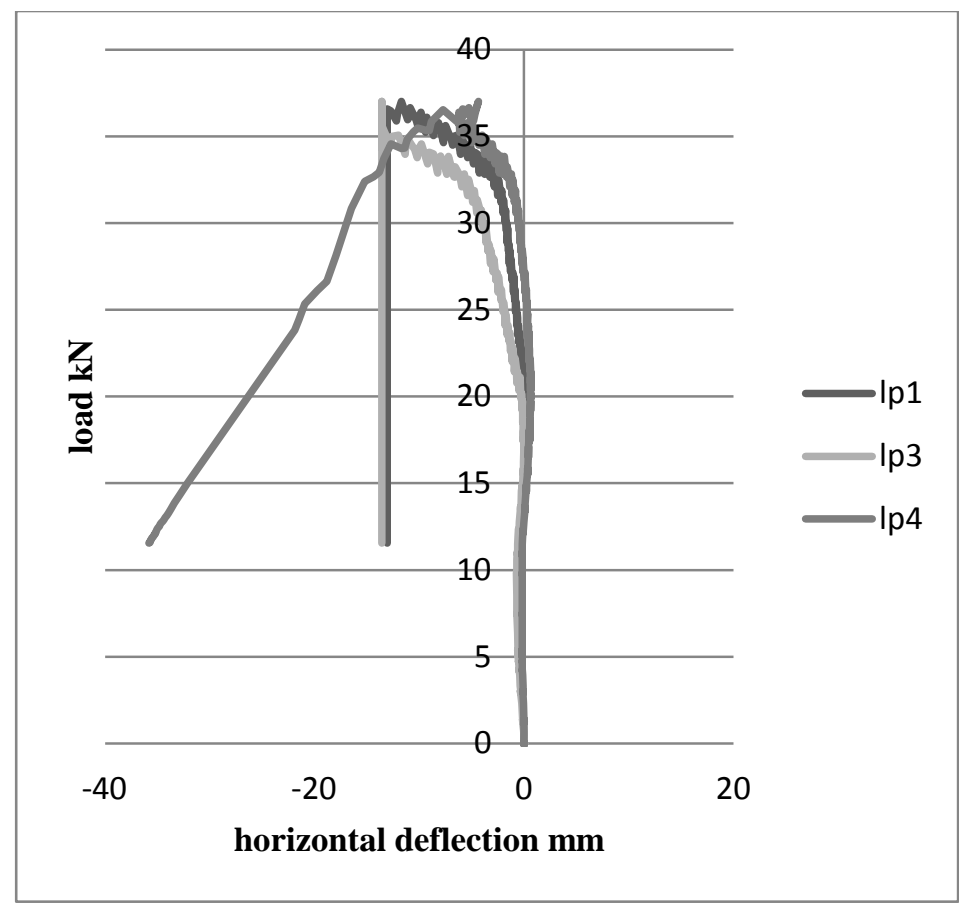

Figure 4. 28 Load versus horizontal displacement in direction of buckling obtained from LPs on the middle column of Wall 4

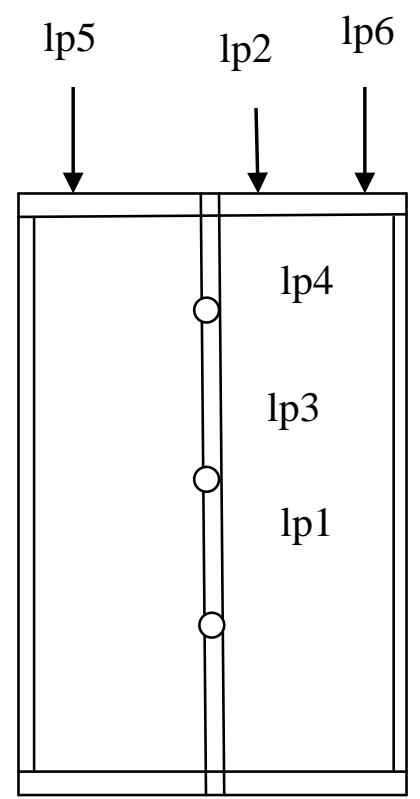




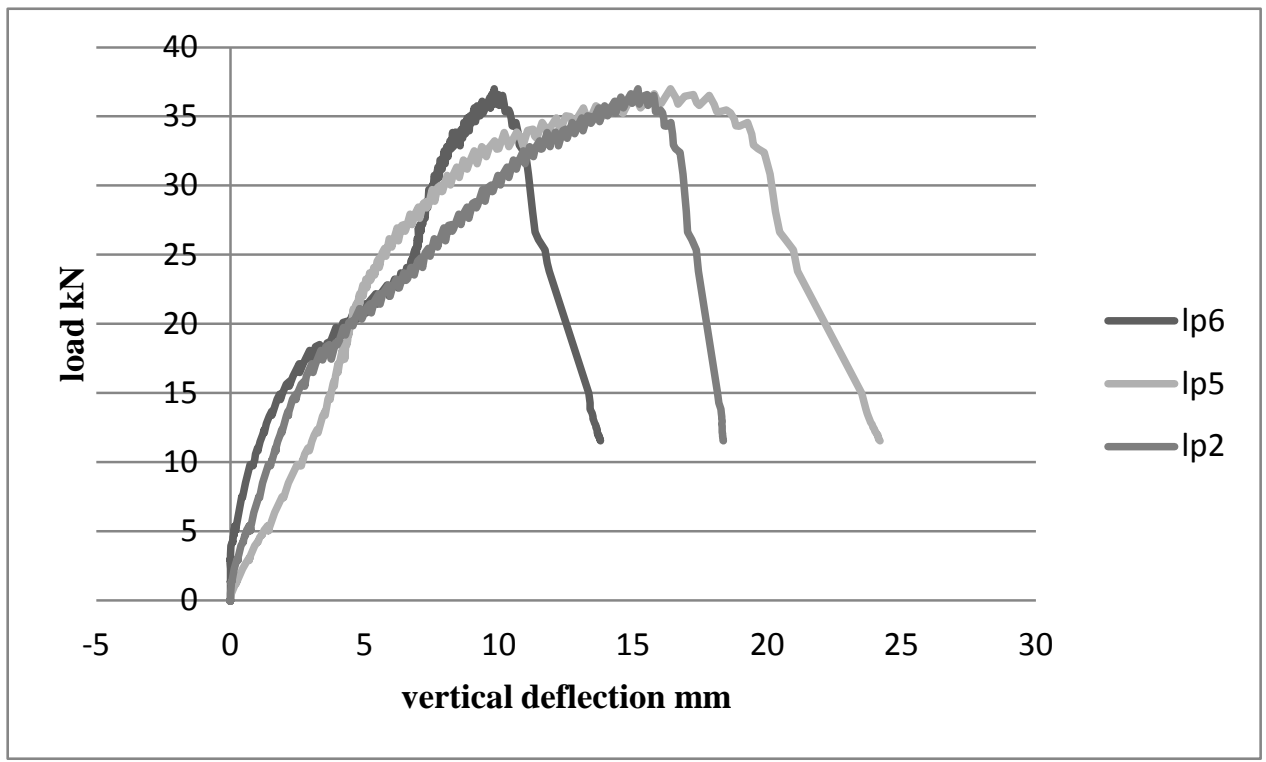

Figure 4. 29 Load versus vertical displacements of the LPs on the top beam of Wall 4 


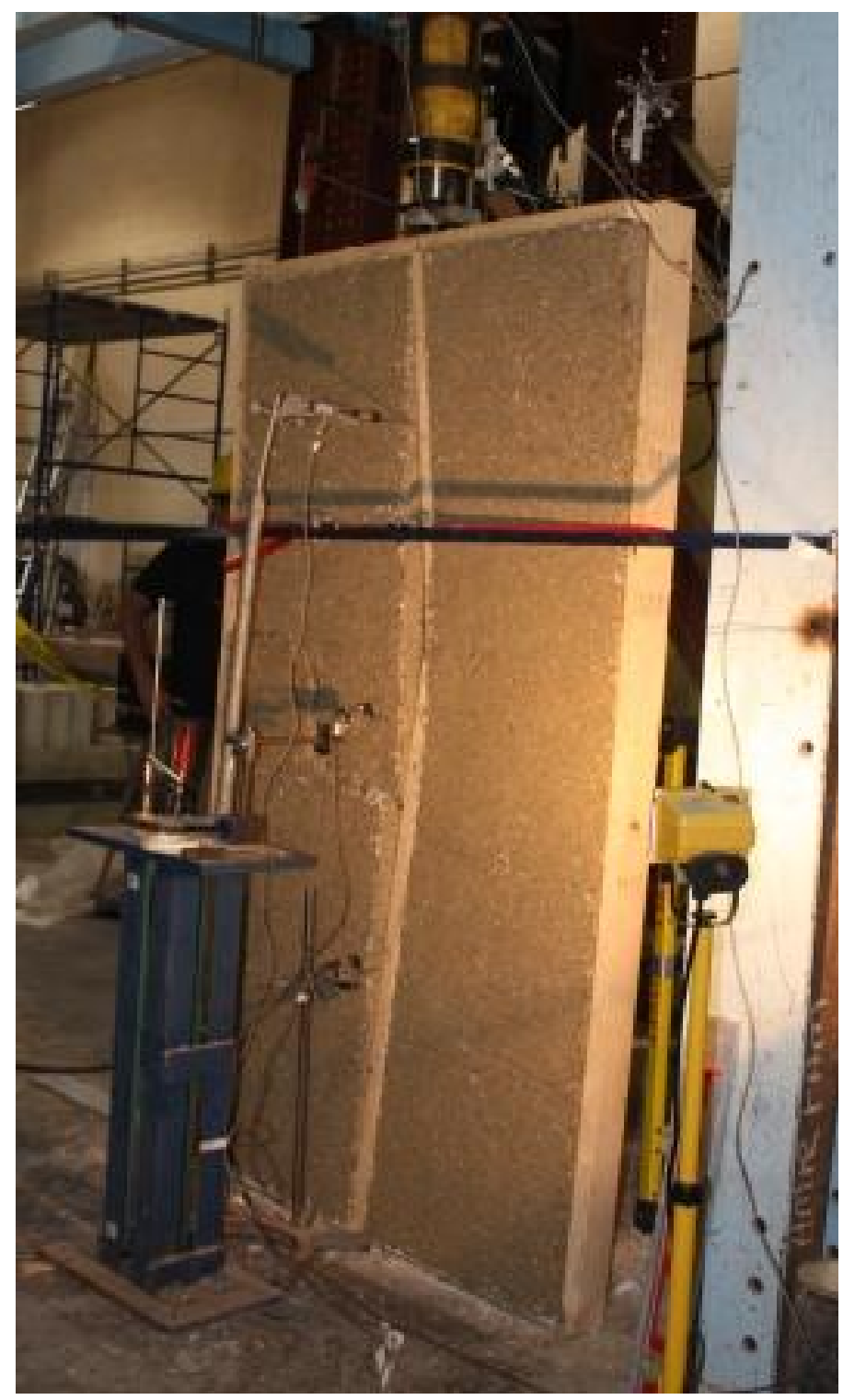

Figure 4. 30 Strong axis buckling failure of the middle column of Wall 5 


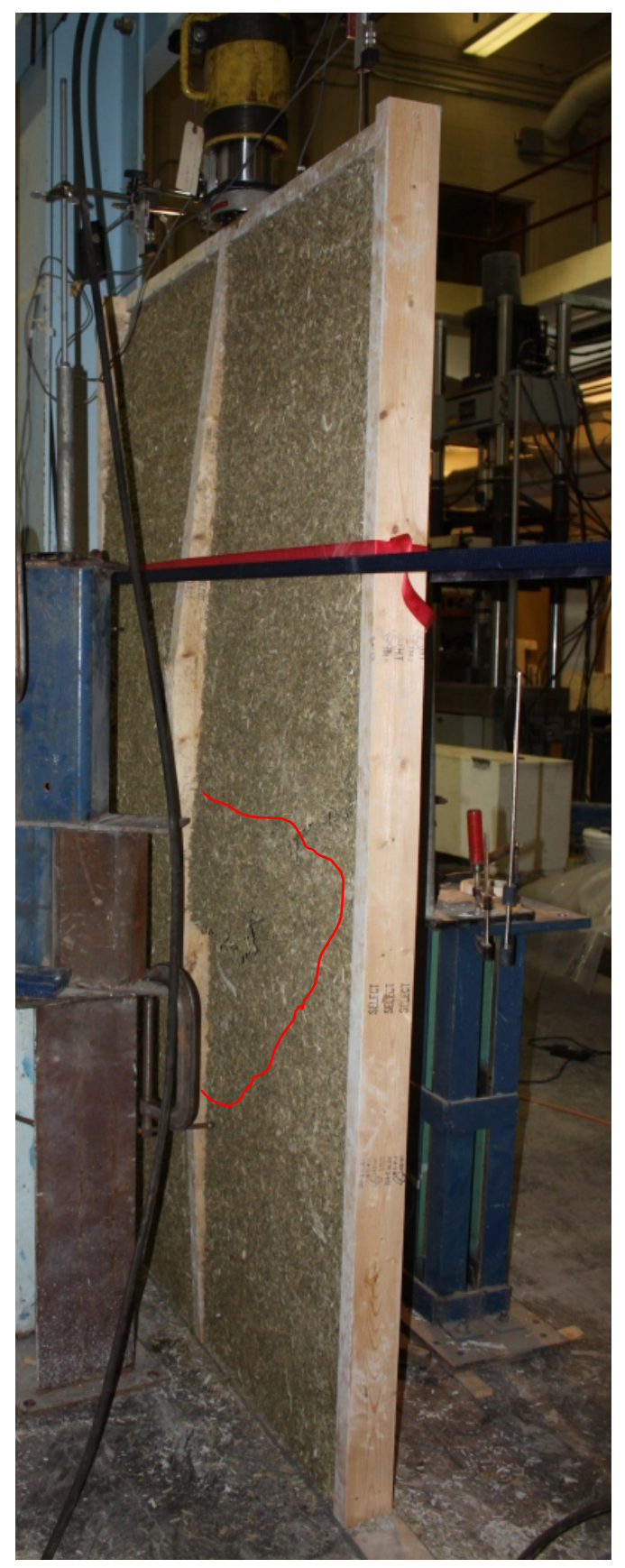

Figure 4. 31 Strong axis buckling failure of the middle column of Wall 5. Failed hempcrete is highlighted. 


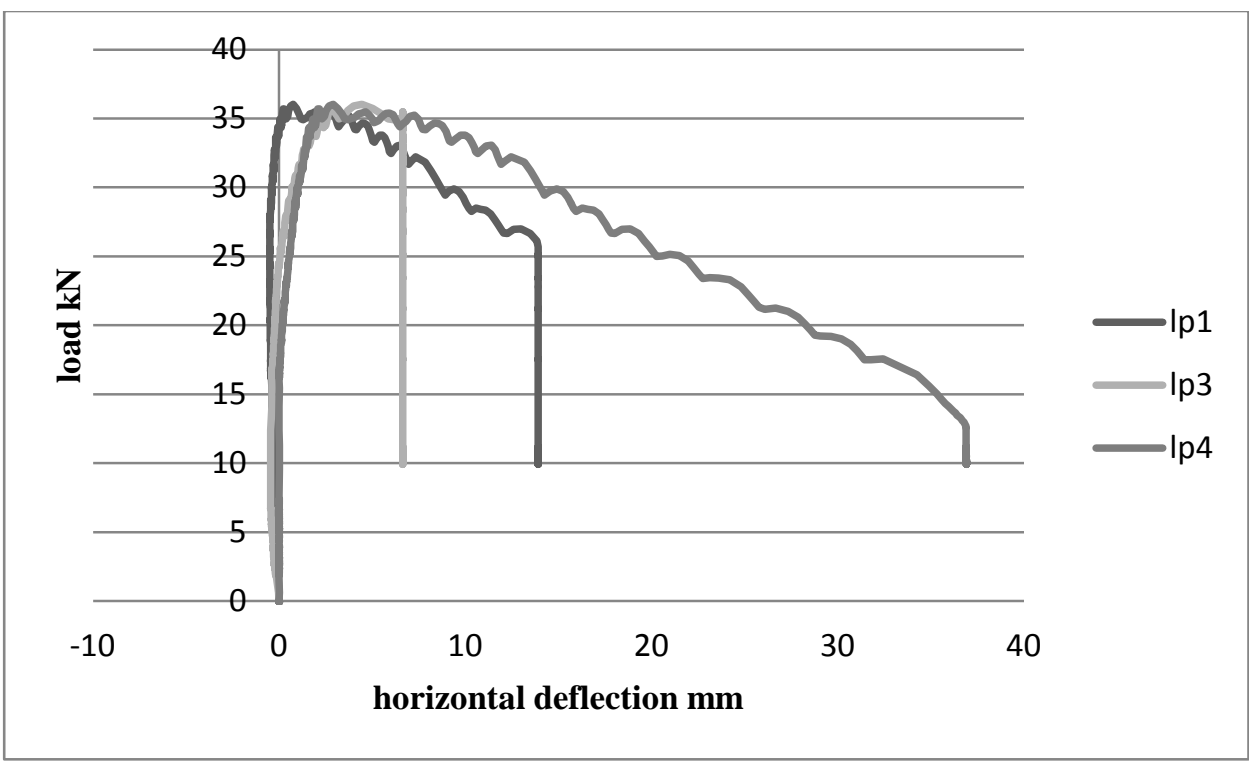

Figure 4. 32 Load versus horizontal displacement in direction of buckling for Wall 5

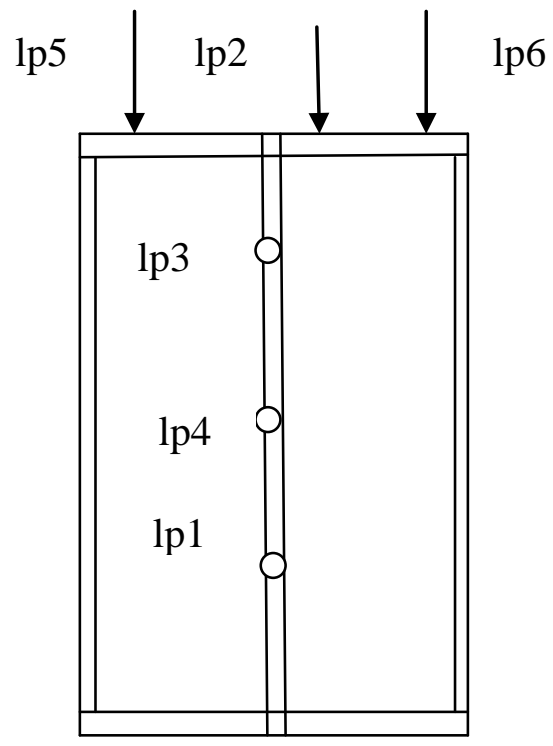




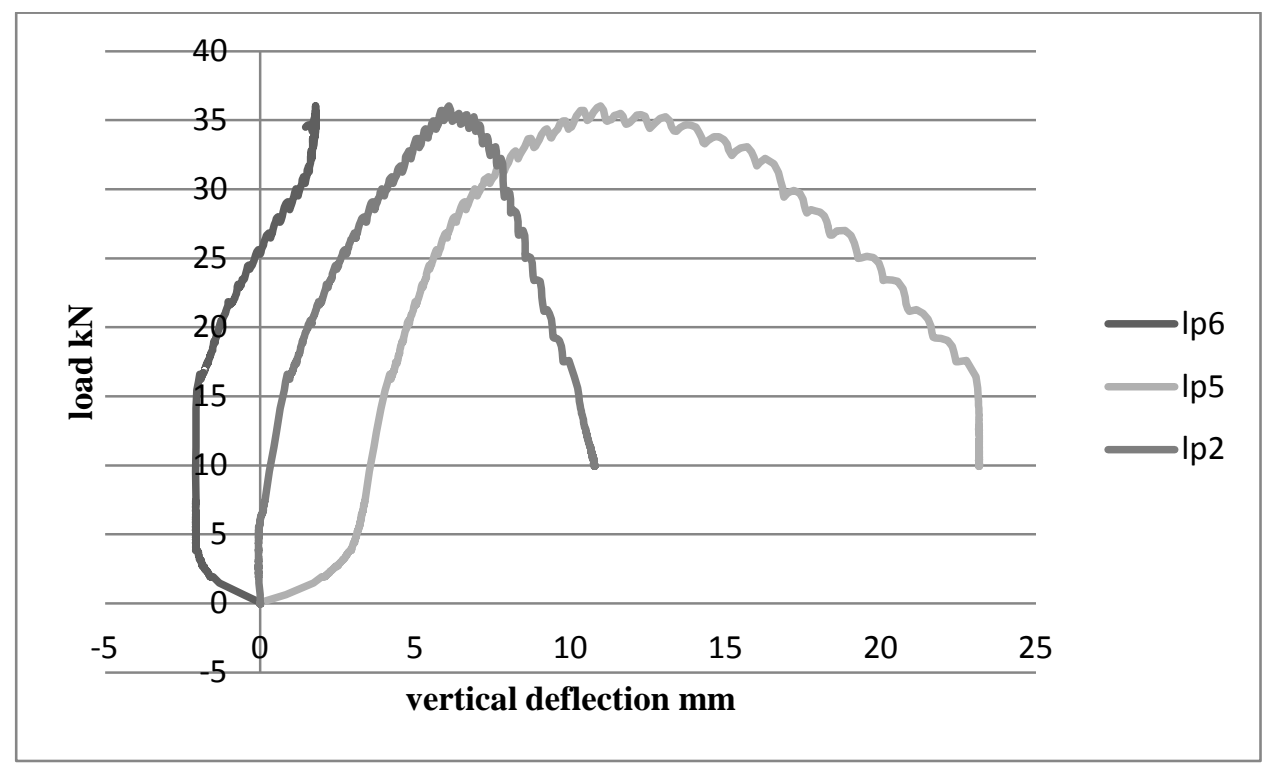

Figure 4. 33 Load versus vertical displacement of the LPs on the top beam of Wall 5 


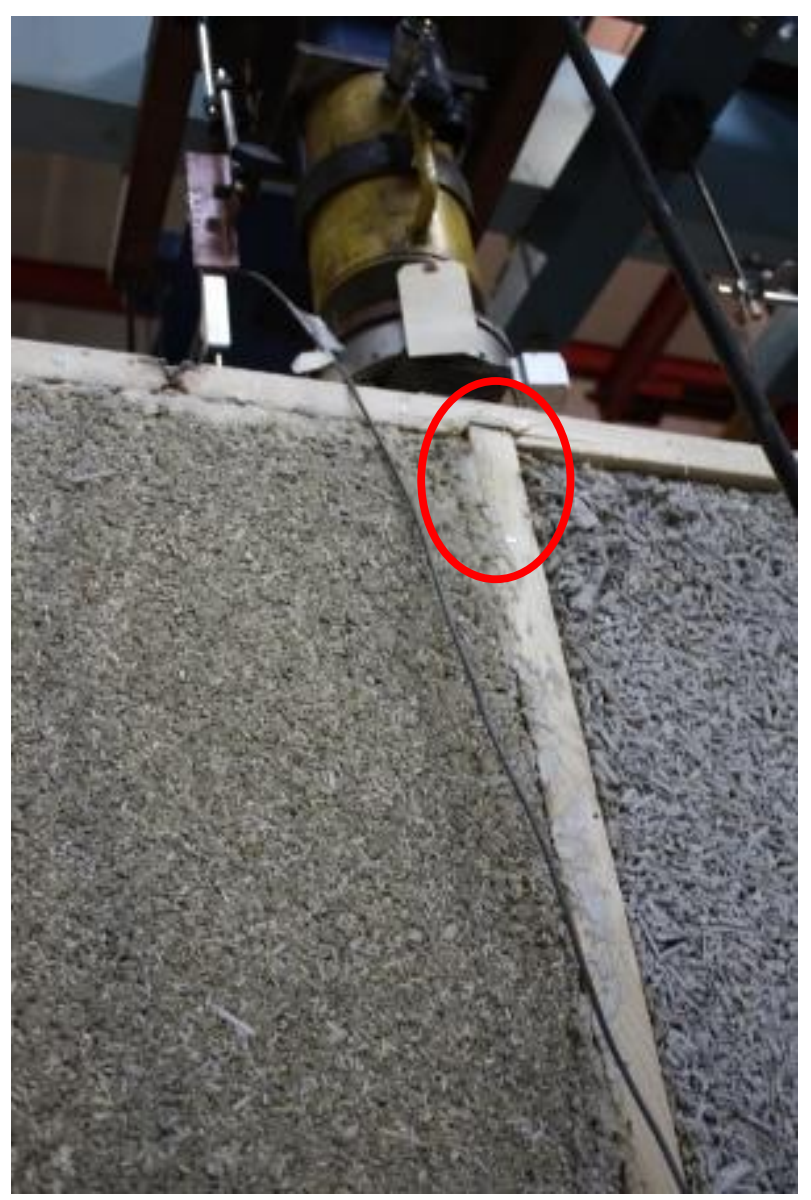

(a)

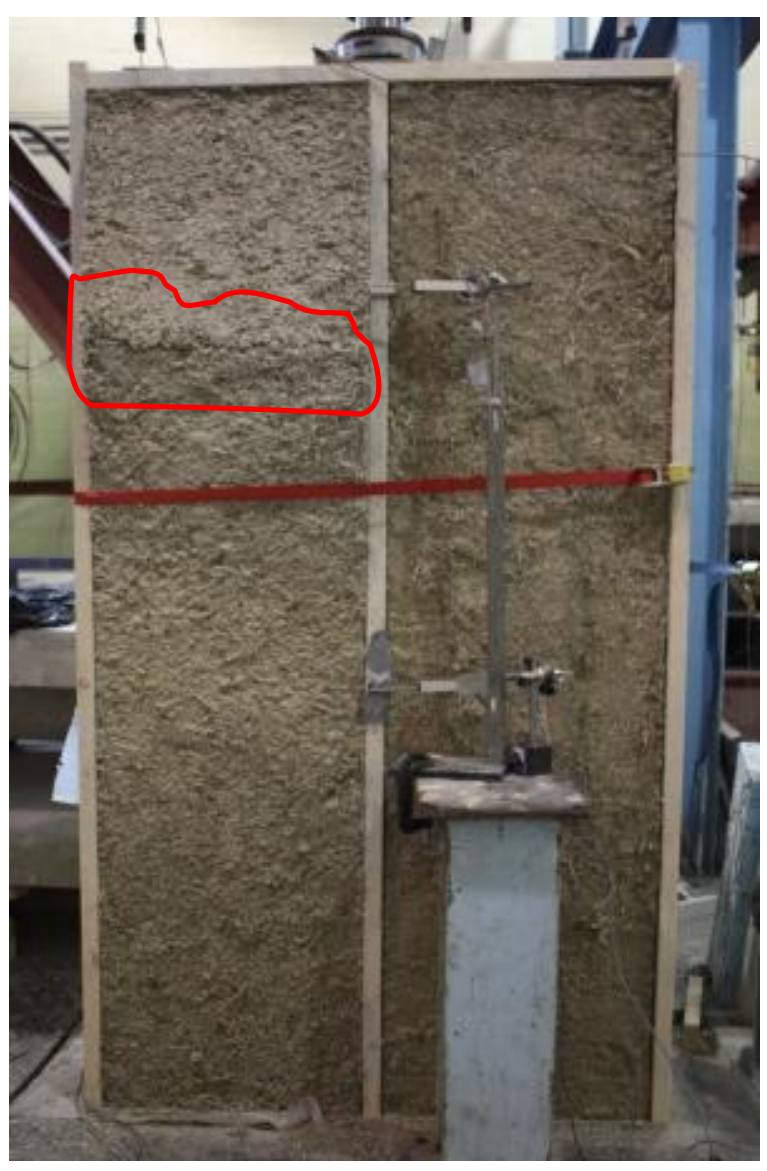

(b)

Figure 4. 34 (a) Bearing failure of middle top beam in wall 7 (b) subsequent failure of hempcrete 


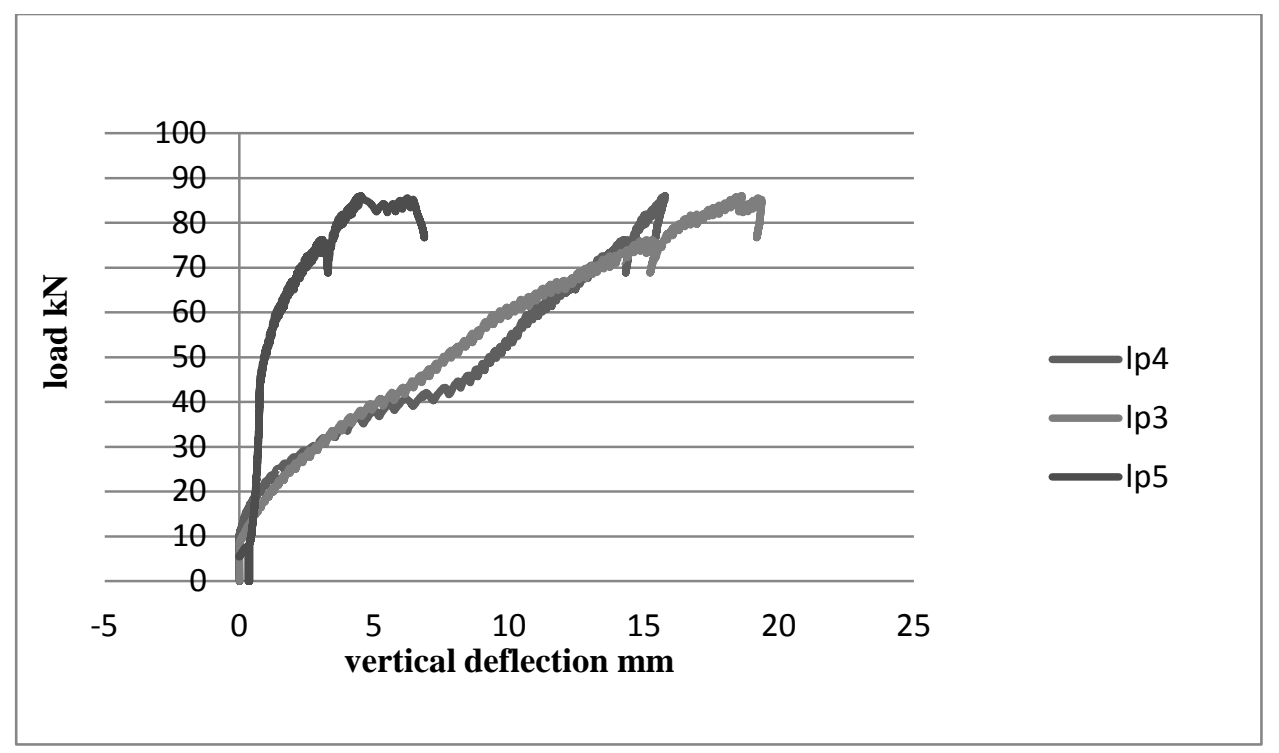

Figure 4. 35 Load versus vertical displacement of the LPs on the top beam of Wall 7

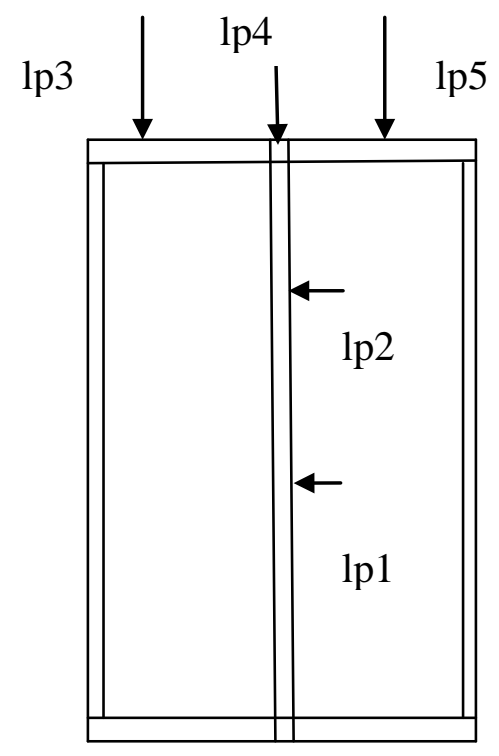




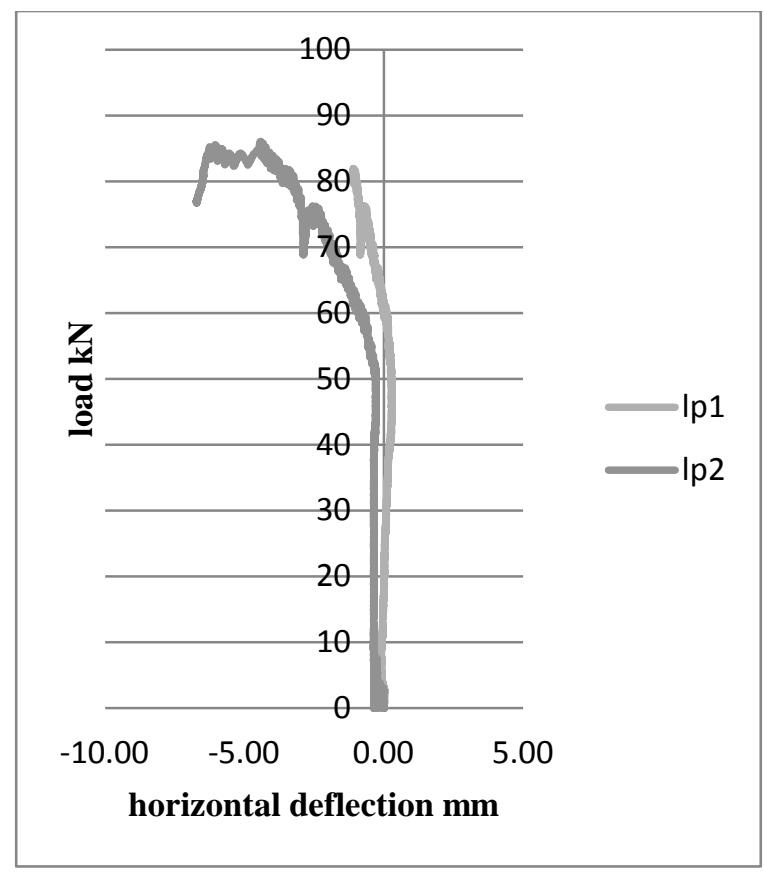

Figure 4. 36 Load Vs Horizontal displacement of middle column. 


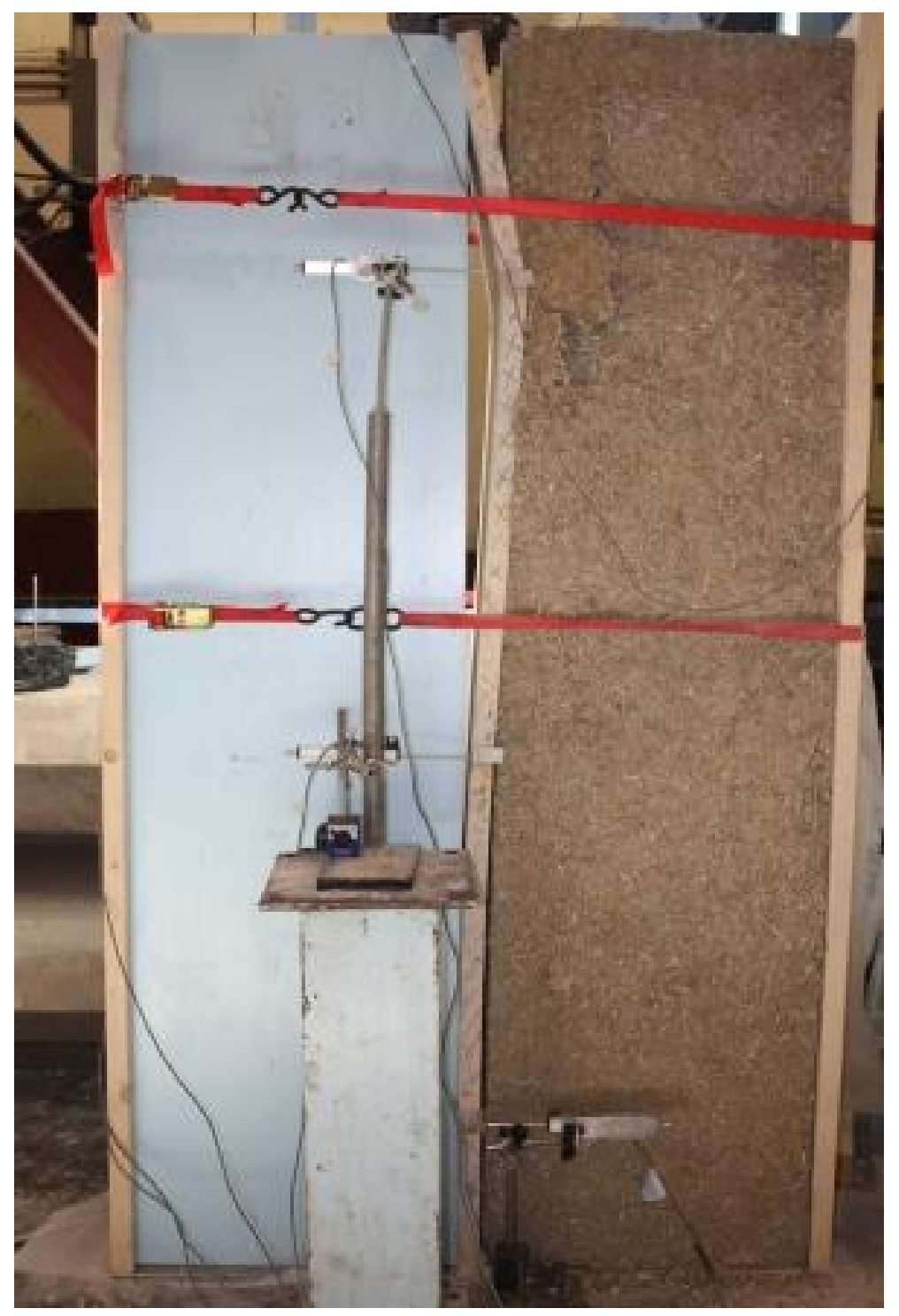

Figure 4. 37 Weak axis buckling failure of the middle column of Wall 8 


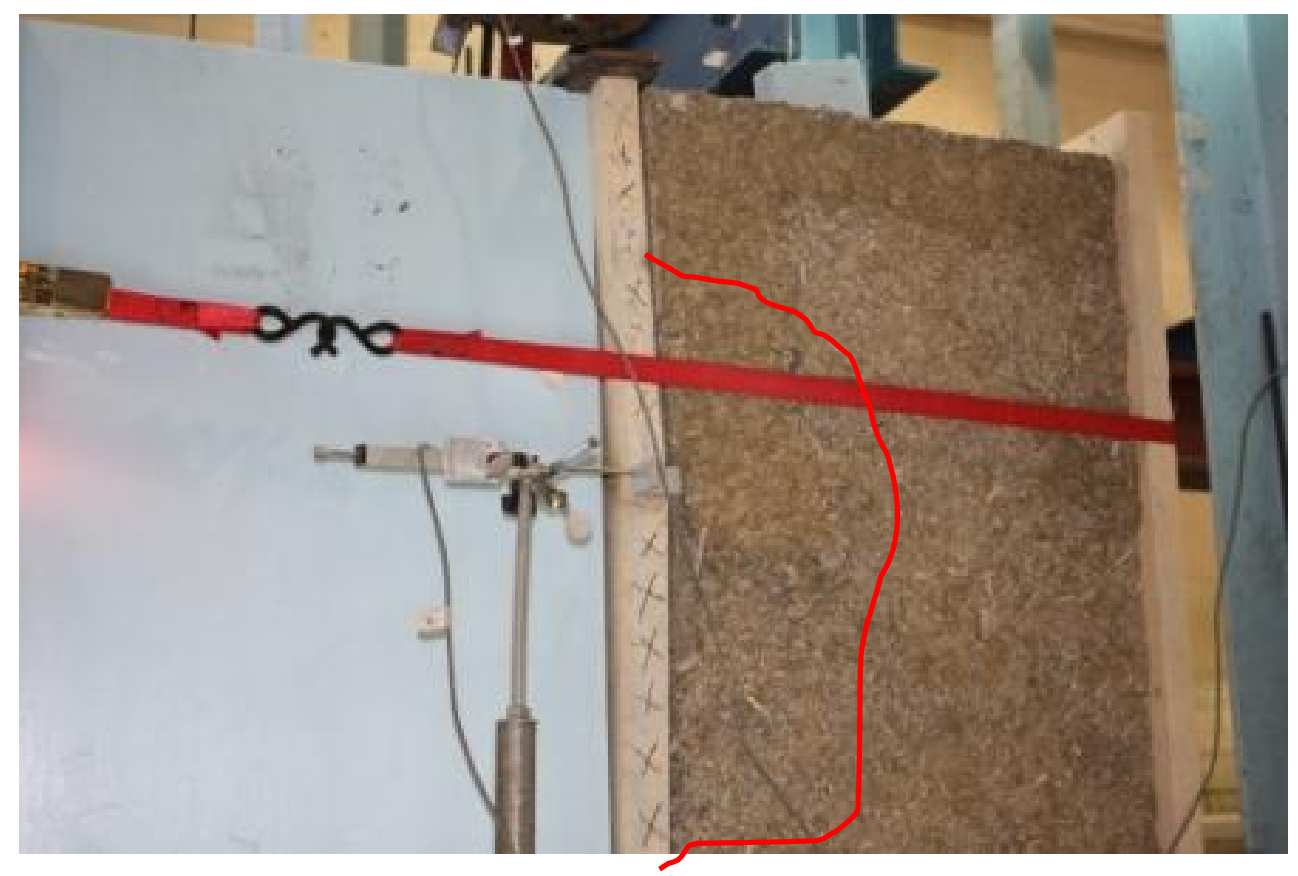

Figure 4. 38 Failed hempcrete 


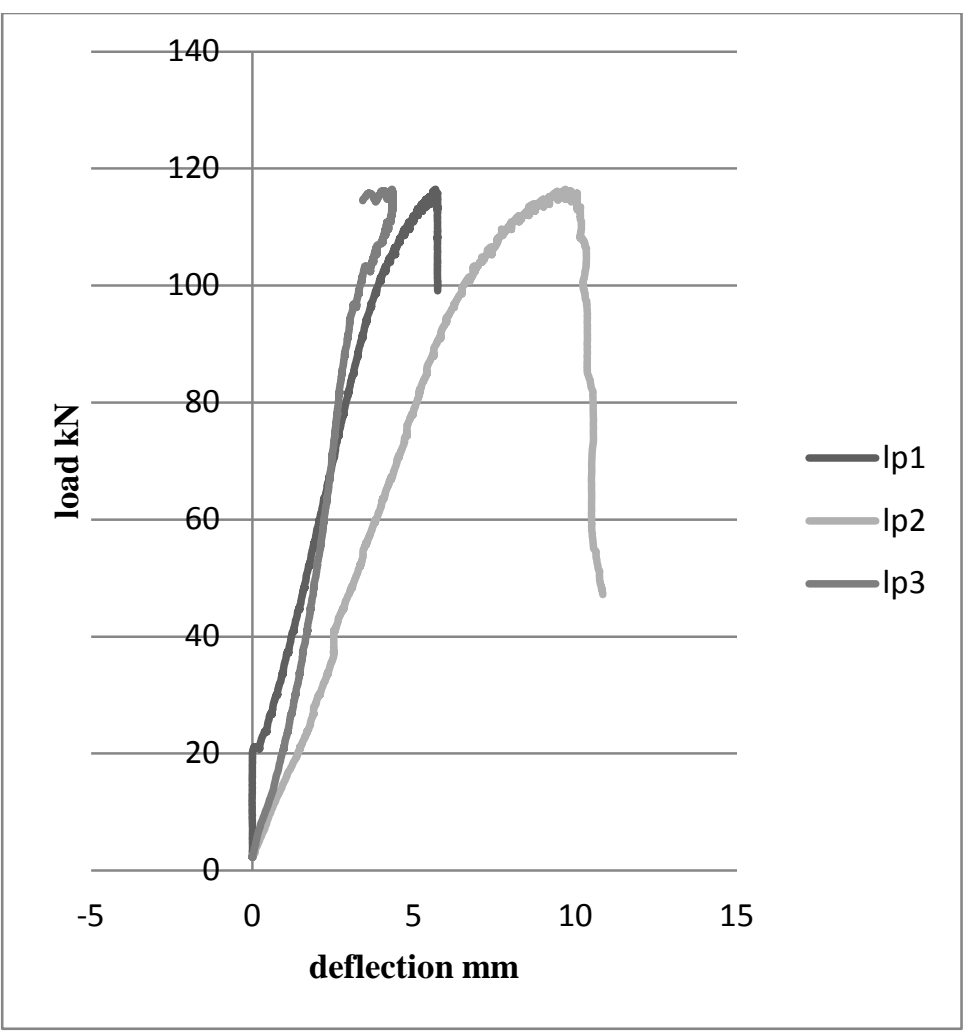

Figure 4. 39 Load versus vertical displacements of the LPs on the top of Wall 8

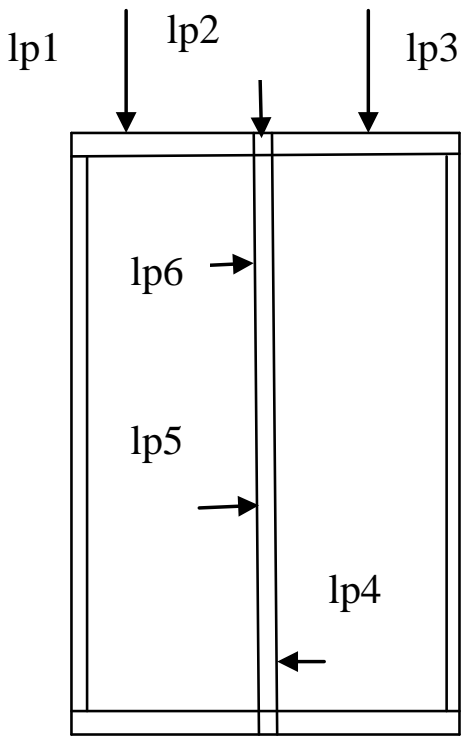




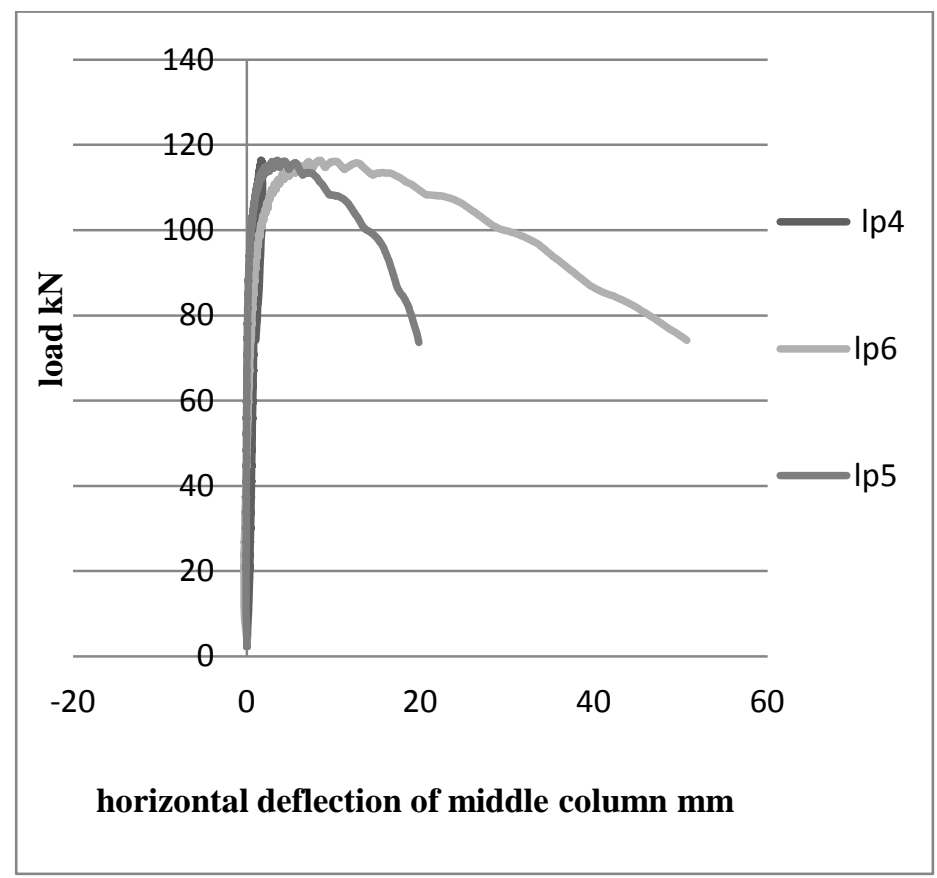

Figure 4. 40 Load versus horizontal displacement in direction of buckling obtained from LPs on the middle column of Wall 8 


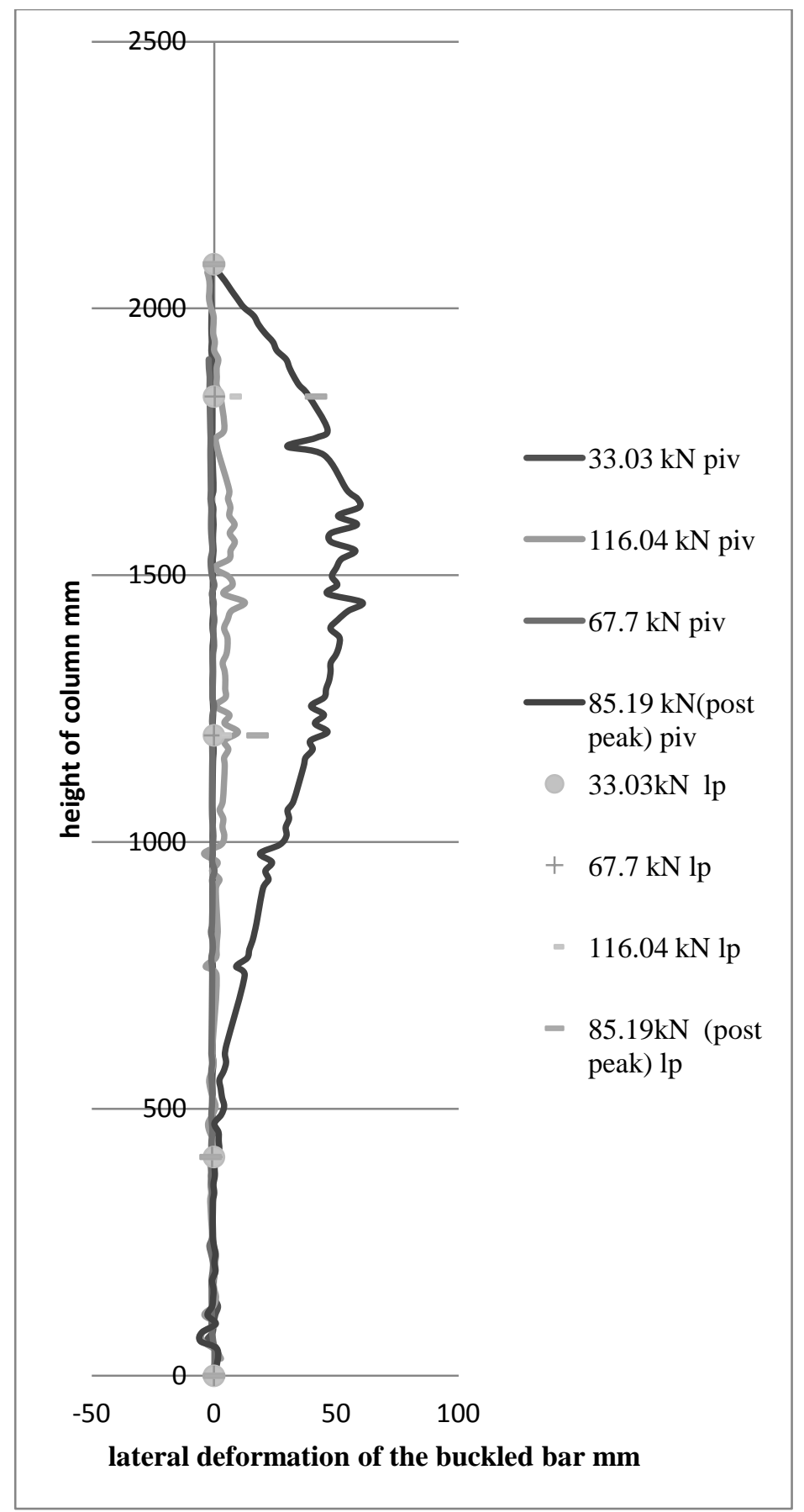

Figure 4. 41 Buckled shape of middle column at different loads (curves obtained from PIV analysis and the points from LPs). 


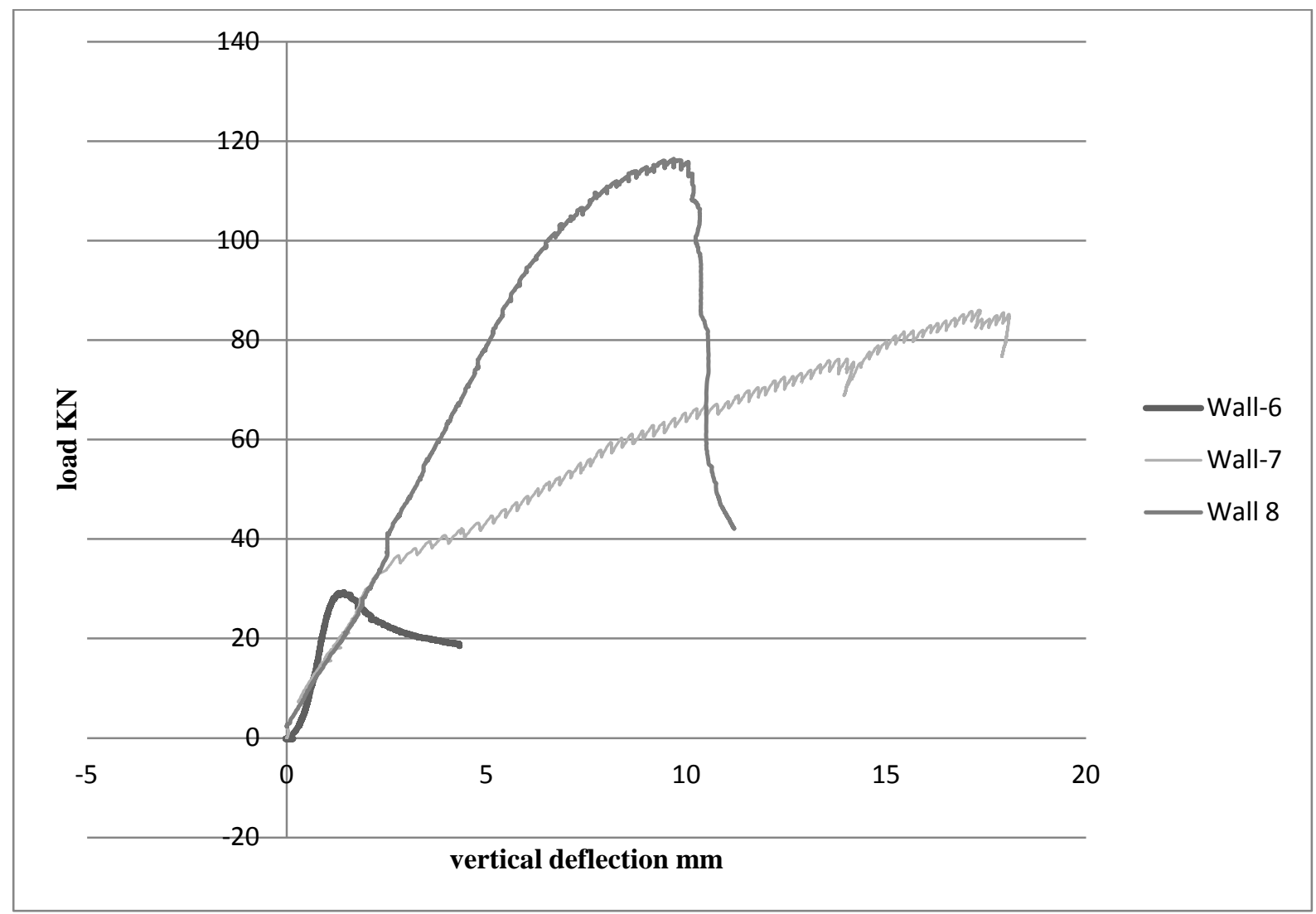

Figure 4. 42 Comparison of the load deflection graphs of wall 6,7 and 8. This depicts the increase in wall strength due to hempcrete infill. 


\section{CHAPTER: ANALYSIS}

The results presented in Chapter 4 indicate that hempcrete can provide lateral support for timber columns and thus increase their buckling resistance. A hempcrete in-filled timber stud wall should be able to withstand greater load than similar wall assemblies without hempcrete infill. However, it is important to be able to quantify the strength added by hempcrete for design of composite hempcrete timber walls in practical situations.

In the tests of Walls 3,4 , and 5, it was observed that the timber columns failed by strong axis buckling, as opposed to Walls 1 and 6 (timber frames without hempcrete). This is because the lateral support provided by hempcrete prevented weak axis buckling and resulted in strong axis buckling being the governing failure mode.

Figure 5.1 compares the load deflection response of Walls 6, 7, and 8. Wall 6 did not have any in-fill. Wall 7 was in-filled with hempcrete, and had conventional timber top and bottom plates. In order to quantify the performance of hempcrete as a bracing material, Wall 8 was designed such that the timber would buckle about its weak axis and thus deflect into the hempcrete. All other modes of failure were prevented (e.g. aluminum plates were used at the top and bottom of the column to prevent bearing failure; and, a section with a strong axis buckling strength 20 times higher than its weak axis buckling strength was selected).

Wall 7 failed at a load about 4 times higher than Wall 6. However, the governing failure mode was a bearing failure of the top and bottom beams. With bearing failure prevented, Wall 8 failed at a load about 5 times higher than Wall 6. If bearing is not prevented as would typically occur in 
conventional timber buildings, it can be expected to be the governing mode of failure for hempcrete in-filled walls.

\subsection{Calculation of Failure Loads According to CSA- O86-01}

The ultimate failure load for each wall tested was calculated using the design equations in the Canadian timber design standard O86-01 (CSA- O86-01, 2005). Material properties used in these calculations were obtained from the ancillary tests described in Chapter 4 . Wall 8 failed by weak axis buckling and deflecting into the hempcrete in-fill. For this result, an analytical model of a column resting on an elastic foundation (Figure5.2) (ref-Theory of elastic stability Timoshenko and Gere-Buckling of bar on elastic foundation.) was used to calculate the failure load. The following section reviews the equations and assumptions used in these calculations.

The ultimate load, $P_{\text {ult }} r_{2}$ of a timber column failing in compression parallel to the grain is given by Clause 5.5.6.2.2 of CSA-O86-01:

$$
P_{u l t r}=\varphi F_{c} A K_{z c} K_{c}
$$

where $A$ is the cross-sectional area; $\varphi$ is the resistance factor and equal to 0.8 for design at ultimate limit states. For the calculation of failure loads of the tested columns, it is set equal to one.

Adjusted specified compressive strength $\mathrm{F}_{\mathrm{c}}$ is given by

$$
F c=f_{c}\left(K_{D} K_{H} K_{s c} K_{T}\right)
$$


where $f_{c}$ is the specified compressive strength parallel to the grain. The current standard for testing timber parallel to the grain requires testing samples 4.8 metres in length (Johns et al 1990). Due to a lack of testing equipment to facilitate samples of this size, $300 \mathrm{~mm}$ long clear wood samples as described in Chapter 4 were tested. It is well known (Johns et al 1990) that the strength of timber parallel to the grain decreases with length due to the increased probability of the presence of knots and other defects. Therefore the strength values obtained from the $300 \mathrm{~mm}$ long samples are likely to be larger than the compressive strength of the actual columns tested. Nevertheless, these values (as presented in Table 4.1) will be used for the value of $f_{c}$ in Equation 5.2 .

$K_{D}$ is a load duration factor and can be set to 1.15 for short duration loads.

Ksc is the service condition factor for compression parallel to grain and can be set to1 since dry conditions can be assumed.

$\mathrm{K}_{\mathrm{t}}$, is the treatment factor. Sometimes wood is treated with preservatives and various treatments like fire retardant. No such treatment was done to the timber in these experiments. Hence $K_{t}$ was set to 1 .

The size factor $K_{z c}$ is:

$$
K z c=6.3\left(\mathrm{~d} * \mathrm{~L}_{\mathrm{d}}\right)^{-0.13}
$$

where $L_{d}$ is the unsupported length in the direction of buckling, and $d$ is the depth in the direction of buckling. The probability of finding defects splits and low $E$ value zones increases with increase in length or width of column dimensions. This factor modifies the specified strength $F C$ for the effect of column dimensions with respect to a standard test specimen dimension (length 
of about $4.8 \mathrm{~m}$ ) used for calibration. As described above, a non-standard test specimen (300 mm length) was used to obtain $F c$, so $K_{z c}$ is set equal to 1 .

The slenderness factor $K_{c}$ is:

$$
K c=\left[1+\frac{F c}{E^{\prime}} K_{z c} \mathrm{C}_{\mathrm{c}}{ }^{3}\right]^{-1}
$$

Here the factor $C_{c}$ is:

$$
C_{c}=\left(\mathrm{K}_{\mathrm{e}} \mathrm{L}_{\mathrm{d}}\right) / \mathrm{d}
$$

where $\mathrm{K}_{\mathrm{e}} \mathrm{L}_{\mathrm{d}}$ is the equivalent unsupported length of the column. The factor $C_{c}$ accounts for the slenderness of the column. The buckling resistance of the column decreases as the factor $C_{c}$ increases.

Where $\frac{F c}{E^{\prime}}=$ strength to stiffness ratio

Where $\mathrm{E}^{\prime}$ is a modified stiffness according to equation [5.4b]

$$
\mathrm{E}^{\prime}=35 \mathrm{E}_{05} \mathrm{~K}_{\mathrm{se}} \mathrm{K}_{\mathrm{t}}
$$

where $K_{s e}$ is the service condition factor, and $K_{t}$ is the treatment factor for the modulus of elasticity. For the present study, both of these factors can be set equal to 1 . The fifth percentile modulus of elasticity, $E_{05}$, can be determined as $0.82 E$, where $E$ is obtained from testing timber parallel to the grain. The results of these tests were described in Chapter 4, and summarized in Table 4.1. 
Several walls failed by bearing of the column into the top beam. The ultimate bearing capacity, $Q_{u l t}$, for timber loaded perpendicular to the grain is given by Clause 5.5.7.2 (CSA-O86-01):

$$
Q_{u l t r}=\varphi F_{c p} A_{b} K_{B} K_{z c p} K_{\mathrm{D}}
$$

where $F_{c p}$ is compressive strength perpendicular to the grain; and $A_{b}$ is the bearing area.

The length of bearing factor, $K_{B}$, captures whether the area of bearing is under high bending stress. It is taken as 1.25 (Wood Design Manual-2005) for a bearing length of 38mm since it does not lie in the area of high bending stress. The size factor $K_{\text {zср }}$ is based on the effect of member orientation on resistance. When loaded in a flat orientation (higher width to depth ratio) wood has a higher resistance to crushing perpendicular to grain than when loaded in the edge orientation (lower width to depth ratio). In the testing undertaken in this thesis, the top and bottom beams were loaded in the "flat orientation" and the factor was taken as 1.15 (Wood Design manual-2005 ). 


\subsection{Buckling of Strut on Elastic Foundation}

Hempcrete infill acts as a continuous lateral support to a timber column thus increasing its buckling strength by reducing the effective unsupported length. This problem can be analytically modelled as an axially loaded column resting on a bed of springs (Figure 5.2). Hempcrete acts as the elastic medium or continuous elastic lateral support to the timber column. The reaction of the medium (hempcrete) at any cross-section (which acts on the column laterally) of the column is proportional to the lateral deflection in the medium at that section.

An energy method has been used to solve this problem for the critical buckling load (Theory of elastic stability Timoshenko and Gere-Buckling of bar on elastic foundation.). The strain energy, $\Delta \mathrm{U}_{1}$, due to the bending of the column can be calculated by assuming a sine wave buckling curve and pinned end conditions. The strain energy, $\Delta \mathrm{U}_{2}$, due to the deformation of the elastic foundation can be determined from the deflected shape of the column and the elastic foundation modulus. $\Delta \mathrm{U}_{2}$ The work done by the compressive force $P$ acting through the vertical deflection at the top of the column as it undergoes buckling is $\Delta \mathrm{T}$. By the Principle of the Conservation of Energy:

$$
\Delta U 1+\Delta U 2=\Delta T
$$

The critical buckling load, $P_{c r}$, is:

$$
P_{c r}=\frac{\pi^{2} E I}{l^{2}}\left(m^{2}+\frac{\beta l^{4}}{m^{2} \pi^{4} E I}\right)
$$

where $E I$ is the modulus of rigidity of the column section, $l$ is the length of the column, and $m$ is the number of half sine waves in which the bar subdivides at buckling. The elastic foundation 
modulus, $\beta$, is defined as the reaction force per unit deflection of the elastic foundation per unit length of column.

$P_{c r}$ takes a minimum value when $\beta=0$, (i.e. there is no elastic foundation) and $m=1$, which is the case of a bar buckling with hinged ends. By gradually increasing the value of $\beta$, a condition is reached when the buckling load for $m=1$ is more than for $m=2$. Thus a column with such a value of $\beta$ buckles in two half sine waves. It can be shown (reference- Theory of elastic stability Timoshenko and Gere-Buckling of bar on elastic foundation.) that this condition is reached when:

$$
\frac{\beta l^{4}}{\pi^{4} E I} \geq 4
$$

Thus for elastic foundations with $\beta$ satisfying the above condition, there will be an inflection point in the column's buckled shape and it will have more than one half sine wave.

The value of $m$ can be calculated as:

$$
\frac{\beta l^{4}}{\pi^{4} E I}=m^{2}(m+1)^{2}
$$

This is the condition where the buckling mode changes from $m$ half sine waves to $m+1$ half sine waves.

For known values of the column dimensions and $\underline{\beta}, m$ can be calculated from Equation 5.9. Then $P_{c r}$ can be represented in the form:

$$
P_{c r}=\frac{\pi^{2} E I}{(K l)^{2}}
$$


where

$$
\mathrm{K}=\left(m^{2}+\frac{\beta l^{4}}{m^{2} \pi^{4} E I}\right)^{-0.5}
$$

Equation [5.7] gives the buckling load assuming an elastic material with no defects. A real timber column will have various defects (knots, out-of-straightness) that will reduce its capacity from that predicted by Equation [5.7]. In this thesis, it is proposed that the effective length $K l$ using Equation [5.11] be substituted in the CSA-O86 Equation [5.1] for the equivalent unsupported length. 


\subsubsection{ASSUMPTIONS}

This section summarizes the assumptions made in applying Equations [5.7], [5.8], and [5.9] for predicting the failure loads of the walls tested. It also summarizes the material properties used for these calculations.

It is assumed that:

- The timber columns are axially loaded and have hinged ends.

- The hempcrete acts as a linear elastic medium, and is homogeneous along the length of the column.

- When buckling into the hempcrete, the column does not lose contact with the hempcrete. This implies that any bending in the column results in deformation of the hempcrete.

- The column buckles in the form of a sine curve.

The elastic foundation modulus $\beta$ was estimated from the cylinder tests of hempcrete. The elastic deformation, $\delta$, of an elastic member under axial force, $P$, is:

$$
\delta=P L / E A
$$

where $A$ is the cross-sectional area; $E$ is the elastic modulus; and, $L$ is the length of the member.

The elastic modulus for the various hempcrete mixes used in this study was obtained from cylinder compression tests. The length and area in Equation 5.12 are based on the timber column area in contact with the hempcrete and the spacing of the columns (Figure 5.3). The hempcrete in contact with column per unit length of the column is:

$$
A=1 x d
$$


where $d$ is the depth of the timber column. The spacing between the timber columns is $L$. Thus the force per unit deformation of the hempcrete is:

$$
\beta=\frac{d E}{L}
$$




\subsection{DISCUSSION ON THE CALCULATED VALUES AND ACTUAL RESULTS}

Equation 5.1 is used to calculate the predicted values of buckling (weak and strong axis) failure strengths of walls using the factors and material properties in Table 5.1. The predicted buckling loads are summarized in Tables 5.2 and 5.3. Equation 5.5 is used to calculate the bearing failure loads of the walls with the results summarized in Table 5.4.

The various parameters needed to predict the buckling load of a strut on an elastic foundation and the equivalent unsupported length are listed in Table 5.5. Using these equivalent unsupported lengths in Equation 5.1, the expected weak axis buckling loads of walls with hempcrete in-fill are calculated and summarized in Table 5.6.

Tables 5.7 and 5.8 compare the calculated loads of different modes of failure of the walls with the actual tested failure loads. Table 5.7 compares the calculated and actual failure loads for the walls without hempcrete in-fill (Walls 1 and 6). Wall 1 has a calculated failure load that is within $8.8 \%$ of the actual value. However, Wall 6 failed at about $44 \%$ higher load than calculated. This may be attributed to the fact that timber compressive strengths can vary widely. The column in Wall 6 may have had higher compressive strength than was assumed based on the compression tests of the timber samples.

Table 5.8 compares the actual failure loads with the predicted failure loads and failure mode for the other 6 walls.

A bearing failure was predicted for Wall 2, and the actual failure mode was bearing. The difference between the predicted and actual failure load for Wall 2 was 101\%. This was mainly 
due to the fact that the dense hempcrete was carrying some load. The load was distributed from the timber column to the hempcrete thus increasing the bearing area and thus the bearing failure load. From the load deflection plot of the wall 2 (Figure 4.19), the displacement downward at maximum load was found to be $25 \mathrm{~mm}$. The hempcrete beside the central column (approximately half width of the wall on both sides, as the beam bent up and rest of the wall lost contact with the top beam, Figure 4.18) underwent the same deflection. This would create a strain of 0.023 on the hempcrete. Thus from the stress-strain diagram of M1 (Figure 4.10), the stress in hempcrete at that strain would be $0.7 \mathrm{MPa}$. The estimated load carried by hempcrete at failure would therefore be $37 \mathrm{kN}$. When this load is added to the maximum bearing failure load from Table 5.4, the estimated failure load is $77 \mathrm{kN}$, which is within $3 \%$ of the calculated failure load.

The difference between the predicted and actual failure load for Wall 3 was $12 \%$. However, a weak axis buckling failure mode for Wall 3 was predicted, and the actual failure mode was strong axis buckling. It was noted earlier that Wall 3 experienced combined axial load and bending at failure due to tilting of the I-section top beam when the wall started to buckle. Thus the failure load is lower than if it had been subjected to pure axial compression. To estimate the bending that occurred at failure, the difference in deflections on each side of the top plate, $\Delta 1$ $-\Delta 2$, (from LPs on either side of the I-section, see Figure 5.4) was used to estimate the rotation of the beam, the eccentricity of the loading, e, and hence the moment, $\mathrm{P}_{\mathrm{ult}}$ times e, applied to the top of the column (Figure 5.4). To estimate the strength that Wall 3 would have had if no bending were present, the beam-column interaction equation from 086-01 was used:

$$
\frac{\mathrm{P}}{\text { Pult }}+\frac{\mathrm{M}}{\mathrm{M}_{\mathrm{r}}} \leq 1
$$


where Pult is the ultimate failure axial load of column; Pr is the axial compressive resistance of the column; $\mathrm{M}$ is the moment applied; and, $\mathrm{Mr}$ is the moment resistance of section.

The estimated eccentricity was $3.9 \mathrm{~mm}$, resulting in a moment $\mathrm{M}=0.227 \mathrm{kNm}$ at ultimate. The nominal moment resistance of a $39 \mathrm{~mm}$ x $89 \mathrm{~mm}$ timber stud is $1.27 \mathrm{kNm}$. Thus, with moment, the strength of the column of Frame 3 is about $50.8 \mathrm{kN}$ and is definitely lower than the weak axis buckling load. Thus strong axis buckling now becomes the critical load. This is about $15 \%$ of the calculated strong axis buckling capacity of the column. Therefore, this moment about the strong axis of the timber column lowered capacity in strong axis which led to failure in this mode.

Walls 4 and 5 both underwent strong axis buckling. These two experiments established that hempcrete bracing was successful in preventing weak axis buckling. Both the predicted and actual mode of failure were strong axis buckling. Bearing was eliminated even with the wooden beams. The actual failure loads of Walls 4 and 5 were within $14 \%$ and 13\%, respectively, of the predicted load.

A weak axis buckling failure (pushing into hempcrete) for Wall 8 was predicted, and the actual failure mode was as predicted. The difference between the predicted and actual failure load for Wall 8 was 28\%. For Wall 8, the potential for buckling with multiple half-sine waves was investigated using Equation 5.9. The critical value is $\frac{\beta 1^{4}}{\pi^{4} \mathrm{EI}}=4$; for the hempcrete and timber column used, $\frac{\beta 1^{4}}{\pi^{4} \mathrm{EI}}=10.39$. Thus, if buckling into the hempcrete, the column should have an inflection point and the buckling mode will have 2 half sine waves. Figure 5.5 gives the PIV image of buckled shape of column initially, clearly depicting the inflection point and two approximate half sine waves. This experimental result is in agreement with the model and Figure 
5.6, which gives the picture of the wall during buckling failure initiation of the wall. The hempcrete was weaker than the Styrofoam on the other side, so that it deformed more and failed, thus allowing a larger buckling sine wave in the hempcrete as opposed to the foam. The buckling sine wave towards the hempcrete continued to increase as the test proceeded until the smaller sine wave became insignificant and the column buckled by pushing and breaking into the hempcrete (Figures 5.7 and 5.8). The model predicts the failure load with an error of $28 \%$. The accuracy of the critical load from the model is based on how correctly the buckling curve is assumed and especially how the assumed end conditions of the bar are consistent with the actual end conditions. Here the assumed end condition is pinned which is not entirely true in the case of the central column. The top beam of the wall was replaced with a steel plate which was placed on the column, to avoid bearing. It did not confine the lateral displacement of the top of the column (Figure 5.5), making it somewhat similar to a free end cantilever, though the hempcrete and the foam did resist some of the lateral movement.

These results have shown that the current CSA-O86-01 code provisions can be used to predict the strength of timber columns infilled with hempcrete, and account for their ability to brace columns over their lengths. Column strengths can be predicted between $3 \%$ and $40 \%$. Using a classic "strut on elastic foundation" buckling analysis in combination with Equation 5.1 to predict the strength of columns buckling into the hempcrete appears promising. Only one result is available, and the strength was predicted within $28 \%$. However, there was good agreement between the predicted and actual buckling mode. Clearly additional testing is needed for this result to have statistical significance. 


\subsection{Parametric Analysis}

To further investigate the ability of hempcrete to brace a timber stud wall, a standard wall with $38 \times 140 \mathrm{~mm}$ timber columns of $2400 \mathrm{~mm}$ height at a standard spacing of $610 \mathrm{~mm}$ was investigated. Gaps between studs were assumed infilled with hempcrete of varying densities. The portion of wall considered here is a single column with hempcrete infill on either side.

The bearing and strong axis buckling strengths were calculated according to Equations 5.5 and 5.1 respectively using the standard values of compressive strengths perpendicular and parallel to the grain (CSAO86-01, Table 5.3.1A). The wall strength in weak-axis buckling of a timber column by pushing into hempcrete was calculated according to Equations [5.1] [5.10] and [5.11]. Elfordy et al (2007) investigated the relationship between the strength or elastic modulus of hempcrete and density (Figure 5.9). The procedure used to manufacture hempcrete in the above study is the projection process (the state of art hempcrete construction process). The elastic modulus obtained from Figure 5.9 Elfordy et al (2007) was used to predict the expected strength of a timber hempcrete composite wall (in weak axis buckling failure by pushing into hempcrete) for different densities of hempcrete. The projection process gives higher values of elastic modulus and compressive strength for same densities of hempcrete as compared to the traditional process. So hempcrete infilled wall strengths (in weak axis buckling) are expected to be lower than predicted here when hempcrete is manufactured using the traditional process.

The results are plotted in Figure 5.10. The critical (lowest) load is identified from the different modes of failure loads for all densities of hempcrete and is plotted Figure 5.10.

From Figure 5.10 it is clear that hempcrete with densities below $180 \mathrm{~kg} / \mathrm{m}^{3}$ do not prevent weak axis buckling effectively. That is, the wall fails in weak axis buckling. For densities of 
hempcrete above $180 \mathrm{~kg} / \mathrm{m}^{3}$ the hempcrete is able to resist weak axis buckling and the wall section undergoes bearing failure. If the bearing failure can be prevented with bearing plates, increasing the density of hempcrete infill can make the wall take up substantial load and fail in weak axis buckling by pushing into the hempcrete at a much higher load. If the density of hempcrete is increased beyond $350 \mathrm{~kg} / \mathrm{m}^{3}$ the strength of the wall cannot be further increased as the wall fails in strong axis buckling. Thus it can seen that even low density hempcrete can contribute to a substantial strength increase to a wood stud wall. Low density hempcrete is economic as it uses very little binder and is also a very good insulator that would reduce heating and air-conditioning costs of the building. 
Table 5. 1 The compressive resistance of wood parallel to grain with different factors and modulus of elasticity.

\begin{tabular}{|c|c|c|c|c|c|c|c|c|}
\hline Wall & fc MPa & $\mathbf{K}_{\mathbf{D}}$ & $\mathbf{K}_{\mathrm{sc}}$ & $\mathbf{K}_{\mathbf{t}}$ & $\mathbf{K}_{\mathbf{H}}$ & Fc MPa & E MPa & $\begin{array}{c}\mathbf{E}_{05} \\
\text { MPa }\end{array}$ \\
\hline $1-5$ & 17.9 & 1.15 & 1 & 1 & 1 & 20.6 & 12500 & 10250 \\
\hline $6-8$ & 28.9 & 1.15 & 1 & 1 & 1 & 33.2 & 13040 & 10734 \\
\hline
\end{tabular}

Table 5. 2 Predicted weak axis buckling strength of walls without any infill.

\begin{tabular}{|c|c|c|c|c|c|c|c|c|c|c|c|}
\hline Wall & $\begin{array}{c}\mathbf{E 0 5} \\
\mathbf{( M P a})\end{array}$ & $\begin{array}{c}\mathbf{F c} \\
\mathbf{( M P a})\end{array}$ & $\mathbf{F c} / \mathbf{E}^{\prime}$ & $\begin{array}{c}\mathbf{b} \\
\mathbf{( m m})\end{array}$ & $\begin{array}{c}\mathbf{d} \\
\mathbf{( m m})\end{array}$ & $\begin{array}{c}\mathbf{A} \\
(\mathbf{m m})\end{array}$ & $\begin{array}{c}\mathbf{k L} \\
\mathbf{( \mathbf { m m } )}\end{array}$ & $\mathbf{K}_{\mathbf{z c}}$ & $\mathbf{C c}$ & $\mathbf{K c}$ & $\begin{array}{c}\text { Pcr } \\
\mathbf{( k N )}\end{array}$ \\
\hline 6 & 10734 & 33.2 & $8.83 \mathrm{E}-05$ & 235 & 38 & 8930 & 2050 & 1 & 53.94 & 0.067 & 20 \\
\hline 1 & 10250 & 20.6 & $5.73 \mathrm{E}-05$ & 89 & 38 & 3382 & 1200 & 1 & 31.57 & 0.35 & 25 \\
\hline
\end{tabular}


Table 5.3 Predicted strong axis buckling strength of all the walls

\begin{tabular}{|c|c|c|c|c|c|c|c|c|c|c|c|}
\hline Wall & $\begin{array}{c}\mathbf{E}_{05} \\
\text { ( MPa) }\end{array}$ & $\begin{array}{c}F_{c} \\
(\mathbf{M P a})\end{array}$ & $\mathbf{F c} / \mathbf{E}^{\prime}$ & $\begin{array}{c}\mathbf{b} \\
(\mathrm{mm})\end{array}$ & $\begin{array}{c}\mathrm{d} \\
(\mathrm{mm})\end{array}$ & $\begin{array}{c}\mathrm{A} \\
(\mathrm{mm})^{2}\end{array}$ & $\begin{array}{c}\mathbf{k L} \\
(\mathbf{m m})\end{array}$ & $\mathbf{K}_{\mathbf{z c}}$ & $\mathrm{C}_{\mathrm{c}}$ & $\mathbf{K}_{\mathbf{c}}$ & $\begin{array}{c}\text { Pcr } \\
(\mathbf{k N})\end{array}$ \\
\hline 1 & 10250 & 20.6 & 5.73E-05 & 38 & 89 & 3382 & 1200 & 1 & 13.48 & 0.87 & 61 \\
\hline 2 & 10250 & 20.6 & 5.73E-05 & 38 & 89 & 3382 & 1200 & 1 & 13.48 & 0.87 & 61 \\
\hline 3 & 10250 & 20.6 & 5.73E-05 & 38 & 89 & 3382 & 1150 & 1 & 12.92 & 0.88 & 62 \\
\hline 4 & 10250 & 20.6 & 5.73E-05 & 38 & 89 & 3382 & 2133 & 1 & 23.96 & 0.55 & 39 \\
\hline 5 & 10250 & 20.6 & 5.73E-05 & 38 & 89 & 3382 & 2133 & 1 & 23.96 & 0.55 & 39 \\
\hline 6 & 10734 & 33.2 & 8.83E-05 & 38 & 235 & 8930 & 2050 & 1 & 8.72 & 0.94 & 280 \\
\hline 7 & 10734 & 33.2 & 8.83E-05 & 38 & 235 & 8930 & 2083 & 1 & 8.86 & 0.94 & 279 \\
\hline 8 & 10734 & 33.2 & 8.83E-05 & 38 & 235 & 8930 & 2083 & 1 & 8.86 & 0.94 & 279 \\
\hline
\end{tabular}


Table 5.4 Predicted bearing strength for each wall.

\begin{tabular}{|c|c|c|c|c|c|c|c|c|}
\hline Wall & $\mathbf{L}_{\mathbf{b}}$ & $\begin{array}{c}\boldsymbol{\varphi} \boldsymbol{F}_{\boldsymbol{c p}} \\
\mathbf{( M P a )}\end{array}$ & $\begin{array}{c}\text { width } \\
\text { of beam } \\
\mathbf{m m}\end{array}$ & $\boldsymbol{K}_{\boldsymbol{B}}$ & $\boldsymbol{K}_{\boldsymbol{z c p}}$ & $\mathbf{K}_{\mathbf{D}}$ & $\begin{array}{c}\boldsymbol{A}_{\boldsymbol{b}} \\
\mathbf{m m}^{2}\end{array}$ & $\begin{array}{c}\boldsymbol{Q}_{\boldsymbol{u l t r}}= \\
\boldsymbol{\varphi}_{\boldsymbol{c p}} \boldsymbol{A}_{\boldsymbol{b}} \boldsymbol{K}_{\boldsymbol{B}} \boldsymbol{K}_{\mathbf{z c} \boldsymbol{p}} \mathbf{K}_{\mathbf{D}} \\
\mathbf{( k N )}\end{array}$ \\
\hline 1 & 38 & 7 & 89 & 1.25 & 1.15 & 1.15 & 3382 & 39 \\
\hline 2 & 38 & 7 & 89 & 1.25 & 1.15 & 1.15 & 3382 & 39 \\
\hline 3 & 38 & 7 & 89 & 1.25 & 1.15 & 1.15 & 3382 & prevented \\
\hline 4 & 38 & 7 & 89 & 1.25 & 1.15 & 1.15 & 3382 & 39 \\
\hline 5 & 38 & 7 & 89 & 1.25 & 1.15 & 1.15 & 3382 & prevented \\
\hline 6 & 38 & 7 & 235 & 1.25 & 1.15 & 1.15 & 8930 & prevented \\
\hline 7 & 38 & 7 & 235 & 1.25 & 1.15 & 1.15 & 8930 & 103 \\
\hline 8 & 38 & 7 & 235 & 1.25 & 1.15 & 1.15 & 8930 & prevented \\
\hline
\end{tabular}


Table 5.5 Calculation of $\beta$ and equivalent unsupported length (kL)for the walls according to the model

\begin{tabular}{|c|c|c|c|c|c|c|c|c|}
\hline Wall & $\begin{array}{c}\text { d } \\
\text { (depth } \\
\text { of wall) } \\
\text { mm } \\
\end{array}$ & $\begin{array}{c}E \\
\text { hempcrete } \\
\text { MPa }\end{array}$ & $\begin{array}{c}\text { Lh } \\
\text { (width of } \\
\text { in-fill) } \\
\text { mm } \\
\end{array}$ & $\begin{array}{c}\boldsymbol{\beta} \\
\mathrm{N} / \mathbf{m} / \mathbf{m}\end{array}$ & $\begin{array}{c}\mathbf{L} \\
\underset{\text { (column) }}{\mathbf{m m}}\end{array}$ & $\beta L^{\wedge} 4 /\left(\pi^{\wedge} 4 E I\right)$ & $\begin{array}{c}\text { m } \\
\text { (buckling } \\
\text { mode) }\end{array}$ & $(\mathrm{kL}) \mathrm{mm}$ \\
\hline 2 & 89 & 12.5 & 550 & 2.022 & 1200 & 8.464 & 2 & 485 \\
\hline 3 & 89 & 2.87 & 550 & 0.464 & 1150 & 1.639 & 1 & 708 \\
\hline 4,5 & 89 & 2.87 & 550 & 0.464 & 2133 & 19.400 & 2 & 717 \\
\hline 8 & 235 & 1.89 & 550 & 0.807 & 2083 & 11.138 & 2 & 800 \\
\hline
\end{tabular}


Table 5.6 Predicted weak axis buckling load of the walls with hempcrete infill support.

\begin{tabular}{|c|c|c|c|c|c|c|c|c|c|c|c|}
\hline $\begin{array}{c}\text { Wall } \\
\text { no }\end{array}$ & $\begin{array}{c}\text { E05 } \\
\text { MPa }\end{array}$ & $\begin{array}{c}\text { Fc } \\
\text { MPa }\end{array}$ & Fc/E' & $\begin{array}{c}\mathbf{b} \\
\mathbf{m m}\end{array}$ & $\begin{array}{c}\mathbf{d} \\
\mathbf{m m}\end{array}$ & $\begin{array}{c}\mathrm{A} \\
\mathbf{m m}^{2}\end{array}$ & $\begin{array}{c}\mathbf{k L} \\
\mathbf{m m}\end{array}$ & $\mathbf{K}_{\mathrm{zc}}$ & $\mathbf{C}_{c}$ & $\mathbf{K}_{\mathbf{c}}$ & $\begin{array}{l}\text { Pcr } \\
(\mathbf{k N})\end{array}$ \\
\hline 2 & 10250 & 20.6 & 5.73E-05 & 89 & 38 & 3382 & 485 & 1 & 12.76 & 0.893 & 64 \\
\hline 3 & 10250 & 20.6 & 5.73E-05 & 89 & 38 & 3382 & 708 & 1 & 18.62 & 0.729 & 52 \\
\hline 4 & 10250 & 20.6 & 5.73E-05 & 89 & 38 & 3382 & 717 & 1 & 18.86 & 0.721 & 50 \\
\hline 5 & 10250 & 20.6 & 5.73E-05 & 89 & 38 & 3382 & 717 & 1 & 18.86 & 0.721 & 50 \\
\hline 7 & 10734 & 33.2 & 8.83E-05 & 235 & 38 & 8930 & 800 & 1 & 21.04 & 0.548 & 163 \\
\hline 8 & 10734 & 33.2 & 8.83E-05 & 235 & 38 & 8930 & 800 & 1 & 21.04 & 0.548 & 163 \\
\hline
\end{tabular}


Table 5.7 The calculated and actual failure loads of walls without hempcrete infill compared.

\begin{tabular}{|c|c|c|c|}
\hline Wall & $\begin{array}{c}\text { Calculated } \\
\text { weak axis } \\
\text { buckling load } \\
\text { without } \\
\text { hempcrete(kN) }\end{array}$ & $\begin{array}{c}\text { Actual } \\
\text { Failure } \\
\text { Load(kN) }\end{array}$ & $\begin{array}{l}\text { Percentage } \\
\text { Difference }\end{array}$ \\
\hline 6 & 20 & 28.7 & 44 \\
\hline 1 & 25 & 27.0 & 9 \\
\hline
\end{tabular}


Table 5.8 The calculated failure loads of different failure modes of walls infilled with hempcrete compared with actual failure loads.

\begin{tabular}{|c|c|c|c|c|c|c|c|c|}
\hline \multirow{2}{*}{ Wall No } & \multicolumn{4}{|c|}{ Predicted } & \multirow{2}{*}{$\begin{array}{c}\text { Expected } \\
\text { failure mode }\end{array}$} & \multirow{2}{*}{$\begin{array}{c}\text { Actual } \\
\text { failure } \\
\text { load } \\
(\mathbf{k N})\end{array}$} & \multirow{2}{*}{$\begin{array}{c}\text { Actual } \\
\text { Failure } \\
\text { mode }\end{array}$} & \multirow{2}{*}{$\begin{array}{c}\% \\
\text { difference }\end{array}$} \\
\hline & $\begin{array}{c}\text { Bearing } \\
\text { Eq. } 5.5 \\
(\mathrm{kN})\end{array}$ & $\begin{array}{c}\begin{array}{c}\text { Strong } \\
\text { axis } \\
\text { buckling }\end{array} \\
\text { Eq. } 5.1 \\
\text { (kN) }\end{array}$ & $\begin{array}{c}\text { Weak axis } \\
\text { buckling into } \\
\text { hempcrete } \\
\text { Eq. } \\
5.1,5.10,5.11 \\
\text { (kN) }\end{array}$ & $\begin{array}{c}\text { Critical } \\
\text { Load } \\
(k N)\end{array}$ & & & & \\
\hline 2 & 39 & 61 & 64 & 39 & Bearing & 79.0 & Bearing & 102 \\
\hline 3 & prevented & 62 & 51 & 51 & $\begin{array}{c}\text { Weak axis } \\
\text { buckling into } \\
\text { hempcrete }\end{array}$ & 57.0 & $\begin{array}{c}\text { Strong } \\
\text { axis } \\
\text { buckling }\end{array}$ & 12 \\
\hline 4 & 39 & 39 & 50 & 39 & $\begin{array}{c}\text { Strong axis } \\
\text { buckling }\end{array}$ & 33.5 & $\begin{array}{c}\text { Strong } \\
\text { axis } \\
\text { buckling }\end{array}$ & 14 \\
\hline 5 & prevented & 39 & 50 & 39 & $\begin{array}{c}\text { Strong axis } \\
\text { buckling }\end{array}$ & 34.0 & $\begin{array}{c}\text { Strong } \\
\text { axis } \\
\text { buckling }\end{array}$ & 13 \\
\hline 7 & 103 & 279 & 163 & 103 & Bearing & 86.5 & Bearing & 16 \\
\hline 8 & prevented & 279 & 163 & 163 & $\begin{array}{c}\text { Weak axis } \\
\text { buckling into } \\
\text { hempcrete }\end{array}$ & 116.7 & $\begin{array}{c}\text { Weak } \\
\text { axis } \\
\text { buckling } \\
\text { into } \\
\text { hempcrete }\end{array}$ & 28 \\
\hline
\end{tabular}




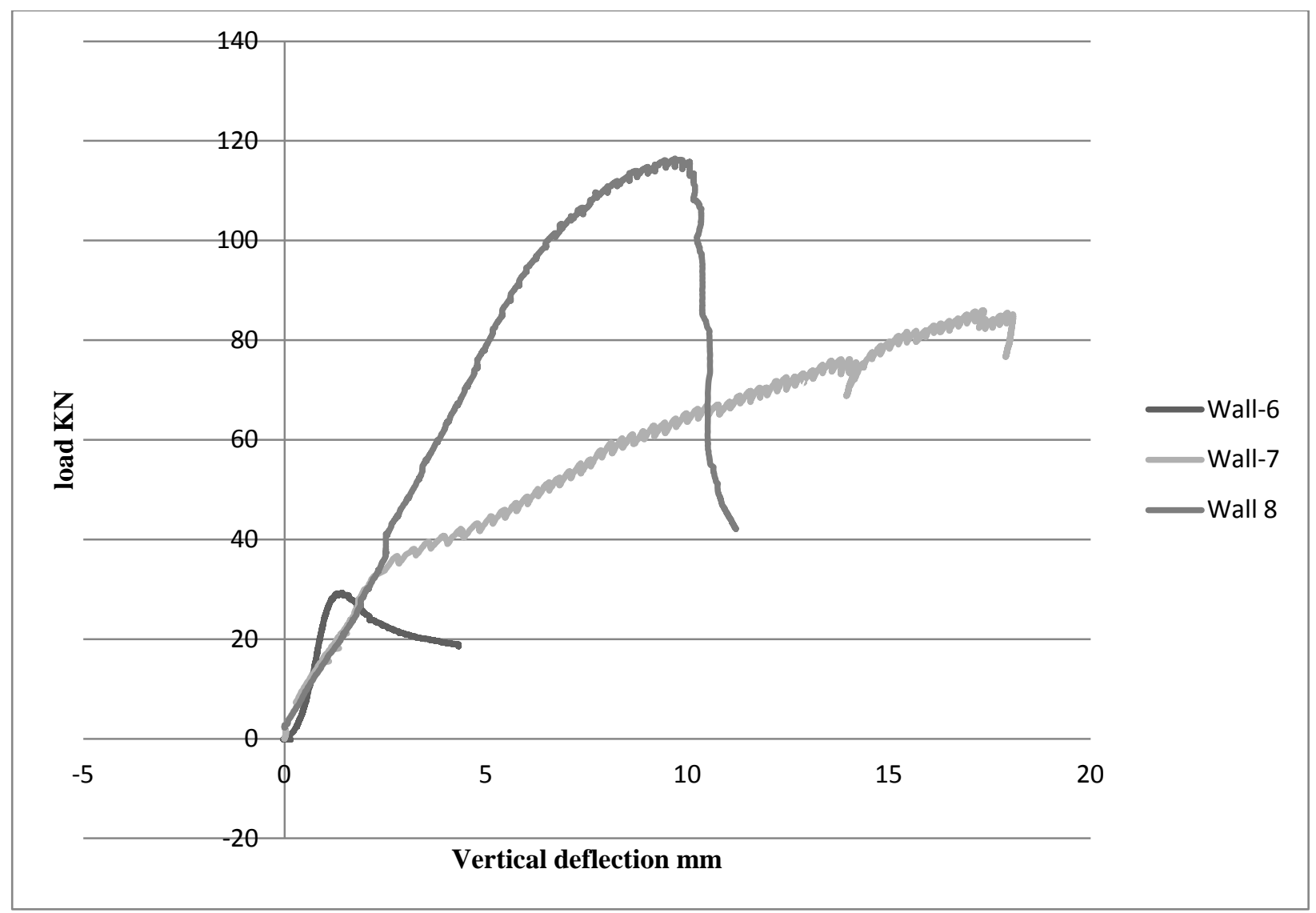

Figure5.1 The comparison of load versus vertical deflection graph of Wall tests 6, 7, 8. Wall 6 had weak axis buckling without any infill, Wall 7 had a hempcrete infill and underwent bearing failure, Wall 8 had hempcrete infill and it underwent weak axis buckling. 


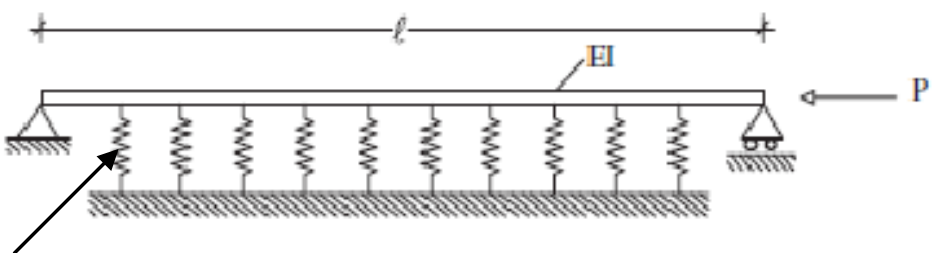

Stiffness $\beta$ per unit length of

Figure5.2 The model of column on elastic foundation (bed of springs). 


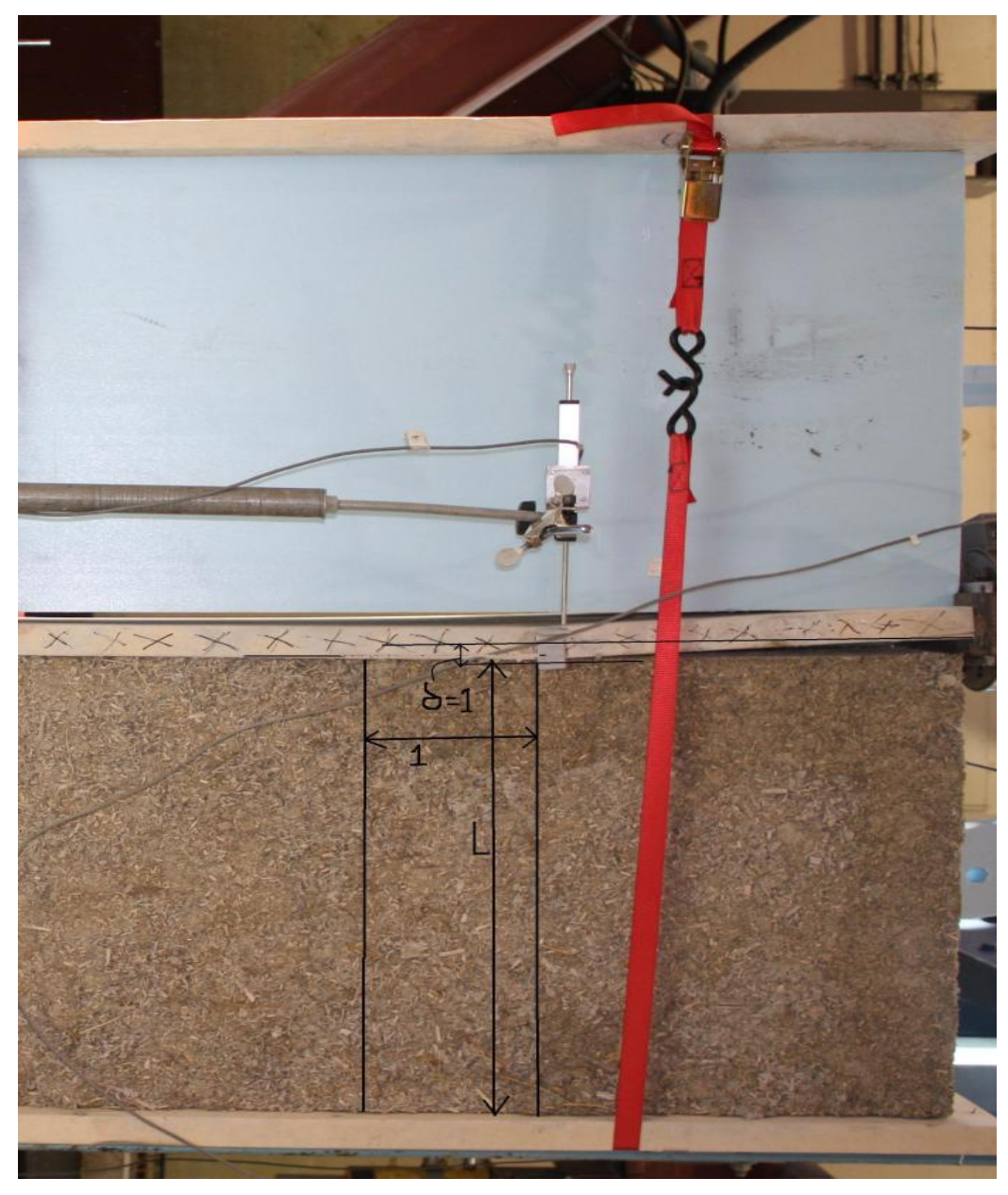

Figure5.3 The analogous situation of the column on elastic foundation with wall 8. Hempcrete acts as the elastic medium. $\beta$ is calculated by force required to cause unit deflection in hempcrete per unit length of column (Table5.5). 


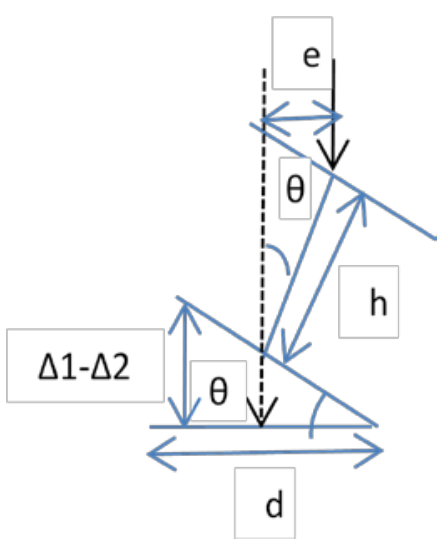

Figure5.4 The compatibility of deflections of the top steel beam of Wall 3. Tilting of the top steel beam created a moment $\mathrm{P}^{*} \mathrm{e}$ about the strong axis, lowering the buckling load about strong axis. 


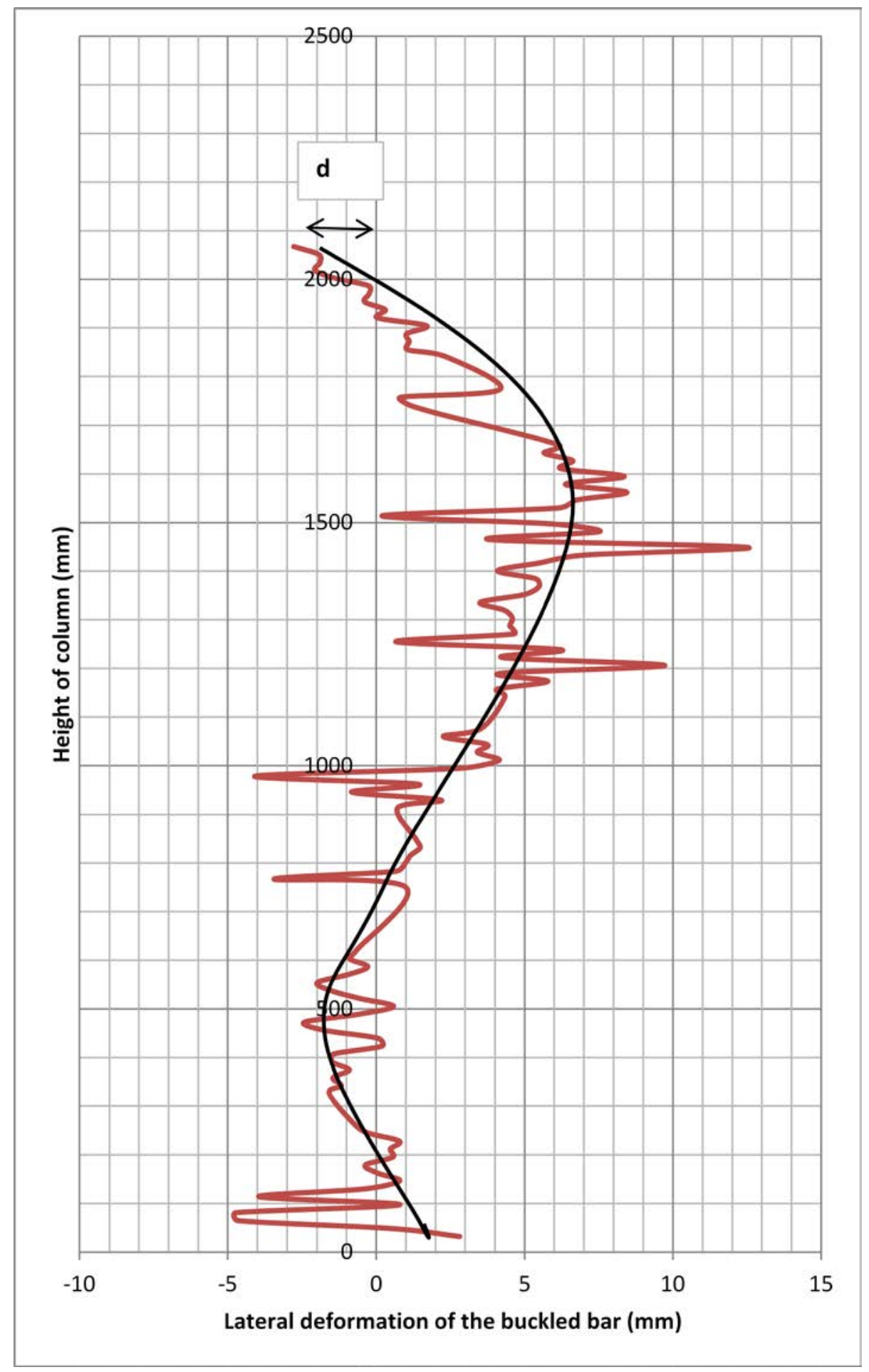

Figure5.5 The initial buckling mode of column of Wall 3 obtained from PIV analysis. 


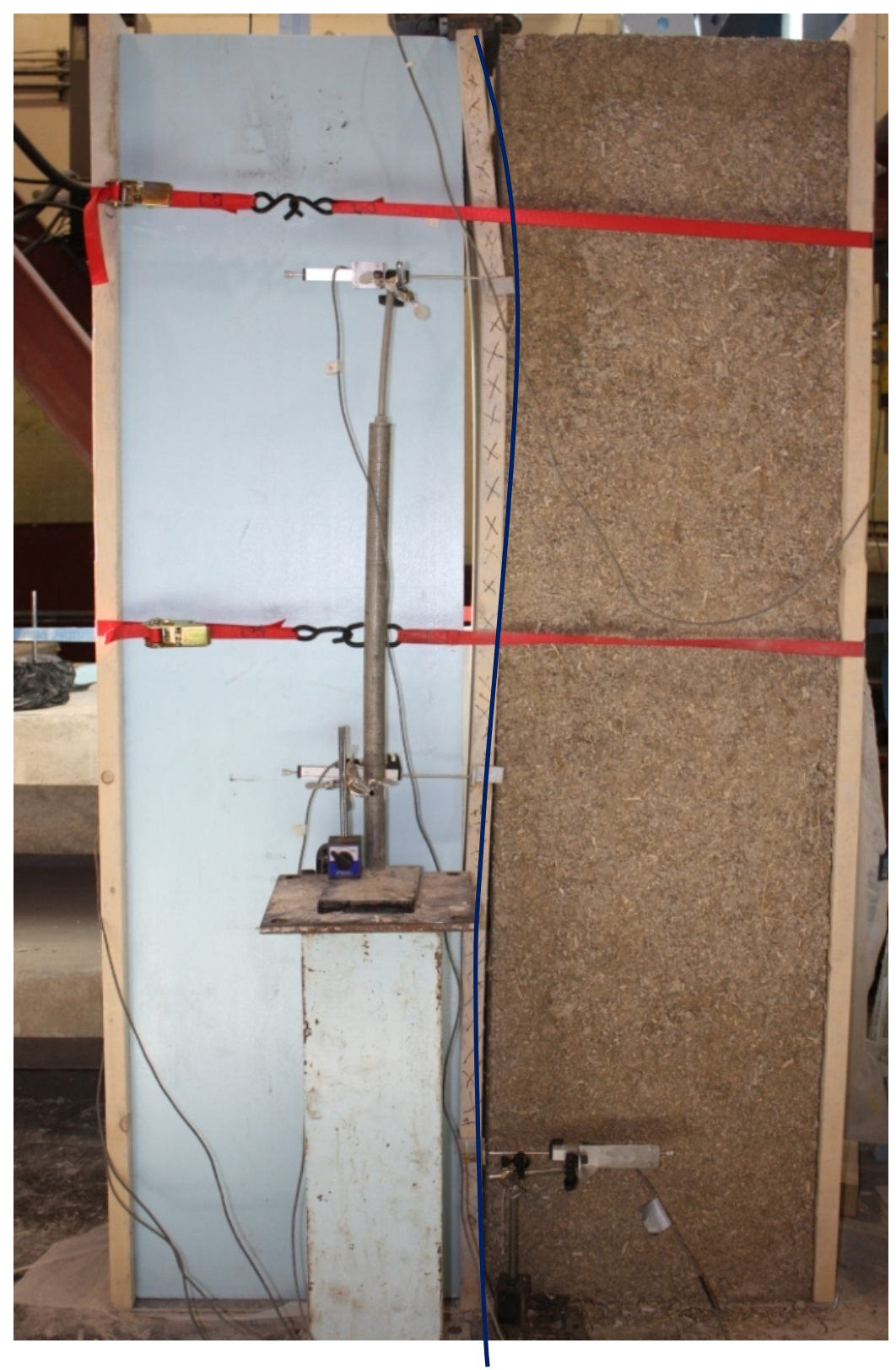

Figure5.6 The initial buckling mode of two half sine waves from the actual picture during the wall test. 


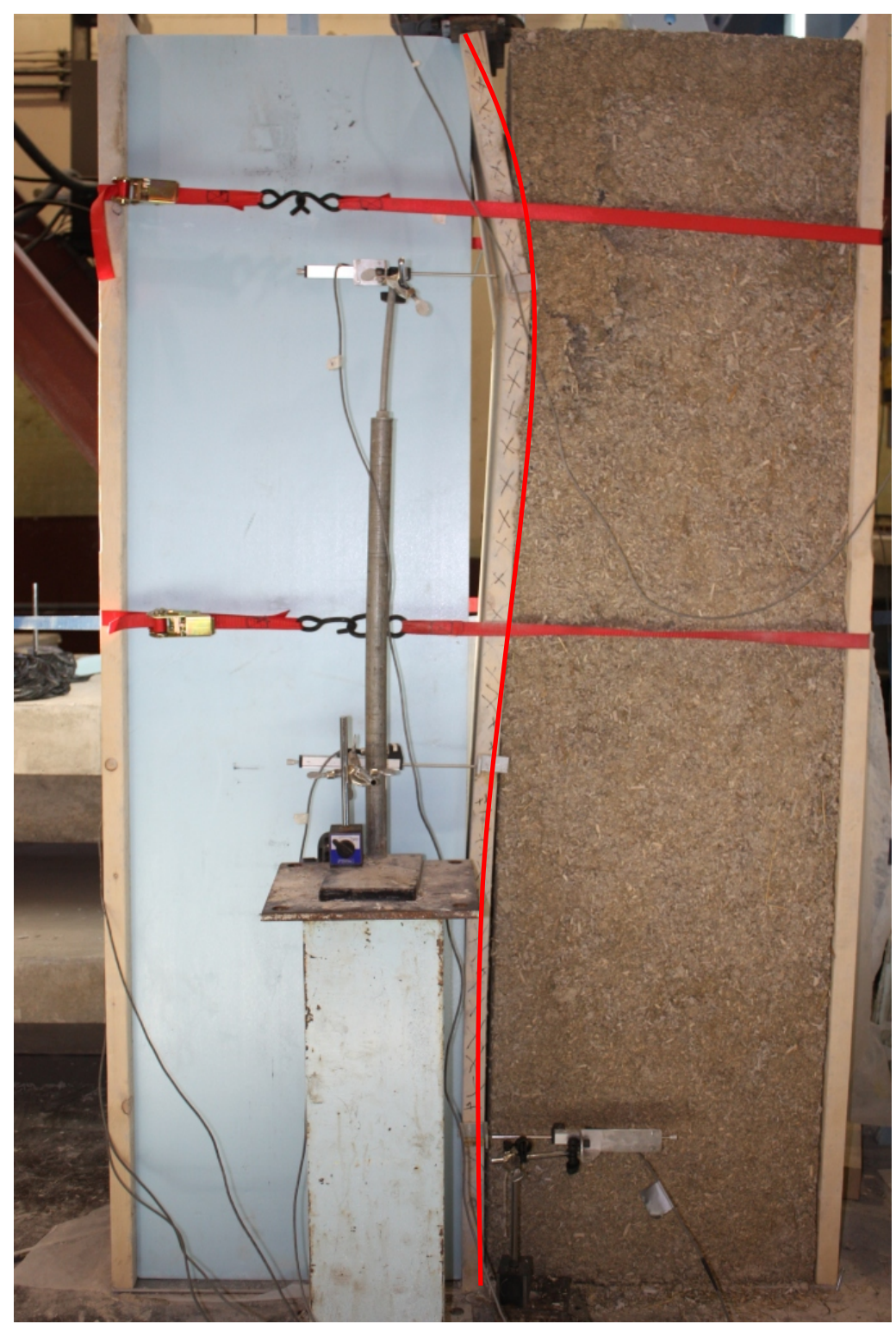

Figure5.7 The final buckled configuration of the central timber column of Wall 8. 


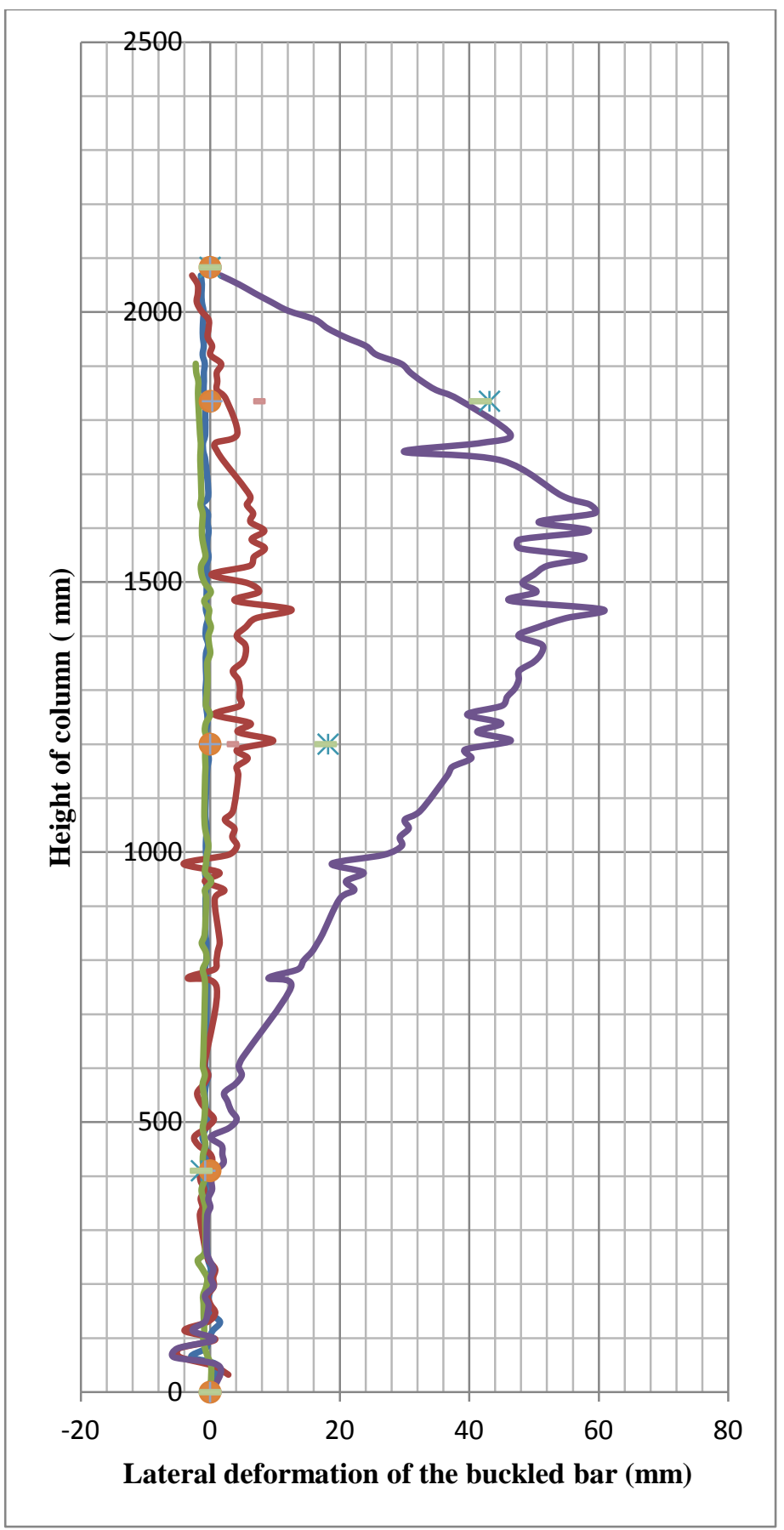

Figure5.8 The final buckled curve obtained from PIV analysis. 


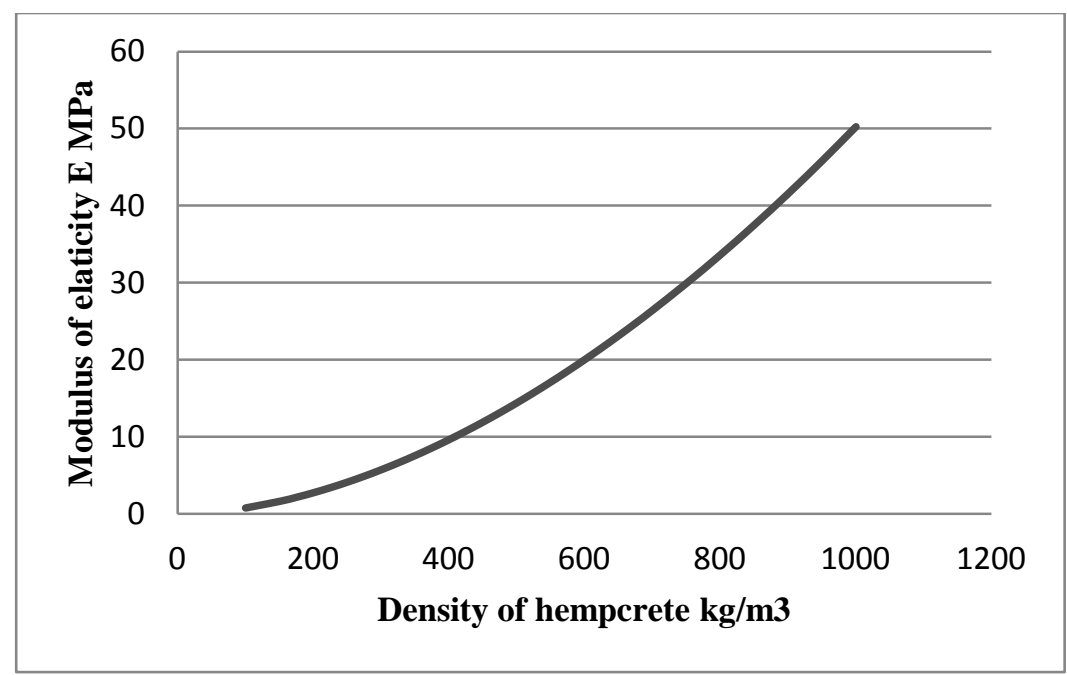

Figure5.9 The approximate relationship between the density and modulus of elasticity of hempcrete. 


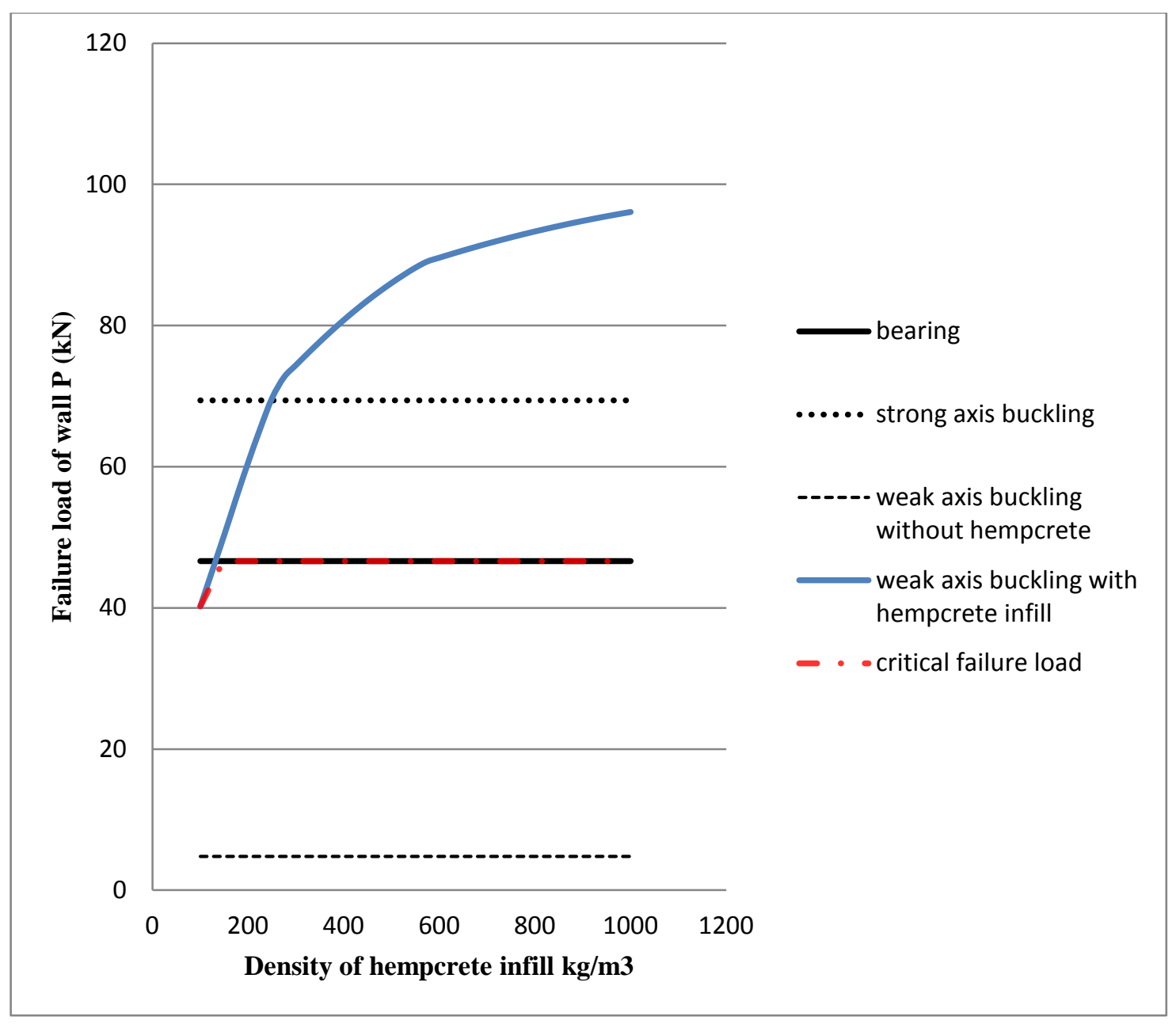

Figure5.10 The variation of strength of timber hempcrete composite wood stud wall with $38 \mathrm{x} 140 \mathrm{~mm}$ columns with the density of hempcrete. 


\section{CHAPTER: CONCLUSION}

The main objective of this research was to assess the structural benefits of hempcrete infill in a composite wood stud wall and to determine if hempcrete can increase the maximum compressive load capacity of such a wall by preventing the weak axis buckling of the timber columns. This research also investigated how the variation of the density of the hempcrete infill in the wall affected the ultimate strength of the wall. Design equations from the current Canadian timber design standard were shown to be adequate for predicting the failure loads of hempcrete in-filled timber walls. This chapter summarizes all the major findings of the research, and lists the various recommendations for future research.

\subsection{MAJOR RESEARCH FINDINGS}

- Hempcrete infill can add strength to timber stud walls by preventing weak axis buckling.

- High density hempcrete $\left(715 \mathrm{~kg} / \mathrm{m}^{3}\right)$ infill can add strength to a wall by itself bearing some load.

- Low density hempcrete $\left(313 \mathrm{~kg} / \mathrm{m}^{3}\right)$ can prevent weak axis buckling of timber columns. Low density hempcrete has higher insulation value (Arnaud and Samri (2007)) and is more economical to build (requires less binder). Hence low density hempcrete can be a very suitable structural infill material.

- The timber code equations (CSA-O86-01) for calculating the compressive strength parallel to the grain and perpendicular to the grain can predict the failure loads due to buckling (without hempcrete's lateral support) and bearing within 16.28\%. (The exception wall 6 where the actual load was $44 \%$ higher than the calculated load).

- The half scale (approximately 1 metre high) hempcrete in-filled walls failed due to bearing of the column into the timber top and bottom beams. Bearing was eliminated in 
the full scale walls (over 2 metres in height) since the strong axis buckling load was reduced due to the increase in height of the columns. Thus for full-scale hempcrete infilled walls, strong axis buckling is the critical failure mode.

- Hempcrete infill can increase up to 4 times the strength of a timber wall by preventing weak axis buckling (Wall6 versus Wall 8) by acting as continuous lateral elastic support.

- The classical model of an axially loaded column on an elastic foundation can be used to estimate an equivalent unsupported length for the laterally elastically supported (by hempcrete infill) timber column in a stud wall. This length can be used in the standard timber buckling design equation to determine the expected weak axis buckling load of a hempcrete in-filled wall. For the present case of one test result for a hempcrete infilled wall with 38x235mm timber columns predicted the load within 28\%. The buckling mode was correctly predicted. One major difference of the experimental conditions with the model was the end conditions of the column which were not entirely pinned as assumed. In actual cases of timber and hempcrete infilled walls the pinned conditions can be assumed. Thus, closer predictions can be expected from the model. 


\subsubsection{DisCUSSION ON PARAMETRIC ANALYSIS}

A parametric analysis was carried out for a standard timber stud wall with $38 \mathrm{~mm}$ x 140mm dimension columns in-filled with hempcrete of different densities. The analysis suggests that hempcrete (when using projection process) below density (180 Kg/m3) was not successful in preventing weak axis buckling. For hempcrete above this density, bearing would be the mode of failure. If bearing was prevented with bearing plates, and the density of the hempcrete infill were increased to $(350 \mathrm{Kg} / \mathrm{m} 3)$ the governing failure mode would be strong axis buckling. 


\subsection{RECOMMENDATIONS FOR FUTURE WORK}

The above research attempts to understand the structural benefits of hempcrete as an infill material. Additional research can be undertaken to clearly define hempcrete's performance as a structural in-fill and set design guidelines for hempcrete in-filled timber stud walls:

- Additional compressive tests on hempcrete infilled walls failing by weak axis buckling into the hempcrete are necessary to validate the model proposed herein.

- Different higher density hempcrete infill walls can be tested to find out how hempcrete can perform as a load bearing material when used compositely with timber. A corresponding modeling can be developed.

- Typical hempcrete walls are usually about $300-500 \mathrm{~mm}$ thick to achieve the required insulation value. Thus the columns are usually surrounded by hempcrete, which can help confine the strong axis. This has the potential to further increase the buckling strength. Such walls should be tested to investigate this hypothesis. 


\section{REFERENCES}

Arnaud, L. and Samri, D. Innovative building material based on line and hemp particles: From ecological and technical interests. International conference on Sustainability in the Cement and Concrete Industry, Lillehammer, Norway, September 16-19, pp. 580-592, 2007.

Arnaud, L. Mechanical and Thermal properties of hemp mortars and wools: experimental and theoretical approaches. Proceedings of the third International symposium, bioresource, hemp and other fibre crops, Germany: Wolfsburg: 2000.

ASTM D143 -09 for Small Clear Specimens of Timber, P.A,USA 2010.

ASTM D 1621 -Standard Test Method for Compressive Properties of Rigid Cellular PlasticsDetermination of Compression Properties. P.A,USA 2008

CSA Standard, O86-01, Engineering Design in Wood,ON, Canada 2005.

Bruijn, P. B. de., Jeppsson, K. H., Sandin, K., Nilsson, C., Mechanical properties of lime-hemp concrete containing shive and fibres . Biosystem Engineering, 103 pp. 474-479, 2009

Buchanan, A. H., Johns, K. C., and Madsen, B. Column design methods for timber engineering. Canadian Journal of Civil Engineering 12(4): 731-744,1985 
Chew, P. and MacDougall, C., Compressive Strength Testing of Hemp Masonry Mixtures. International conference on Sustainability in the Cement and Concrete Industry, Lillehammer, September 16-19, 2007, Norway, , pp. 600-615.

Elfordy. S., Lucas. F., Tancret. F., Scudeller. Y., Goudet. L. , Mechanical and thermal properties of lime and hemp concrete ("hempcrete") manufactured by a projection process. Construction and Building Materials, 22 (2008) pp. 2116-2123.

Harris. R., Shanks. J., Hodsdon. T., Borer., The Wales Institute for Sustainable Education(WISE): Non-conventional materials in Mainstream Construction. Proceedings of the $11^{\text {th }}$ International Conference on Non-conventional Materials and Technologies (NOCMAT 2009)6-9 September 2009, Bath, UK.

Johns. K. C., A continuous design formula for timber columns. Canadian Journal of Civil Engineering 18: pp.617-623, 1991.

Lippiatt, B., Selecting cost effective green building products: BEES approach. J. Construction .Eng. Management., 125(6), p.448, 1999.

Madsen, B., Structural Behavior of Timber. Timber Engineering Ltd., First Edition, 1992.

Meadows, D., ASTM international and sustainable development keeping pace with new global market. Standardization News, 32(4), p.30, 2004. 
MacDougall. C., Natural Building Materials in Mainstream construction: Lessons from the UK. Journal of green building, Volume: 3, Issue: 3, Pages: 3-14 2008.

Swan, A. J., Rteil, A., Lovegrove, G., Sustainable Earthen and Straw Bale construction in North American Buildings: Codes and Practice. Journal of Materials of Civil Engineering, June 2011, pp.866-872.

Stern, N. H., The economics of Climate change: The stern review. Cambridge University Press, UK, 2007.

Timoshenko, S. P., Gere, J. M., Theory of Elastic Stability. McGraw-Hill Book Company, 1961.

Vardy, S., MacDougall. C., Magwood, C., Spick. A., Design and construction of the 4Cbuilding. Journal of Green Building, Vol 1, No. 2, pp. 49-62, 2006.

Walker, P., The Good Old Ways. Materials World, January, pp. 27-29, 2006.

White, D. J., Take, W. A, and Bolton, M. D, Soil deformation measurement using particle image velocimetry (PIV) and photogrammetry. Geotechnique 53, No. 7, 619-631,2003.

Wood Design Manual 2005-A complete reference for wood design in Canada-Canadian Wood Design Council. 